\title{
22 Grams: \\ Quantifying the Contemporary Human Body in Building 22
}

by

Jaclyn Squizzato

A thesis submitted to the Faculty of Graduate and Postdoctoral Affairs in partial fulfillment of the requirements for the degree of

Master of Architecture

in

M. Arch. Professional

\author{
Carleton University \\ Ottawa, Ontario \\ (C) 2014 \\ Jaclyn Squizzato
}




\title{
TITLE OPTIONS
}

\author{
The Invisible Man in Architecture \\ Re-Building the Human Body \\ Re-Cycling the Human Body in Architecture \\ Re-(Image)ining the Body in Architecture \\ Re-(Draw)ing the Body into Architecture
}

21 Grams:

Quantifying the Contemporary Human Body in Building 22 


\begin{abstract}
The human body has acted as a valuable model for architectural construing and construction since antiquity. Specifically in architectural construction the body has been utilized to create a variety of multi-dimensional representations which can facilitate layered readings of buildings. These readings depend on dynamic or static body models to establish architectural analogies and metaphors. Historically anthropomorphic analogies and metaphors were enabled by theological models of the body, which were aligned with an understanding of the body as a whole that contained the soul. However, with progressive scientific exploration in the 17 th and 18 th centuries, a technical understanding of the body as a series of mechanistic parts was developed. This thesis will discuss the influence of this shift to demonstrate a corresponding evolution in architectural anthropomorphism. This thesis will also examine how analog architectural representations benefit from the inclusion of the body, to enable multi-dimensional readings of drawings. Finally a contemporary understanding of the body in Building 22, also known as The Azreli School of Architecture and Urbanism, will be addressed in an attempt to physically re-integrate the Master of Architecture program back into the 5th floor of Building 22. In particular, the importance of the street as a design element which encourages visual and physical porosity, centralized circulation, and multiple functionalities will be analyzed as an instrument to develop a modular system which reflects both a contemporary understanding of the body and of Building 22 .
\end{abstract}




\section{ACKNOWLEDGMENTS}

Digital Campus Innovation Project \& CIMS ...

for the use of the Building 22 Architectural Model.

My family \& friends ...

for your encouragement.

Building $22 \ldots$

for being a home away from home. 


\section{LIST OF ILLUSTRATIONS}

(Figure 1) Page 6. Building 22: View from 4th Floor to the Pit. Squizzato, Jaclyn. Carleton University, 2014.

(Figure 2) Page 29. The Jonathan Stone House in Belmont Massachusetts, with

Regulating Lines. Hale, Jonathan. The Old Way of Seeing. New York: Houghton Mifflin Company, 1994. 49.

(Figure 3) Page 30. Francesco Di Giorgio Martini Church Plan. http://leonardodavinci. stanford.edu/projects/vitruvian/history/architecture.html. Last Modified: Fall 2002.

(Figure 4) Page 31. Carlo Scarpa's Brion Tomb. http://iamwhatismissing.tumblr.com/ post/37266778925/journeysofgrace-brion-cemetery-carlo-scarpa. Last Modified: Dec 5th 2012. Edited by Squizzato, Jaclyn. Carleton University, 2014.

(Figure 5) Page 43. Exercise 1: Iteration 1. Squizzato, Jaclyn. Carleton University, 2014.

(Figure 6) Page 43. Exercise 1: Iteration 2. Squizzato, Jaclyn. Carleton University, 2014.

(Figure 7) Page 47. View Along 4th Floor Street of Building 22. Squizzato, Jaclyn. Carleton University, 2014.

(Figure 8) Page 48. View Along 5th Floor Corridor of Building 22. Squizzato, Jaclyn. Carleton University, 2014.

(Figure 9) Page 53. Compilied Body Model. Squizzato, Jaclyn. Carleton University, 2014.

(Figure 10) Page 53. Hand Width Against Wood Sub-Structure. Squizzato, Jaclyn. Carleton University, 2014. 
(Figure 11) Page 53. Finger Width Against Formwork Trace. Squizzato, Jaclyn. Carleton University, 2014.

(Figure 12) Page 53. Body Width Between Wood Sub-Structure. Squizzato, Jaclyn. Carleton University, 2014.

(Figure 13) Page 55. Compilied Body Model. Squizzato, Jaclyn. Carleton University, 2014.

(Figure 14) Page 55. Finger Width Against Window Frame. Squizzato, Jaclyn. Carleton University, 2014.

(Figure 15) Page 55. Hand Width Against Window Frame. Squizzato, Jaclyn. Carleton University, 2014.

(Figure 16) Page 55. Hand Length Against Concrete Block. Squizzato, Jaclyn. Carleton University, 2014.

(Figure 17) Page 55. Foot Length Against Concrete Collumn. Squizzato, Jaclyn. Carleton University, 2014.

(Figure 18) Page 56. Systems, Junk, Ergonomic Materials Within 4th Floor Studio. Squizzato, Jaclyn. Carleton University, 2014.

(Figure 19) Page 58. Compilied Body Model. Squizzato, Jaclyn. Carleton University, 2014.

(Figure 20) Page 58. Finger Width Against Window Frame. Squizzato, Jaclyn. Carleton University, 2014. 
(Figure 21) Page 58. Foot Width Against Tile. Squizzato, Jaclyn. Carleton University, 2014.

(Figure 22) Page 58. Knee Height Against Drywall. Squizzato, Jaclyn. Carleton University, 2014.

(Figure 23) Page 59. Systems, Junk, Ergonomic Materials Within 5th Floor Hallway. Squizzato, Jaclyn. Carleton University, 2014.

(Figure 24) Page 66. View Towards 4th Floor Street 'Benches'. Squizzato, Jaclyn. Carleton University, 2014.

(Figure 25) Page 67. Palazzo Rucellai Bench. Elet, Yvonne. Seats of Power: The Outdoor Benches of Early Modern Florence. Journal of the Society of Architectural Historians. Vol. 61, ( 2002). pp $444-469.458$.

(Figure 26) Page 81. Existing 4th Floor Building 22: Programming Analysis. Squizzato, Jaclyn. Carleton University, 2014.

(Figure 27) Page 82. Existing 5th Floor Building 22: Programming Analysis. Squizzato, Jaclyn. Carleton University, 2014.

(Figure 28) Page 83. Renovated 5th Floor Building 22: Programming Analysis. Squizzato, Jaclyn. Carleton University, 2014.

(Figure 29) Page 84. Renovated 5th Floor Building 22: Program Analysis. Squizzato, Jaclyn. Carleton University, 2014.

(Figure 30) Page 86. Partition 1: Metal Structure. Squizzato, Jaclyn. Carleton University, 2014. 
(Figure 31) Page 87. Partition 1: Wood Structure. Squizzato, Jaclyn. Carleton University, 2014.

(Figure 32) Page 88. Partition 1: Wood Sub-Structure. Squizzato, Jaclyn. Carleton University, 2014.

(Figure 33) Page 89. Partition 1: Glazing and Wood Variant. Squizzato, Jaclyn. Carleton University, 2014.

(Figure 34) Page 90. Partition 2: Metal Structure. Squizzato, Jaclyn. Carleton University, 2014.

(Figure 35) Page 91. Partition 2: Wood Structure. Squizzato, Jaclyn. Carleton University, 2014.

(Figure 36) Page 92. Partition 2: Wood Sub-Structure. Squizzato, Jaclyn. Carleton University, 2014.

(Figure 37) Page 93. Partition 2: Glazing and Wood Variant. Squizzato, Jaclyn. Carleton University, 2014.

(Figure 38) Page 94. Partition 3: Metal Structure. Squizzato, Jaclyn. Carleton University, 2014.

(Figure 39) Page 95. Partition 3: Wood Structure. Squizzato, Jaclyn. Carleton University, 2014.

(Figure 40) Page 96. Partition 3: Wood Sub-Structure. Squizzato, Jaclyn. Carleton University, 2014. 
(Figure 41) Page 97. Partition 3: Glazing and Wood Variant. Squizzato, Jaclyn. Carleton University, 2014.

(Figure 42) Page 98. Partition 4: Metal Structure. Squizzato, Jaclyn. Carleton University, 2014.

(Figure 43) Page 99. Partition 4: Wood Structure. Squizzato, Jaclyn. Carleton University, 2014.

(Figure 44) Page 100. Partition 4: Wood Sub-Structure. Squizzato, Jaclyn. Carleton University, 2014.

(Figure 45) Page 101. Partition 4: Glazing and Wood Variant. Squizzato, Jaclyn. Carleton University, 2014.

(Figure 46) Page 102. Partition 5: Metal Structure. Squizzato, Jaclyn. Carleton University, 2014.

(Figure 47) Page 103. Partition 5: Wood Structure. Squizzato, Jaclyn. Carleton University, 2014.

(Figure 48) Page 104. Partition 5: Wood Sub-Structure. Squizzato, Jaclyn. Carleton University, 2014.

(Figure 49) Page 105. Partition 5: Glazing and Wood Variant. Squizzato, Jaclyn. Carleton University, 2014.

(Figure 50) Page 107. Partition Detail: Wood and Metal Joint. Squizzato, Jaclyn. Carleton University, 2014. 
(Figure 51) Page 108. Partition Detail: Mobile Window Joint. Squizzato, Jaclyn. Carleton University, 2014.

(Figure 52) Page 110. L5 Street Renovation: 3 Months. Squizzato, Jaclyn. Carleton University, 2014.

(Figure 53) Page 111. L5 Street Renovation: 12 Months. Squizzato, Jaclyn. Carleton University, 2014.

(Figure 54) Page 112. L5 Studio Renovation: 3 Months. Squizzato, Jaclyn. Carleton University, 2014.

(Figure 55) Page 113. L5 Studio Renovation: 12 Months. Squizzato, Jaclyn. Carleton University, 2014.

(Figure 56) Page 114. L5 Computer Lab Renovation: 3 Months. Squizzato, Jaclyn. Carleton University, 2014.

(Figure 57) Page 115. L5 Computer Lab Renovation: 12 Months. Squizzato, Jaclyn. Carleton University, 2014.

(Figure 58) Page 117. Acoustic Plan. Squizzato, Jaclyn. Carleton University, 2014.

(Figure 59) Page 118. Acoustic Section A. Squizzato, Jaclyn. Carleton University, 2014.

(Figure 60) Page 119. Acoustic Section B. Squizzato, Jaclyn. Carleton University, 2014.

(Figure 61) Page 120. Composite Building 22 Section: L1 Revit Export, L2 - L3 1971 Building 22 Section, L4 - L5 Hand Drawn Section. Squizzato, Jaclyn. Carleton University, 2014. 


\section{LIST OF APPENDICES}




\section{CONTENTS}

$\begin{array}{ll}\text { i } & \text { Title Options } \\ \text { ii } & \text { Abstract } \\ \text { iii } & \text { Acknowledgments } \\ \text { iv } & \text { List of Illustrations } \\ \text { x } & \text { List of Appendices }\end{array}$

\section{CHAPTERS}

a Proportion $\quad \ldots 9$

b Symmetry $\quad \ldots 12$

c Modularity $\quad \ldots 15$

d Scale $\quad \ldots 17$

e Oeconomia $\quad \ldots 19$ 
a Constructing

b Scale

9

The Drawings

...79

a Space Programming Analysis $\quad \ldots 80$

b Partitions $\quad \ldots 85$

c Details $\quad \ldots 106$

d Views $\quad \ldots 109$

e Porosity $\quad \ldots 116$

10

Postscript

$\ldots 120$

11

Foot-Notes 


\section{Pre-Face}


In 2007 during the first Introduction to Architecture seminar, at the Azreli School of Architecture and Urbanism, Marco Frascari ${ }^{1}$ asked the first year class what could seem a simple question:

\section{What is architecture?}

The answers from the students were at first hesitant - architecture was building construction, a vessel for the body for some, a response to site conditions for others, or even the simplification of form to achieve functional space. After a few moments the responses stopped and the class looked around at one another, plainly surprised by the multitude of 'things' that architecture encompassed. To my surprise, Frascari then continued the lecture saying that we were all very correct and that architecture was also every discipline we could hope to study.

After 5 years at the Azrieli School of Architecture and Urbanism, and a single year in the architectural profession, I am now attempting to answer my own version of the question Frascari posed in 2007.

What makes great architecture? 
While I acknowledge that this question is imprecise and consequently open ended, I also believe it has great value in its ability to guide an architect towards establishing personal guidelines for design. Accordingly, my personal definition of successful architecture in 2014, is that building should primarily strive to incorporate and accommodate the human body in a multiplicity of metaphoric, symbolic, and experiential ways. This is necessary because on a fundamental level, architecture is constructed to house the human body, and should facilitate this inhabitation both physically and mentally.

The question "What makes great architecture?" has also provided a personal means through which to question my own architectural education; specifically the teaching practices I have been exposed to at the Azreli School of Architecture and Urbanism during both my Undergraduate and Master degrees. Specifically, within the Azreli School of Architecture and Urbanism there is an importance placed on hand drawing and model making as a means of architectural construing ${ }^{2}$. While this belief is widely accepted within the school, it is typically viewed as a romanticized and mildly technophobic ideal in the eyes of new students and professionals ${ }^{3}$.

Consequently it is important to consider the validity of hand drawing and analog model making in 2014, since the architectural profession is increasingly valuing digital means of representation. In contrast to the economy of digital production, analog drawing takes much greater amounts of time but facilitates the process of architectural cosmopoiesis ${ }^{4}$. Analog drawing enables cosmopoiesis to occur by creating a tangible joint; between the movement of the hand holding a drafting instrument and the inscription surface. This joint enables a drawing to be interpreted at once by the architect, during the process of design, and subsequently by later viewers who are able to visually identify the 
relationship between body movement and drawing traces. This process of inscription, rather than transcription, is essential to engaging the body physically and mentally in the process of architectural construing. The transition from analog to digital drafting, reduces this essential ability for architectural construing to occur through the human hand, and body. This thesis will probe the ability of analog systems to facilitate the process of architectural construing and construction with the human body.

Within Building $22^{5}$ (Figure 1) the transition to digital modes of representation has also physically affected the use of spaces throughout the school, resulting in a decrease in studio use in the upper years of the Bachelor of Architectural Studies program ${ }^{6}$. Specifically, digital systems compress the entire process of architectural construing (massing compositions, material selection, final models and drawings) into a single model, which may be produced away from the studio environment. This removal of the architectural design process from studio spaces, reduces the ability for student collaboration by physically separating the student body from one another. Kathryn $\mathrm{H}$. Anthony, in the essay "Studio Culture and Studio Life", reiterates this view, stating that the studio is a "casual and improvisational environment (that) encourages them (students) to interact with one another and critique each other's work." The ability for students to interact with one another in a collaborative environment in Building 22 is facilitated by the physical and visual porosity of the studio spaces. Visual and physical porosity of studio space is important because it enables students to be aware of each other's work as it progresses; this in turn allows students to receive feedback throughout the design process from their peers. Porosity of spaces is also essential within Building 22 at large, to reduce social margins between professors, faculty and students. Specifically, the visual and physical porosity of the spaces along the 4th floor 'street', the central circulation corridor, enables chance encounters between social groups. The street also accommodates 
a variety of programs, such as eating, sleeping, housing models in construction, facilitating presentations and providing both a public and private space for discussion. The multiplicity of programs which the street is capable of accommodating, is largely due to the presence of the 'street seat' or bench, which lines both edges of the street. This bench has both the functional use of acting as circumstantial steps, as well as housing the extreme diversity of programs previously mentioned.

However, the successful porosity, circulation strategies and multiple functionalities of design elements, present in the original 4th floor of Building 22 is not reflected in the 5th floor addition completed in 1985 . The 5th floor features a narrow dry-wall corridor as the primary circulation. This central corridor has limited views into adjacent programmed spaces, and provides no location for public or private discussion. Unlike the 4th floor, there is no circulation between programmed spaces. Additionally, all mechanical, structural and electrical systems are hidden behind acoustic ceiling tile or drywall, reducing the ability of the 5th floor to demonstrate its own construction and act as an educational system for students to learn construction methodologies through the very fabric of the building. The goal of this project is to re-examine the 5th floor addition, and propose an economically minded intervention which physically reintegrates the student body back into the studios, classrooms, and computer labs. This renovation entails a moderate physical renovation, re-programming and new construction within the current 5 th floor of Building 22. The renovation seeks to encourage visual and physical porosity between programs, re-establish a central circulation corridor in the form of a street, reveal a didactic construction, and create design elements which have multiple functionalities. The goal of the completed renovation proposal will be to provide studios, classrooms, display areas, offices and social spaces to allow the current Master of Architecture students ( 8 credits and 13 credits programs) to return to Building 
22. The consolidation of all Architecture programs into a single faculty will allow a more integrated learning environment, where students from all years gain exposure to work being produced within the school ${ }^{8}$.

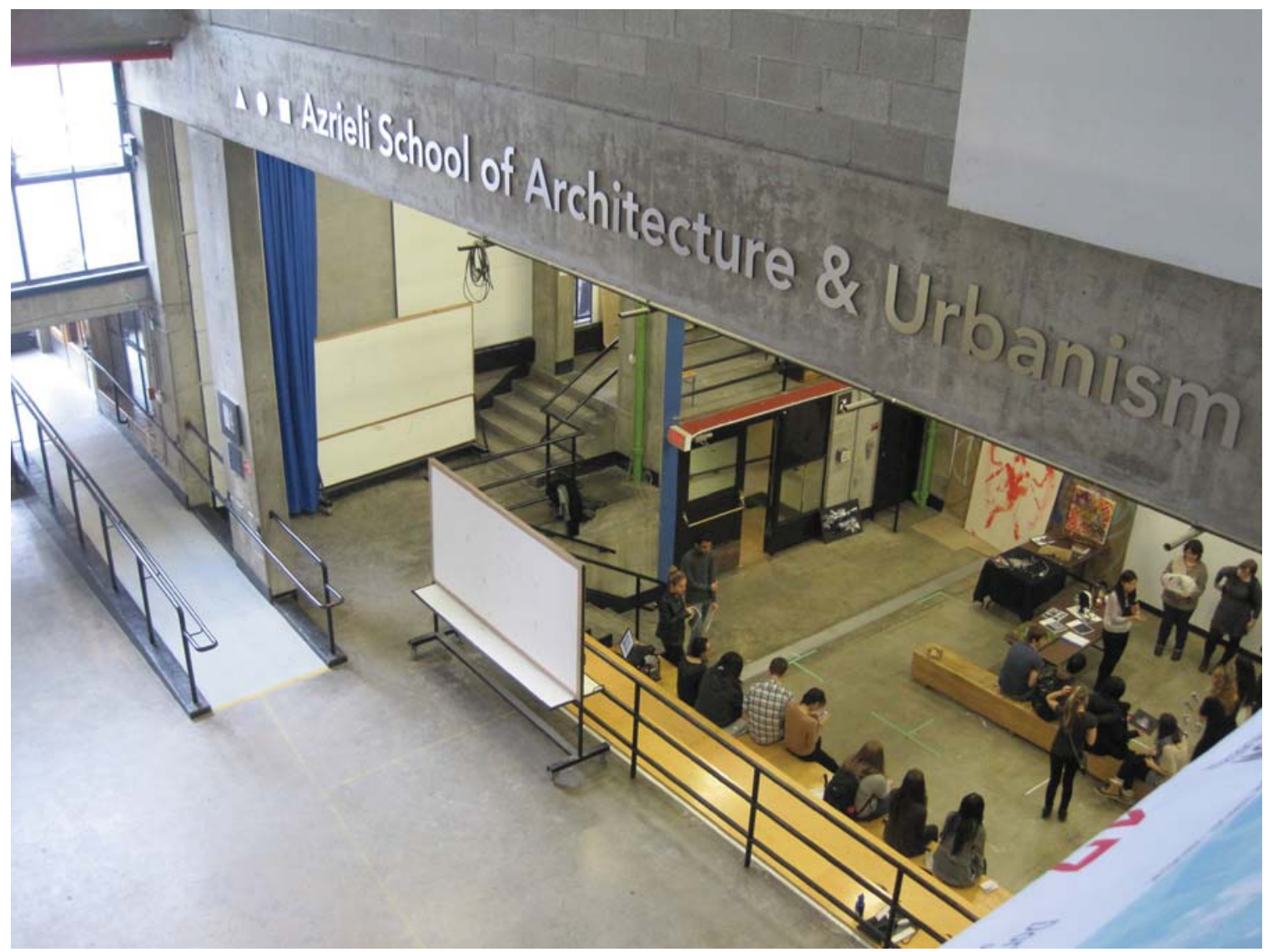

(Figure 1) Building 22: View from 4th Floor to the Pit 
The Basic Body 
In the "The Ten Books on Architecture", Vitruvius states that "architecture consists of Order, which in Greek is called taxis, and of Arrangement, which the Greeks name diathesis, and of Proportion, Symmetry, Decor and Distribution which in Greek

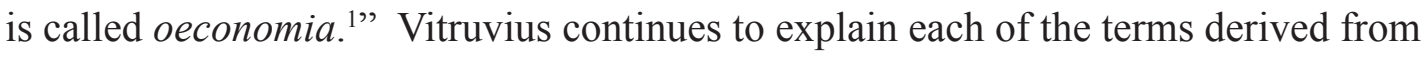
oeconomia, stating that proportion implies a graceful semblance and allows the display of details suitably through symmetry ${ }^{2}$. Symmetry is the appropriate harmony rising out of details of a work ${ }^{3}$, decor is the utilization of details from precedents while obeying convention $^{4}$, and finally distribution (or economy) is the wise control of expenses in site work $^{5}$.

The translation inherent in these definitions removes a specific meaning from oeconomia. Consequently, the original Vitruvian concept of oeconomia which was grounded in proportion, has been lost in contemporary language. Instead proportion is now commonly understood as a blanket term which includes multiple anthropomorphic models such as; symmetry, scale, module and proportion. This shift in language, has distorted an understanding of contemporary anthropomorphic models in architectural construing and construction. As such, it is important to isolate a specific understanding of proportion, module, symmetry and scale, as these terms have come to encompass the most basic models of the human body in architectural construing and construction. 
Proportion 
... is a concept which originally descended from the Pythagorean tradition of mathematics, and was based on the diatonic scale in music. The diatonic scale was established through the harmonious relationship of mathematical ratios; octave (1:2), fifth $(3: 2)$ and fourth $(4: 3)^{6}$. While, this scale was not directly incorporated into architecture it was understood to demonstrate that there was an underlying harmony inherent in the geometries of nature, which could be interpreted and applied to architectural construction.

In the Renaissance period, humanist architect Leon Battista Alberti (Feb 18 1404 - April 20 1472) maintained the relationship between geometric harmony and architectural scales, discussing in De Pictura, that the "theoretical underpinnings of geometry ... (were) not a mathematical issue but rather a divine ideal that brought an imperfect human being into closer harmony with the divinely created order of the universe." The importance of a divine ideal based in the geometric proportions of the human body interpreted through architecture was also maintained by Palladio in his Four Books on Architecture. Specifically, Palladio established geometric relationships which could be translated into architectural forms, through "seven sets of proportions for rooms, all based on whole number musical consonances ... ${ }^{8}$

Fast forwarding to the Modern period, Le Corbusier employed a similar methodology in establishing his own proportional architectural measurements in Le Modular, to generate architecture through anthropometric geometries. The Modulor was intended originally to be a universally valid system of measurement, bridging between the Metric and Imperial scales, with dimensions originating from the Vitruvian Man. The system generated two scales, the Red and Blue, which respectively decomposed the human body into a series of related anthropometric geometries. 
Reflecting on these definitions, proportion could be understood as the geometric or mathematic relationship of parts which are generally believed to produce harmony through metaphor, because of their comparative relation. This notion of comparative relation is founded in the etymological origin of the word proportion, which derives from the compound Latin "pro" (for) + "partio" (division) $)^{9}$. 
Symmetry 
... is the bilateral, or axial, balance related to the arrangement of parts in the physical forms of living organisms. Typically, symmetry may be understood as, "that preference for bilateral balance around a central axis that is found in the formal architectures of all civilizations and widely in vernacular buildings. This seems to be so universal and deeply ingrained that its origins are almost certainly biological ${ }^{10}$ ". Historically in primitive cultures, the preference towards bilateral symmetry most likely originated from an understanding that asymmetrical forms in living organisms were a result of illness. This primitive preference towards bilateral symmetry may offer an explanation of the preference towards symmetry in early architectural forms. While bilateral symmetry is the most common form of symmetry encountered in Western architecture, symmetry between two axes crossing at right angles was also frequently used during the Renaissance to determine the expression of an ideal anthropomorphic architectural form.

The first challenge to symmetrical architectural forms appeared during the $18^{\text {th }}$ century in Britain, with the advent of Picturesque painting ${ }^{11}$. The Picturesque style considered nature in the form of landscape, rather than organisms to provide the model for paintings, and by extension buildings. Architecture, in this period had to be full of variety, textures, and exhibit a determined lack of symmetry ${ }^{12}$. Asymmetrical forms were also used during the Gothic Revival, Arts and Craft Movement, and the International style, as a means of "achieving the spatial fluidity and formal contrasts that were seen as an expression of the dynamism of modern life. ${ }^{13}$ " This shift in representation of the 'dynamism of life' demonstrates a translation in the understanding of the physical body; originally from a symmetrical and visually complete whole, towards an asymmetrical form in contemporary culture which is a composition of parts. 
In conclusion, symmetry is the axial, balance associated with the relation of parts of the physical forms of living organisms. This notion of a 'relation of parts ${ }^{14}$, is associated with proportion, and derives from the etymological origin of the word symmetry, from the 1500's Greek "symmetria", which was understood as an "agreement in dimensions, or due proportion"15". "Symmetria" is a compound word from Greek "syn" (together) and "metron" (meter) ${ }^{16}$. It should also be noted that the "metron", in this context was not understood as a geometric measurement, but more specifically a "a verse; that by which anything is measured. ${ }^{17}$ " This understanding was closely related to Old English "metan", which translates to "compare or estimate" 18 ". 
Modularity 
... the module was initially adopted by ancient Greeks during the defining of Classical Column Orders, "the chosen module was half the diameter of the column measured at its base, divided in to 30 equal parts. ${ }^{19 "}$ Vitruvius elaborated on this idea in his "Ten Books on Architecture", with the belief that in a temple a certain part could be selected as a standard. The understanding of a module in this sense, was closely aligned with the notion of proportion, as a means to establish a unified anthropometric system of measurement to instill a easily identifiable cosmological harmony in architectural forms.

The XVII C. has shifted the conception of the module away from a anthropometric system of proportion, believed to attune buildings to the idealized form of the physical human body, towards an arrangement of prefabricated parts predominant in the Industrial Revolution. Increasingly so more recently, prefabricated parts have been favoured in building because they enable cost reduction, rapid design and expedient construction. On this smaller material scale, modularity can be understood as the component use of building elements, such as concrete block or acoustic tile. On a larger scale, modularity has also been adopted as a design strategy in pragmatically motivated buildings; such as, Moshe Safdie's Habitat 67 project from the 1968 Montreal Expo.

In conclusion, modularity is the selection of a standard 'part', which has specific measurement, and may be used repeatedly in design and construction. Multiples of a module can be used to create a proportionate scale of measurements. The etymology of the word module, is from Latin "modulus", which translates to a "small measure, or that which is composed of interchangeable units ${ }^{20 "}$. Modulus is composed of Latin "modus" and "-ule", which respectively translate to "proper rhythm, song, or a kind of musical scale $^{21 "}$ and "small, little. 22 " . . . is the grouping of subsidiary parts (modules) into larger wholes. The independent 
Scale 
identity of a material module within a scale is dynamic rather than static, as the module can be understood to have a varying material identity when it is considered either in isolation (module) or within a multiplicity of itself (scale). For example, the materiality of a single ceramic tile taken against a concrete floor will be understood differently, than if that same tile is interpreted within a tiled kitchen floor. This notion derives from "Artificial Light", a short collection of architectural anecdotes written by Keith Mitnick ${ }^{23}$. Scale, within this understanding is the most malleable of the terms associated with anthropomorphic architectural models because it is context dependant. This adaptability derives from scale being a mathematical relationship of divisible parts to both one another and a larger whole.

This notion of a whole comprised of divisible parts, derives from the etymological origins of scale (n.), from Proto-Germanic "skcelo" which translates to "split or divide"24". The root of "skcelo", which is "(s)kel-" was originally derived from the Old English "scalu", which was understood as a "drinking cup, or scale of balance. ${ }^{25 "}$ "Scalu", also had a close relationship to "scealu'26", which was a "husk or a shell27", so shells were typically used as drinking cups. Interestingly, drinking cups were also traditionally made of skulls. ${ }^{28}$ This original notion of scale identifies a very literal relationship between the physical body (skull) and language used to understand 'scale'.

Scale (v.) is also etymologically related to the body through Italian "scala", which was a "ladder, or flight of stairs ${ }^{29 "}$ " "Scala" is from stem "scandere", which translated "to climb" $b^{30 "}$. In this sense the origin of scale, is in the act of physically elevating the body along steps or a ladder, by stepping.

The variety of terms that oeconomia encompasses is not only due to the 
Oeconomia 
translation inherent in both language and architecture, but also the changing relationship of the body to constructed space through time. Initially, the integration of the human body in architectural thought, and built form, was an attempt to establish a reliable and relatable system of harmony. However, architecture's continued reliance on the body to establish systems of scale, module, proportion, and symmetry, indicates that the relationship between body and architecture is not only based in language and anthropomorphic analogy.

At this stage, I would like to suggest that the search for an anthropomorphically relatable system, able to naturally instill harmony in constructed forms is first identified in Vitruvius's "10 Books on Architecture", as a necessity for beauty. Specifically, Vitruvius states that buildings should be durable, useful and beautiful, being unified under the triad of - firmitas, utilitas, and venustas. The recognized importance of beauty (venustas) in the constructed environment is perhaps the catalyst for the variety of systems, which have both successfully and unsuccessfully related architecture to the human form. These varying metaphoric, symbolic and experiential anthropomorphic models are consequently a result of changing social and cultural models of the body. Le Corbusier offers a similar sentiment towards the importance of beauty in architecture, in Vers Une Architecture $(1923)$

"You employ stone, wood, and concrete, and with these materials you build houses and palaces, that is construction. Ingenuity is at work. But suddenly you touch my heart, you do me good. I am happy and I say:

This is beautiful.

That is Architecture. ${ }^{31}$ ", 


\section{The Body in Constructing (Macro)}


The human body has had a long history of association with both the construing and constructing of architecture ${ }^{1}$. The importance of this original association is typically traced back to the theoretical writings of Vitruvius, an architect from the $1^{\text {st }}$ century BC. In his, “Ten Books on Architecture”, Vitruvius introduced the idea of architectural anthropomorphism based on modulated measurements by recounting anthropomorphic practices present during the Hellenistic-Roman period.

Specifically, architectural anthropomorphism during the Hellenistic-Roman period was based on the understanding that "man could represent his universe through the topological projection of his own body ${ }^{2}$ ". This was because the human form served as a microcosm for the universe, and a representation of the higher harmonies inherent in nature ${ }^{3}$. The ability for human identification within the architecture was considered a necessity in this context, because it allowed man to better understand his own physical form and place in the cosmos. Consequently, buildings had particular shape because they were both constructed "by man and interpreted through the human form". An embedment of an anthropomorphic proportionality was therefore not only essential to reference the higher harmony of the universe, but also necessary to stimulate the imagination of both the designer and builder ${ }^{5}$. Anthropomorphically proportional systems in architecture, during this period not only inform the use of the body as a theoretical instrument in architectural construing, but also as a practical tool in architecture constructing. This understanding of the body as an essential instrument in the architectural practice is also reflected by Vitruvius, in the "Ten Book on Architecture".

In his "Ten Books on Architecture", Vitruvius compares the human body to the body of a building, suggesting herein an embedded rule for architectural form founded on proportional geometry. This type of proportion may best be understood as, "the 
correct relation of one thing to another or between parts of a thing or an incremental unit of measure ${ }^{6}$. Vitruvius continues to reinforce the idea of an ideal proportioning system in De Architectura prior to introducing the Vitruvian Man, iterating that "ideal building should carry proper notion of proportion in relation to the ideal physical form of man. Building needs this proportion in order for proper management." Interestingly the human figure Vitruvius presents to demonstrate his proportional system, is lying down with arms and feet contained within a circle and square ${ }^{8}$. This static manifestation of the body demonstrates that a Vitruvian understanding of proportions was based strongly in stationary anthropometric geometries, and a symbolic understanding of the body as a vessel which enabled cosmological anthropomorphism.

During the Renaissance following Vitruvius's example, the humanist architect Leon Battista Alberti (1404 - 1472) continued the theoretical development of architectural anthropomorphism through corporeal metaphors which parallelled the body and architectural construction ${ }^{9}$. Concurrently, the Sienese architect painter, sculptor, and engineer Francesco di Giorgio Martini (1439 - 1502) developed correlations between human proportions and architecture by superimposing images of the body over architectural details and plans. Di Giorgio's application of the whole body to architectural representations demonstrates a metaphoric understanding of the body, perhaps best elaborated by the chiasm, "architecture as a metaphor for the human body, and the human body a metaphor for architecture. ${ }^{10 "}$ Specifically, in the example of Francesco di Giorgio Martini's church plan (C. 1465) (Figure 3) the human body is physically ascribed atop the plan of a church, metaphorically providing relationships between the different forms and programs. Interestingly, the body is represented in a contrapposto, or asymmetrical, stance, where the angle of the hips contrasts the angle of the shoulders. This stance is worth note because despite its asymmetrical nature, it is used to rationalize a symmetrical 
architectural form. The body in this instance is represented as a living, mobile entity whose dynamic form demonstrates the symbolic ability of the whole body to facilitate cosmological metaphors in architecture.

It is interesting to note that the value of the human body in architectural models, prior to and including the 15 th century, was closely aligned with the notion that the body could not be considered as a purely physical entity. Rather the body had to be thought of in conjunction with "that which gave its materiality significance - the essence contained within the body. A belief in the presence of that essence, a belief in the existence of an anima, a soul or a thinking entity, necessarily informed any possible perspective of the body. ${ }^{11}$ "To consider the body exclusively as a physical object was impossible because the body's' primary function was to act as a vessel for the soul. The consequences of these theological and cosmological views of the body, inherently demonstrate the origins of the Hellenistic-Roman notion of symbolic proportion and the cosmological anthropomorphism which both Vitruvius and Alberti favor.

In 1543, the interior of the body is explored in Vesalian science, with the publication of De Humani Corporis Fabrica. This publication while still maintaining the poetic theory that the body, the world and the heavens correspond to one another in an endless system of replication, marks a shift in the understanding of the body away from a purely theological or cosmological form. Specifically, during the late 16th century and early 17th century, the body is understood through the new progressive language of colonization. This transition is discussed in "The Body Emblazoned", a book which details the anatomical history of the body. Essentially, the metaphorical colonization of the body occurs in two stages; as the body is first explored and subsequently categorized into a series of productive parts. These parts are then analyzed with Cartesian precision, 
and are understood as components in a complex system.

Following this 17 th century understanding of the body as a series of parts, the descriptive language for the body again changes. This time away from an understanding of the body based in colonization, towards an "image of body as machine. ${ }^{12 "}$ The implications of this shift are immense and specifically in architecture the body is no longer capable of maintaining the layered metaphors which held to natural, and consequently, hierarchal systems. Instead, the body is now susceptible to logical processes and becomes "a system, a design, a mechanically organized structure, whose rules of operation, though still complex, could, with the aid of reason, be comprehended in the most minute detail. ${ }^{13 "}$ Consequently, principles of investigation hereafter proceed to document and categorize the measure, weight and number of body parts. This final transformation marks the adoption of one set of quantitative metaphors, at the expense of the qualitative metaphors which previously dominated architecture. This quantitative body corresponds to the 21 st century model of the body which has become a subject mechanism, capable of situational restoration through the constructive technology of modern medicine.

Not surprisingly, the shift towards a mechanistic body model in contemporary architecture has resulted in a decrease in the use of cosmological body models in architectural construction. One example, which attempts to bridge between symbolic and mechanistic representations of the body can be found in the "Old Way of Seeing", by Jonathan Hale. Specifically, Hale discusses the notion that a symmetrical relationship of architectural parts enables man to form a psychological connection to architecture ${ }^{14}$. Jonathan Hale discusses the importance of architectural symmetry through the example of the Stone House. The Stone House is comprised of an original 5 bay house, and 
a later single bay addition. The single bay addition, Hale writes, creates a tangible proportionality by not placing a window where a viewer expects one to occur (Figure 2). This visual relationship is reinforced, in a graphic which utilizes regulating lines to reestablish the location of the missing window and the relationship between architectural parts. The absence of the 'missing' window is purported to create an asymmetrical façade, which is still capable of reflecting the original symmetrical form of the 5 bay house. Hale further argues that the altered symmetrical order engages the viewer because it modifies the predicted architectural ordering system. This ordering system, is anticipated because there is a perceived relationship between the human body and the architectural composition. The viewer expects an architectural order because he projects an understanding of his own physical form onto the architecture, allowing him to embody the constructed environment. This particular perception of the body in building is most closely related to the Hellenistic-Roman representation of the body, which focuses on reinforcing cosmological anthropomorphic relationships. However, the relevance of a symmetrical body as a means to establish harmonious relations within an architectural whole, is absent in contemporary culture and this reality goes unmentioned by Hale. Instead, the analysis of the Stone House attempts to return to a historic understanding of the body through the conduit of a contemporary mechanistic body model. The result is a hybrid body model, which deconstructs the facade of the Stone House into parts and subsequently reassembles these parts into a external surface, in an attempt to apply a harmonious understanding to their physical relationship. The most eloquent demonstration of this misnomer is the application of the harmonious body, which could only be applied and considered in architecture as a whole, to an external, localized series of parts. This produces a superficial reading of the Stone House, which does not consider the internal relationship of programs, materials or people. 
In order to establish a correlation between architecture and the contemporary human body, it is necessary to re-identify a multiplicity of layers within which the human body and architecture can be read. This re-definition is attemped through an analysis of modern architectural details which utilize the human body as module, measure and metaphor. A successful demonstration of the body enabling a multiplicity of readings in an architectural project, can be found in the Brion Tomb ${ }^{15}$, constructed by Carlo Scarpa (1906 - 1978). The Brion Tomb is unique in that Scarpa utilizes the human body as a generator for the geometric relationships of details, experiential qualities of spaces, and functional circulation patterns. One instance where a geometric relationship of parts is used to reinforce a symmetrical anthropomorphism is in the composition of the land bridge which passes over the main tomb. Specifically, the symmetrical form of the bridge enables a viewer to identify that a missing 'piece' is present in the overall composition of the architecture ${ }^{16}$ (Figure 4). The body also provides the logic for a window design in the wall facing the entrance of the Brion Tomb where Scarpa utilizes the relationship of “'three female figures ... to give a rhythm to the tripartite construction of an impassable window. ${ }^{17 "}$ The geometry of this window is generated by both the intersection of two circles, and by the geometry of a central female figures face. In this way the intersection of the circles is a moderated relationship between the physically perfect geometry of the circles and the imperfect human face, with the rule for intersection determined by the position of the central figures features. Marco Frascari speculates in "The Body and Drawings of Carlo Scarpa", that the origin of this detail was based in the experiential condition of setting one's forehead against the cool metal of a window frame. ${ }^{18}$ Carlo Scarpa also considers the circulation patterns of visitors to the tomb, noting in the drawing margin for the Brion Tomb entrance steps, "if (steps are) moved to the right everyone will go to the right. ${ }^{19}$ " 
Scarpa's attention to detail demonstrates that the body is considered in a variety of forms, from the macroscopic which can inform experiences and circulation patterns, to microscopic which can provide a rule for the relationship of architectural parts. This new model for architectural anthropomorphism is neither the cosmological anthropomorphism of Francesco Di Giorgio Martini, or the symbolic symmetry of Jonathan Hale. Instead Scarpa re-creates an understanding of the body based on the layering of both qualitative and quantitative relationships. These relationships respond to the programmatic, social and functional necessities of the architecture while maintaining dynamic interactions with the microscopic and macroscopic body. The resultant of the process of reinterpreting the body at various scales and situations is arguably a return to a tangible harmony of parts which earlier body models sought to establish. While it is impossible to establish a specific definition of harmony - it is at least fair to acknowledge that each piece of the Brion Tomb seems appropriate in its shape, size, and location; creating an arrangement of parts from which nothing can be added or taken away. 

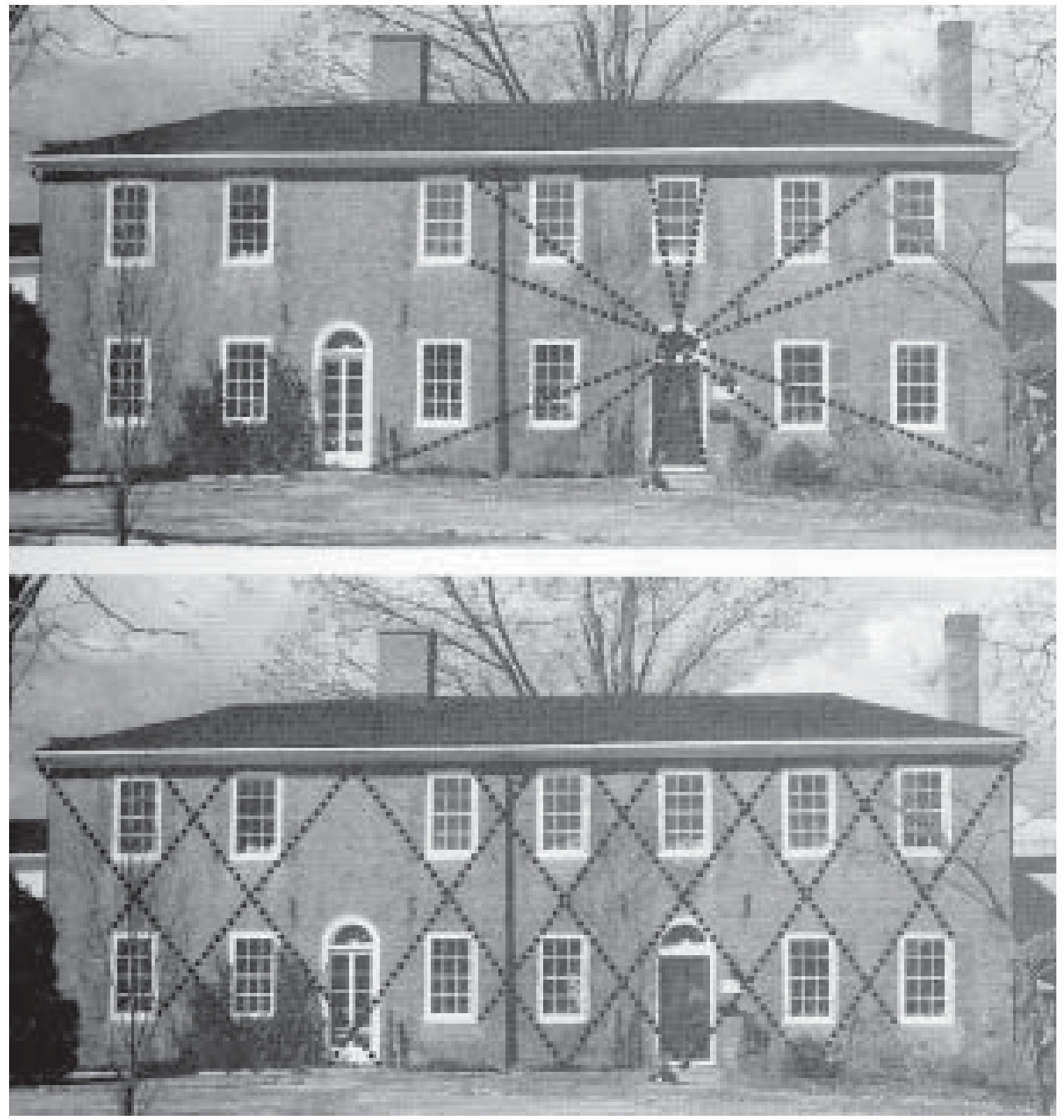

(Figure 2) The Jonathan Stone House in Belmont Massachusetts, with Regulating Lines. 


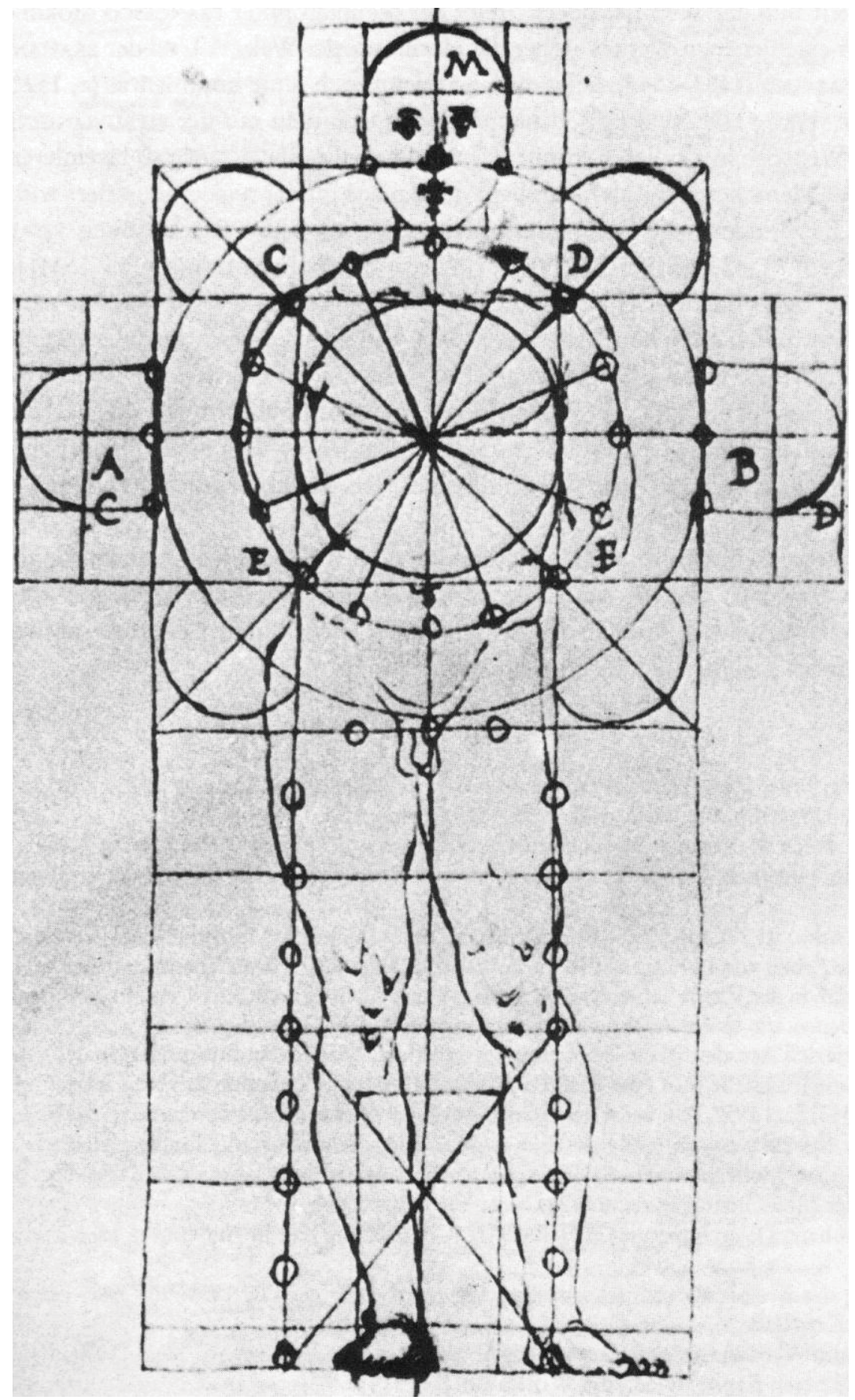

(Figure 3). Francesco Di Giorgio Martini Church Plan. 


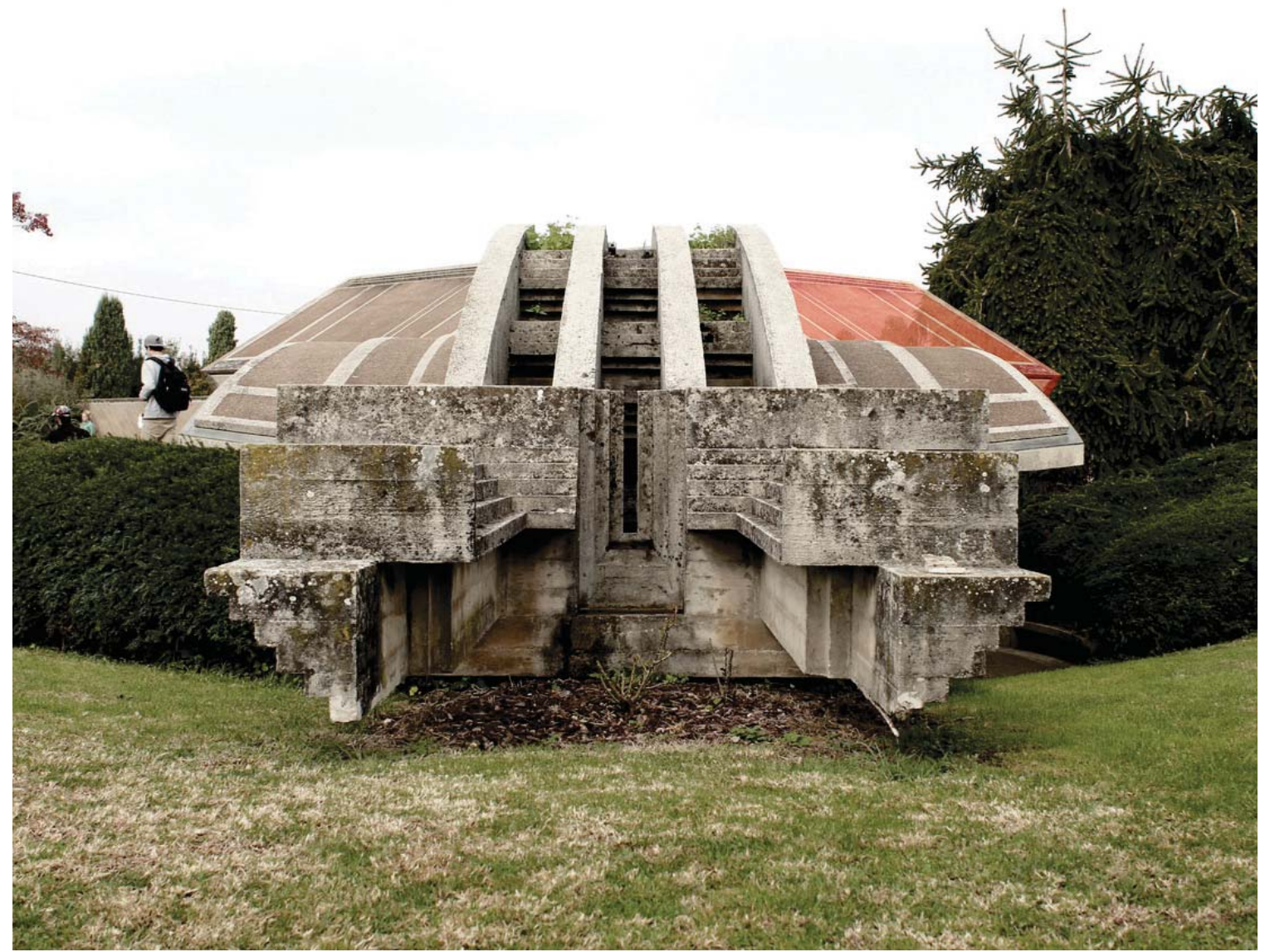

(Figure 4) Carlo Scarpa's Brion Tomb. 


\section{The Body in Construing (Macro)}


As previously discussed, the human body has historically served as a microcosm for architecture being an instrument through which systems of anthropometric and proportional geometries were derived. These systems of measurement were utilized not only in the physical construction of architecture, but also in the scaling of architectural drawings. The ability of anthropometric systems to directly reference the human body have varied, primarily because of the variety of body dimensions which are dependent on culture, sex, and age. Historically, anthropometric scales were first attained through the amalgamation of a variety of body parts from multiple subjects. The Egyptians in particular created scales of canonic proportions, through the "aggregate measurements from various subjects admired for their beauty. ${ }^{\text {" }}$ This approach rationalizes anthropometry founded primarily in the body, and secondly in geometry. The language of these anthropometric measuring systems were also anthropocentric, specifying the elbow (cubit), the finger (digit), the thumb (inch), the foot (pace) as key lengths ${ }^{2}$. The disadvantage of these scales was that the actual measures of each unit (finger, thumb, foot) varied with culture, making cross-cultural interpretation of architectural drawings challenging. In response to this difficulty the imperial and metric scales were created and adopted as primary systems of measurement. The meter was initially developed in 1797 as a universal system of scale that would apply a consistency to the magnitude of measurements. The metric system is based on a standard set of prefixes in powers of ten, with base units that could be used to develop both larger and smaller increments of measure (I.E. 10 millimetres in a centimeter, 100 centimeters in a meter.) However, mathematically based systems of scale do not acknowledge the historic belief that the inclusion of anthropometry was essential to architectural construing. Le Corbusier argues in favour of historic anthropometry in Le Modular, developing the Red and Blue scales which are based on a decomposed postural body. 
In "Le Modulor", Le Corbusier addressed the importance of establishing a new architectural scale which would directly embed anthropomorphic measurements in constructed architectural forms. Le Corbusier criticized the metric system particularly, stating that the "meter is nothing but a number, governed by the decimal system, incapable in architecture of qualifying an interval. Indeed it is a dangerous tool, for through starting out with abstract numbers - one is tempted to perpetuate it." Essentially, Le Corbusier considered the metric system to reduce measurements to symbols and dislocate architecture "from its object, which is to contain men"4 This was because the metric system was, as previously mentioned, developed as a division the mathematically perfect ten into a calculation of one forty millionth part of the meridian of the earth. Ironically, the original intent of the scale was to create a series of measurements for all people for all time ${ }^{5}$. Despite this, Le Corbusier maintained that the standardization of measurements which the metric system enabled, sought first to accommodate geometry and secondly the human body. This claim is at least partially true, as the development of the metric system coincides with the approximate development of the 18th century anatomical understanding of the body as a series of component parts. This shift in anatomical understanding removes the necessity for direct anthropometric metaphors in systems of measure. This removal, as well as the inability of the body to provide a universal scale without extreme abstraction, aids the ability of mathematic ratios to dominate the metric system. Despite this, Le Corbusier maintained that it was essential to include the body on a fundamental scale in measurement systems and established the Red and Blue scales to reincorporate the body into architecture. These new systems accommodated both geometric and gestural movements, which originated from body postures and movement. 
Despite Le Corbusier's intention to create a new universal system of measurement founded in anthropometry, the Red and Blue scales were not easily adapted to building. The difficulty inherent in the scales were that they acted as an absolute system for design, rather than a guideline towards quantitatively re-incorporating the body into architecture. Consequently, the scales were implemented by only a handful of Le Corbusier's most passionate admirers and never adopted as a universal scalar system. The belief that the embedment of an anthropometric measurements in building facilitates architectural construing, originates from the Hellenistic-Roman notion that it was essential for man to identify his own body in the constructed forms of his environment. Essentially, the inclusion of the body in building enabled a higher harmony of parts to be demonstrated, and architecture to not only be perceived by one's sight but also through metaphor and symbolic relation. Therefore, the historic identification of both the physical and symbolic body in the building enabled cosmopoiesis founded firstly in the body and secondly in mathematic ratios. Cosmopoiesis is essentially the ability for architecture to influence man's understanding of himself within the world, and is introduced by Marco Frascari in the "Eleven Exercises in the Art of Architectural Drawing: Slow Food for the Architect's Imagination". In "Eleven Exercises", Frascari establishes that cosmopoiesis is essential in architecture because it allows architecture to reflect an "understanding of buildings, conditions, processes and events in human world-making." This 'world making' is the ultimate goal of architecture, and must be considered so that architecture is created both for the body and from the body.

Since the body no longer operates through symbolic and metaphoric models, a contemporary body model must be established to understand how architecture can be created both for and from the human form. I would like to suggest, that the inclusion of the contemporary human body in architecture need not be achieved 
through anthropometry. Le Corbusier's confidence that the embedment of body based measurements would allow the re-incorporation of the body into architectural construing and construction at a fundamental level, necessitates that the body still have symbolic significance. However, the contemporary understanding of the body is not based on symbolic or metaphoric relations, but rather on a mechanistic body model. This type of body model does not require architectural anthropometry, because it operates as a functional system of parts. This shift enables the contemporary body to rely on mathematical relationships, to establish functional quantitative systems in architectural construction. Essentially, the necessity for quantitative mathematical systems to facilitate anthropomorphic cosmopoiesis in construction is void. However, the contemporary body is capable of facilitating cosmopoiesis in architectural drawings, as discussed extensively by Frascari in the "Eleven Exercises".

Specifically, Frascari demonstrates that hand drawing is successful at enabling cosmopoiesis, because it is an interactive and generative process, reflecting more than the physical architectural form it typically represents. The practice of architecture is often removed from the physicality of building, so drawing in this way can act as a mediator between conception and construction. Drawings are not only a process of construction but a means through which architects are able to order and express their cosmopoetic attempts. They represent more than just building because they are not static presentations of a construction. Drawings are rather dynamic representations capable of being read through their varying line weights, line types and materiality. Essentially, analog drawings are composed of a series of traces formed by the dexterous hand, layered to create a palimpsest. The layering of traces in this type of drawings engages re-interpretation of the design, during the process of designing, by the architect. This iterative process is essential to cosmopoiesis. However, in contemporary architectural 
practice the ability for architecture to enable cosmopoiesis is debilitated by popular digital systems of representation.

In the Introduction of "Eleven Exercises" Frascari addresses the inability of digital systems to facilitate cosmopoiesis, stating that computer modeling "speeds up tasks and in theory at least, increases precision and photographic actuality, but produces building that lack grip and traction in time ${ }^{7 \%}$. This loss of grip in time and space produces architecture that typically creates a "sense of disconnection from time and place. Therefore, models when representative of an architectural product are less capable of enabling cosmopoiesis because they are literal representations of a constructed form; they are transcriptions rather than inscriptions. Cosmopoiesis is therefore reliant on the mediation of the process of construing and constructing architecture, and is most successful when operating within a reading of traces. 


\section{Ex. 1: Reification of the Body in Analog Drawings}


As previously established, the process of drafting facilitates cosmopoiesis at the joint created between the movements of the hand and the inscriptions which the hand produces. Traditionally, drafting was understood as an essential skill through which the architect was able to express not only the product of constructed space, but also the process of experiencing that space. This was achieved through the use of a variety of line weights, line types and line materiality to communicate qualities of space. Contrastingly digital drawings exclude the hand from the process of drafting, largely removing the ability for anthropomorphic cosmopoiesis and an experiential reading of drawings. Exercise 1 affords a critique of the current modes of drafting which reduce plans, sections, elevations and details to a static transcription.

In analog drafting the relationship between the hand and the traces the hand produces is founded in an understanding that the meaning of lines is not based solely in their geometry but equally in the materiality the lines represented. Consequently, when reading a analog drawing an architect's attention is not drawn only to the geometries the forms that the lines demonstrate, but also the experiences the lines manifest. For example, a stone wall may be digitally represented as a thick black line, while in analog it may be drafted in charcoal as a thick surface with a irregular line weight. While a digital representation in this case would demonstrate a heavier material, a analog representation is capable of conveying an irregular surface texture, an indication of colour in addition to the heavy material depicted in a digital representation. This understanding of the multilayered qualitative and quantitative reading of the analog representation, may in turn facilitate an interpretation of the space which the stone wall is adjacent to. In this way, lines serve to deliver the architects' cosmopoetic attempts, penetrating beyond their basic physical geometrical manifestation. Lines when used in architectural drawings in this way, are a process of inscription rather than transcription. 
The shift in architectural drawings towards a process of transcription can arguably be traced back to the introduction of AutoCAD in 1982. Following the introduction of $\mathrm{CAD}$, digital lines in contemporary drafting rarely demonstrate material or experiential qualities of architecture; instead they define only geometric boundaries. In part, this reduction can be attributed to the contemporary understanding of the line as a static object, discussed extensively by Tim Ingold in "Lines: A Brief History". Specifically Ingold argues that the reduction of the line to a product may have occurred because of the familiarity of the line as a representational tool. Apprehending lines as they are commonly seen on paper, motionless and prone to extended examination, allows them to be perceived as an object. In this way the architect's eye surveys a page but has no necessity to inhabit $\mathrm{it}^{1}$. This type of viewing of lines is an objective surveillance, set apart from the dynamic act of architectural cosmopoesis.

Unfortunately the reduction of the line to a transcription negates the cosmopoetic ability of architectural drawings, reducing them also to a self-referential product and a demonstration of a future building. Ingold discusses the separation of the hand from drawing, stating that lines are "now committed to paper by way of a mechanical process that bypasses the work of the hand. In typing and printing, the intimate link between manual gesture and the inscriptive trace is broken. ${ }^{2 "}$ For contemporary architects, plans are printed onto a page, and are absent of any of the anthropomorphic traces which produced it. This enables building to appear as a pre-composed artifact, which "bears no witness to the activity of those whose labours brought it into being..." 
Tim Ingold also discusses, that the separation of the body from drafting may be linked to a change in perception of the surface; from a thing typically viewed as a landscape, which one moves through, to a screen which one looks at and upon which images are projected ${ }^{4}$. This shift in understanding is in part due to the technology of print, which decomposed the link between manual gesture and graphic inscription ${ }^{5}$. The separation of manual gesture from graphic inscription in turn, facilitated the reduction of drawing into a series of product driven computational sequences. This reduction removed the multitude of activities typically associated with the process of inscription, in favour of a printed transcription. Gestures involved in this process of transcription have no relationship to the geometries they deliver.

In an attempt to re-identify the relationship between the dynamic body and contemporary architectural drawing based in digital media, I proposed an exercise to create a multi-dimensional model capable of mediating between digital and analog architectural representations. The intent of the exercise was to incorporate $2 \mathrm{D}$ static and 3D dynamic lines into a single architectural model. The goal of the exercise was not to produce specific forms, but rather catalyze the relationship between the body and architectural representation with drawing, to produce space.

The first step towards creating a model capable of demonstrating the relationship between the human body and drawing, was to literally draw a base for the analysis. The 2D drawing component did not have specific requirements excepting that it be large enough to physically interact with and composed of a variety of line weights. As such, I chose the most basic tool in analog drafting to become the base for the exercise; a lead holder scored in plan into a mirrored surface at a scale of 5:1. The intent of the mirrored surface as a material base for the drawing, was to enable the body and $2 \mathrm{D}$ drawing to 
visually merge on a single plane. Once the lead holder was drawn into the mirrored surface, a series of 'key' points were established. These key points were determined based on location and the number of intersections crossing through a given point. The centre line of the entire composition was also given hierarchical preference since it visually centers the entire composition.

Once established, the key points were drilled through with three drill bit thicknesses; a small, medium and large. After drilling through the points, string was used to begin connecting the points and physically visualizing the gestural process the drawing and drilling took. Consequently, the locations where the hand occupied a greater amount of time, coincided with the points that had the most intersections and the largest drill holes. String passing through these point becomes thicker, while small drill points with a single intersection contain only a single strand of thread. At this stage the gestural process of inscription has become manifest, and can begin establishing a relationship to the 2D drawing.

The final stage of the exercise was to incorporate the human body into the exercise to physically manipulate the string. This step is resolved when the digital images of the manipulation are layered, enabling the space between the body and drawing to be graphically represented. Interestingly, the movement of the body in trace making process which is essential to cosmopoiesis is transferred to the digital representation of the exercise. Specifically, the gestural body traces are made visible through the ghosting of a series of images which digital media best facilitates. 


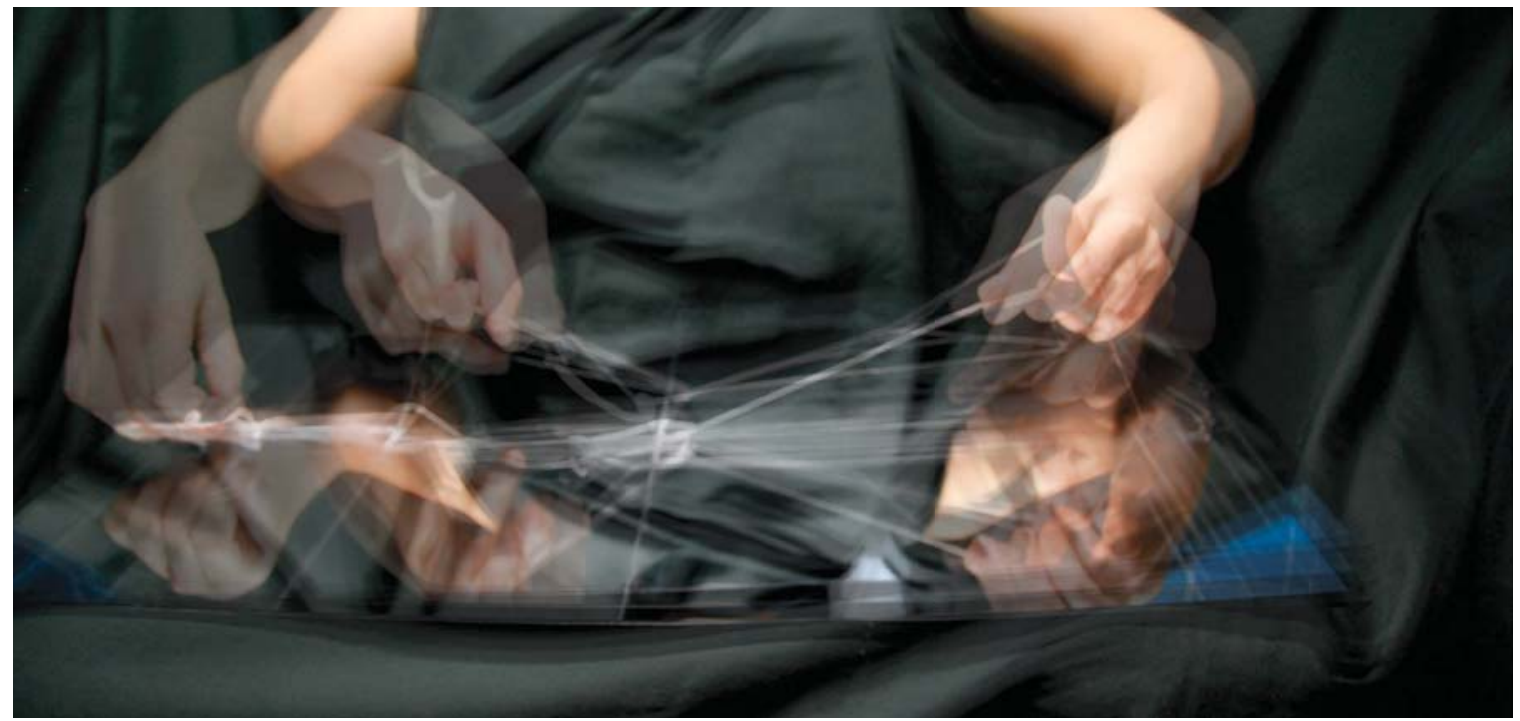

(Figure 5) Exercise 1: Iteration 1.

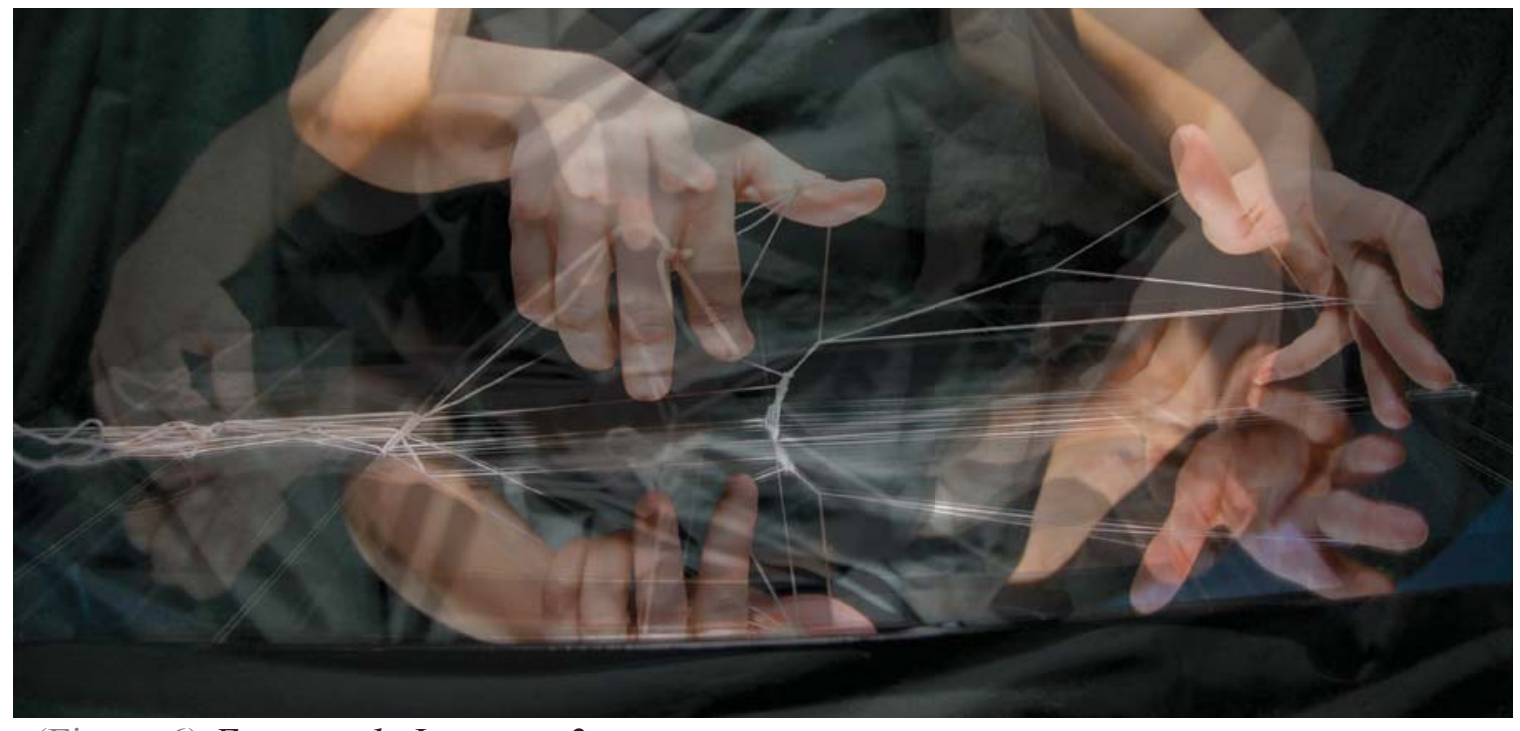

(Figure 6) Exercise 1: Iteration 2. 


\section{The Student Body in Building 22}


In 1968, Carleton commissioned a new purpose built structure for the School of Architecture from Elin Corneil, Carmen Corneil and Jeff Stinson ${ }^{1}$. Construction of the project ended in 1973, and since Building 22 has enjoyed 41 years of use by The Azreli School of Architecture and Urbanism. Original design ideas prioritized interconnectivity of student spaces within Building 22, and operated through a street system modeled off Jane Jacobs's theories of urban complexity ${ }^{2}$. This 'street' model can be easily identified at the ground level, and in the $4^{\text {th }}$ floor of Building 22. Specifically, at ground level pedestrian traffic is moved along the West / East axis, beside the appropriately termed "Pit". The "Pit", as the name suggests, is a recessed space adjacent the ground level street, where presentations occur and large models may be constructed. Its lack of visual, physical and acoustic enclosure ensures that the space is informal and adaptable.

The $4^{\text {th }}$ level street runs along the North / South axis, and is located between the four studio spaces which each respectively house a different 'year' of students. The street design is particularly successful on the 4th floor, as it facilitates chance encounters between students, faculty, and staff because of its visual and physical porosity. Terri Fuglem discusses this porosity specifically, in the article "Carmen Corneil at Carleton", stating "we can describe the (Carleton) building as being organized about its own internal 'street system'. Both have many similar traits: ... options for development along their edges ... common facilities and events for the community and for daily contact between members." The studio spaces were also particularly essential in the design of Building 22 because previously students required large, barrier free workspaces to construct drawings and models, perform material experimentations and store work. These spaces required durability, and were responsible for informing the poured and block concrete materiality dominant in Building 22. 
In contrast to the durability of the original building, the 5th floor, constructed in 1985, is materially composed of painted drywall surfaces and drop acoustic tile ceiling. This addition was originally constructed to allow the expansion of the Carleton Engineering School. As such, the 5th floor currently houses an amalgam of engineering computer labs, unused spaces, and a handful of rarely occupied architecture studios. The studios which occupy the 5th floor currently, are a selection of the M. Architecture and M. Architecture 1 programs. The remainder of students from the Master degrees, occupy the 4th Floor of the Azreli Pavilion located across campus. The separation of the Undergraduate and Master programs into different buildings, promotes not only the division of students but also a separation of knowledge. Currently students in the M. Architecture programs are unaware of Undergraduate projects, and vice versa. This lack of awareness means that there is little exchange of design ideas or collaborative discussion between programs. In addition to the separation of the programs the 5 th floor is largely unoccupied by either Undergraduate or Master students.

In an attempt to remedy this separation and disuse, the project seeks to economically renovate the 5th floor to more comprehensively reflect The Azreli School of Architecture and Urbanism and its student body. The renovation will include an assessment of the current programming from both Building 22 and The Azreli Pavilion, to establish the current requirements for offices, studio, presentation areas, computer lab and classroom spaces ${ }^{4}$. 


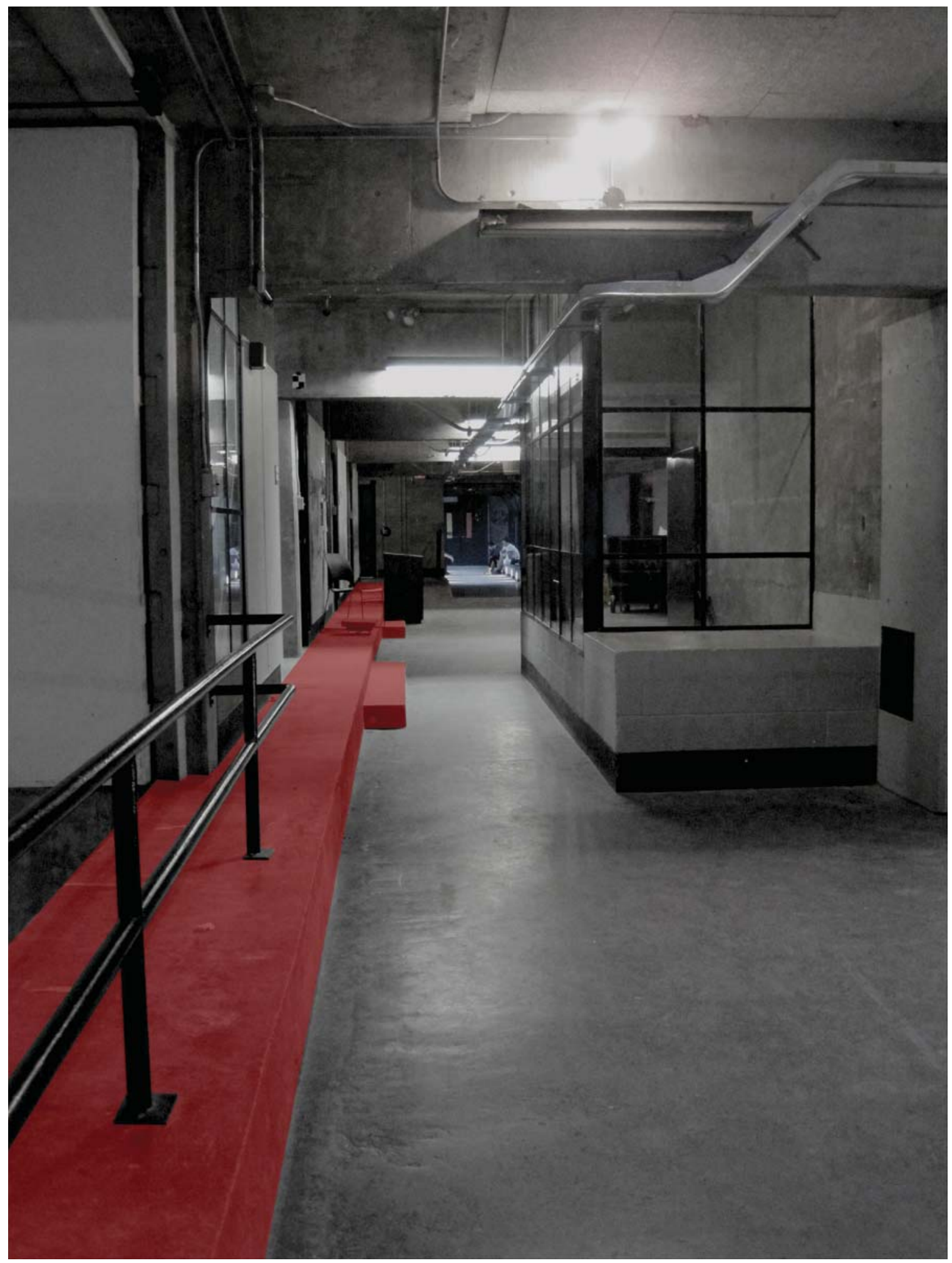

(Figure 7) View Along 4th Floor Street of Building 22. 


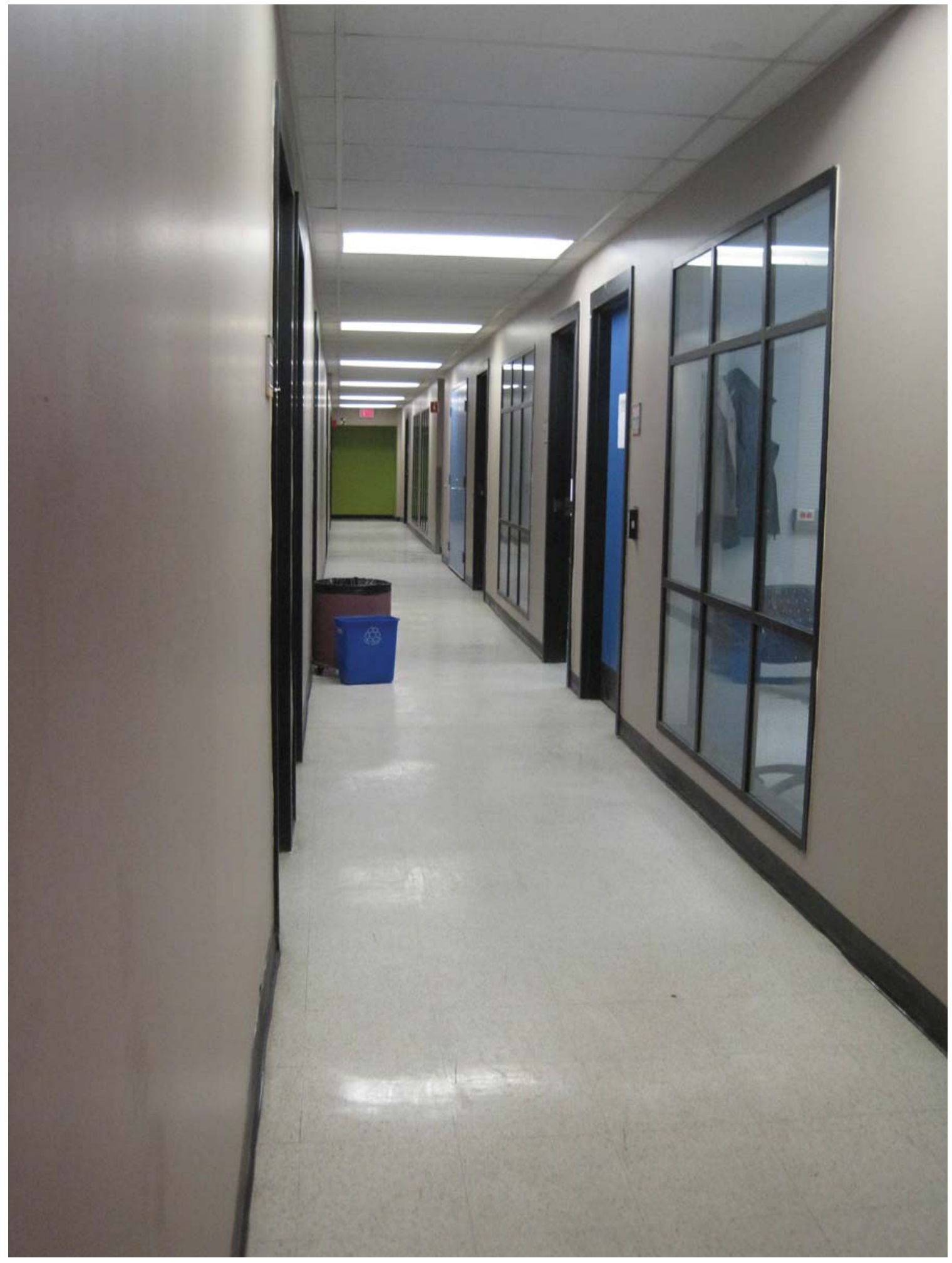

(Figure 8) View Along 5th Floor Corridor of Building 22. 
Ex. 2:

Anthropomorphic Models in Building 22 
Exercise \#2, was a attempt to identify a new anthropomorphic model grounded both in the student body and architecture of Building 22. The goal of the exercise was to establish key ways in which the student body occupy and use the basement, a 4th floor studio space, and the 5 th floor corridor ${ }^{1}$. The original exercise, was only based in a documentation of the student body and the relationship of this body to Building 22 . This analysis however, did not allow a re-interpretation of the habits and habitat of the student body. To enable this re-interpretation, the documentation of the different spaces were layered to re-create representations of the body. Exercise \#2 also sought to identify how student occupation of space, visually and physically affects an understanding of the materiality of that respective space. Specifically, the spaces students occupy have gradually been filled with a variety of objects, systems, projects, and materials which both visually and physically obscure the original material scale of Building 22 . The variety of these objects inherently changes the way the individual body circulates through, and occupies space. These objects typically fall into three categories; 
1: Ergonomic Materials - all objects which facilitate student work. This includes chairs, desks, and lockers.

2: Junk - all objects which students leave in the space that may, or may not, have to specific relationship to performing a task. This includes food wrappers, projects, papers, bottles, ETC.

3: Systems - all systems which facilitate student inhabitation and create a comfortable and livable environment. This includes mechanical, electrical and ventilation systems which line the studio bays and ceilings.

Each of these categories has a different visual scale, and mobility. For example, ergonomic and junk material are highly mobile and can affect circulation patterns dependant their location. Contrastingly, systems are typically static but directly affect the habitability of space. Systems also provide a visually relatable scale in areas which are not physically accessible. For example, the presence of exposed mechanical and electrical system in studio facilitate a visual relationship between students and the ceiling, while also educating students about the respective system construction. This exercise explores the changing role of the body in relation to three spaces within Building 22; the L1 Master of Architecture Studio, the L4 $3^{\text {rd }}$ year Studio Space, and the L5 hallway. The exercise also establishes three types of spaces present in Building 22; programmed, semiprogrammed, and un-programmed. 
L1 Studio: The L1 studio is occasionally occupied by a handful of M. Architecture students, who use the space for writing and model making. As such, the studio is categorized as a semi-programmed space because, while it may be re-programmed for eating or sleeping, it typically functions as a studio.

The L1 Studio space exercise was the first, and least successful, attempt to define the body in the Building 22. The reconstituted graphic in this instance maintains the original architectural forms of the studio space and consequently mutates the body in an attempt to re-stitch a series of architectural fragments. This reduces the body to a static image, and negates its dynamic relationship to the established categories. The poured concrete materiality of the L1 Studio also does not physically or visually relate to the physical body; enabling a limited series of relations between the body and concrete pours, form-work marks, and electrical systems. The exposed systems present in the ceiling facilitate perhaps the most opportunity for visual inhabitation, because of their varied size and colour which respectively demonstrate their functional use. 

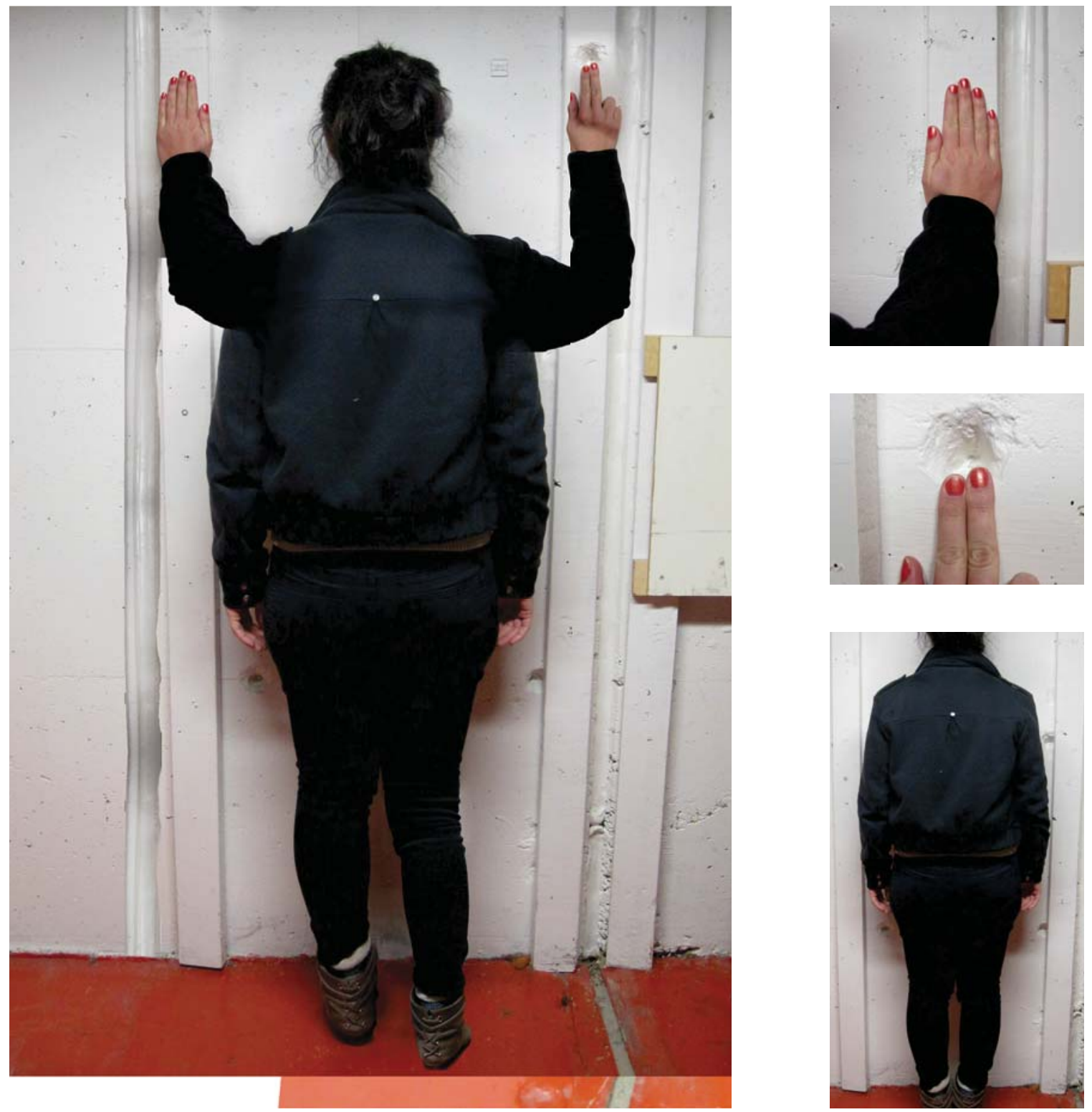

(Figure 9) Above Left: Compilied Body Model

(Figure 10) Above Right, Top: Hand Width Against Wood Sub-Structure

(Figure 11) Above Right, Middle: Finger Width Against Formwork Trace

(Figure 12) Above Right, Bottom: Body Width Between Wood Sub-Structure 
L4 Studio: The L4 studio is currently inhabited by third year Bachelor of Architectural Studies students. In this instance, the studio functions as a semi-programmed space (Figure 26), because the area facilitates the adaptive re-programming and re-organization of student inhabitation, the primary use of the space is for model making and drafting.

The L4 $3^{\text {rd }}$ Year Studio space reveals a dynamic arrangement of systems, junk and ergonomic objects. The systems in particular, are "engaged in an elaborate dance with the structure: either bracketed by it, or bound to it, or woven around and through the frame." Visually, they enable a relative understanding of scale within the un-inhabitable ceiling. Additionally, the mobility of both ergonomic objects and junk, as well as the quantity, contribute to a dynamic student inhabitation of the studio. The open and unrestricted nature of the studio space, in this instance, perfectly accommodates the variety of objects and uses students bring to their work areas.

In this exercise neither the body nor architecture seeks to statically accommodate one another. The resultant representation is a layered image which, literally and metaphorically, blurs the boundaries between the body and Building 22 . The materiality of the space also facilitates visual inhabitation, with anthropometric relations being established against the concrete block wall, structural column, and window. 

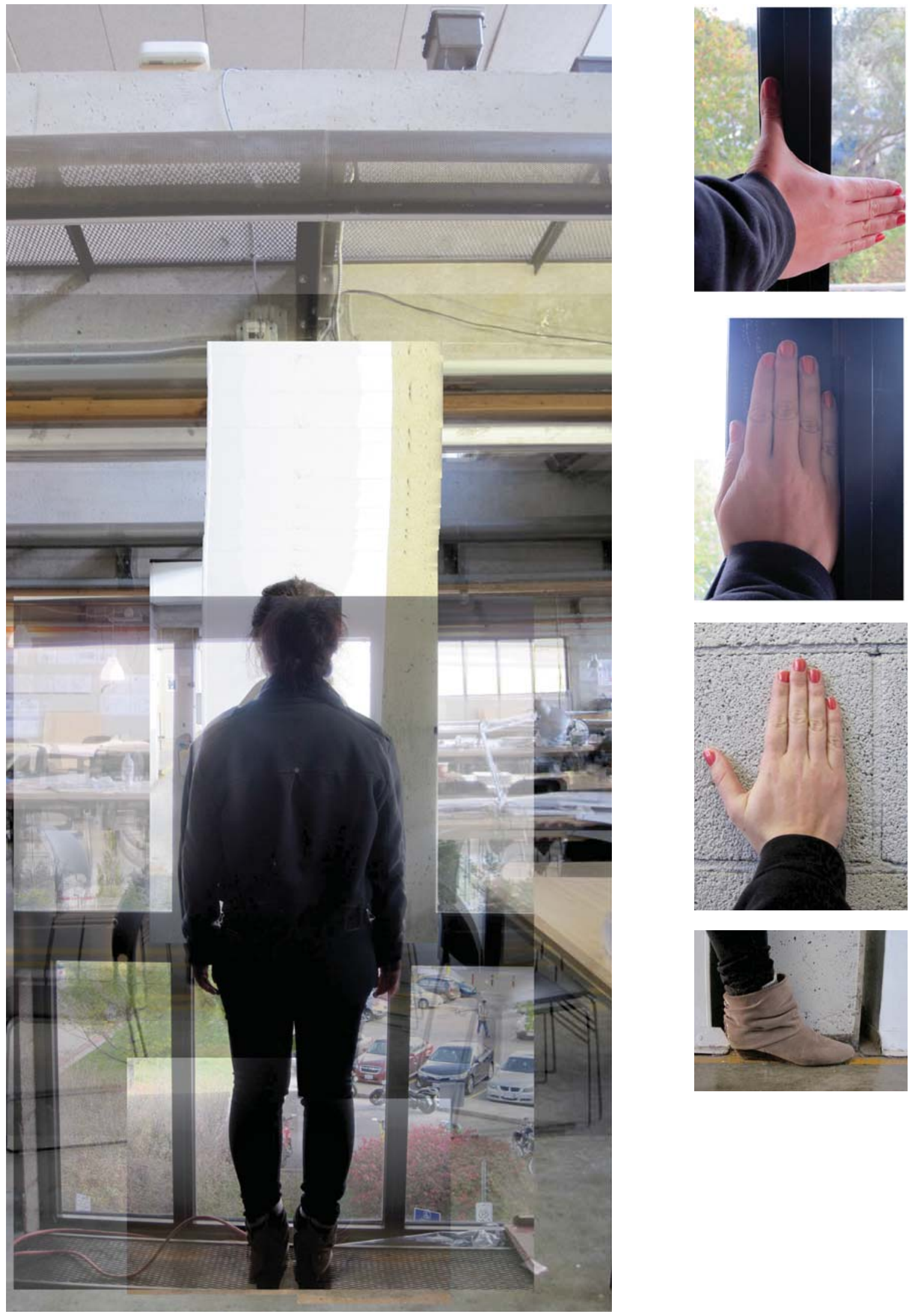


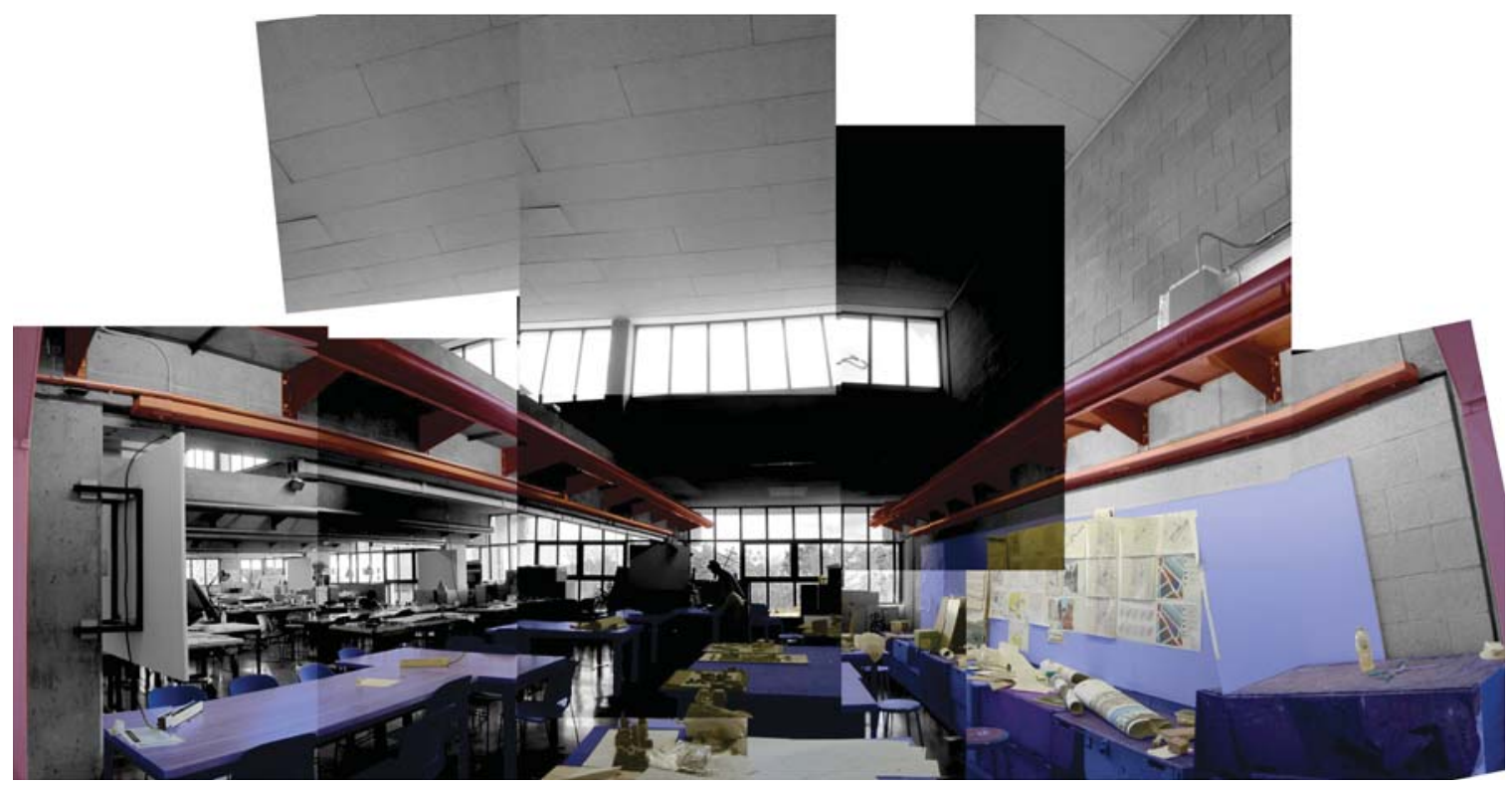

(Figure 13) Previous Page. Left: Compilied Body Model

(Figure 14) Previous Page. Right, Top: Finger Width Against Window Frame

(Figure 15) Previous Page. Right, Top Middle: Hand Width Against Window Frame

(Figure 16) Previous Page. Right, Bottom Moddle: Hand Length Against Concrete Block

(Figure 17) Previous Page. Right, Bottom: Foot Length Against Concrete Collumn

(Figure 18) Above: Systems, Junk, Ergonomic Materials Within 4th Floor Studio 
L5 Hall: The L5 hallway is occupied by both Architecture and Engineering students as they move between classes and buildings. This is a semi-programmed space (Figure 27), because while it affords the opportunity for chance encounters between students and faculty, it is most commonly used for circulation. It is worth note that since the hallway is a circulation space the quantity of ergonomic objects, systems, and junk is reduced.

Despite this, the contrast between the L4 Studio and the L5 addition, in terms of materiality and student presence, is dramatic. This in part may be because L5 disregards the architectural language of the original buildings' exposed structure, open-concept spaces and anthropometrically relatable materiality. L5 instead features drywall corridors, light steel frame structure ${ }^{3}$ and poorly lit computer labs. The visual and physical porosity between studio spaces and the primary circulation core, present in the street model, is also not translated into the $5^{\text {th }}$ floor addition. Rather, the street in the 5 th floor affords no un-programmed space for students to occupy and adapt. The visual porosity which is also dominant between floors in the original Building 22, is neglected in the 5th floor addition. The sole visual connection to the $4^{\text {th }}$ floor in fact, occurs through an enclosed glass skylight; this visual connection is essential and reinforces the 4th and 5 th floor differences in circulation, materiality and visual porosity.

In this exercise neither the body or architecture of the hallway seek to accommodate one another. This produces a relatively dynamic graphic, which utilizes details primarily from the small lookout point on the L5. This is worth noting because the lookout point is the only instance of un-programmed space which students may access outside their studios. The relationship between un-programmed space and the body is unique within Building 22, because these spaces provide opportunities for atypical student occupation (eating, sleeping, and working). 

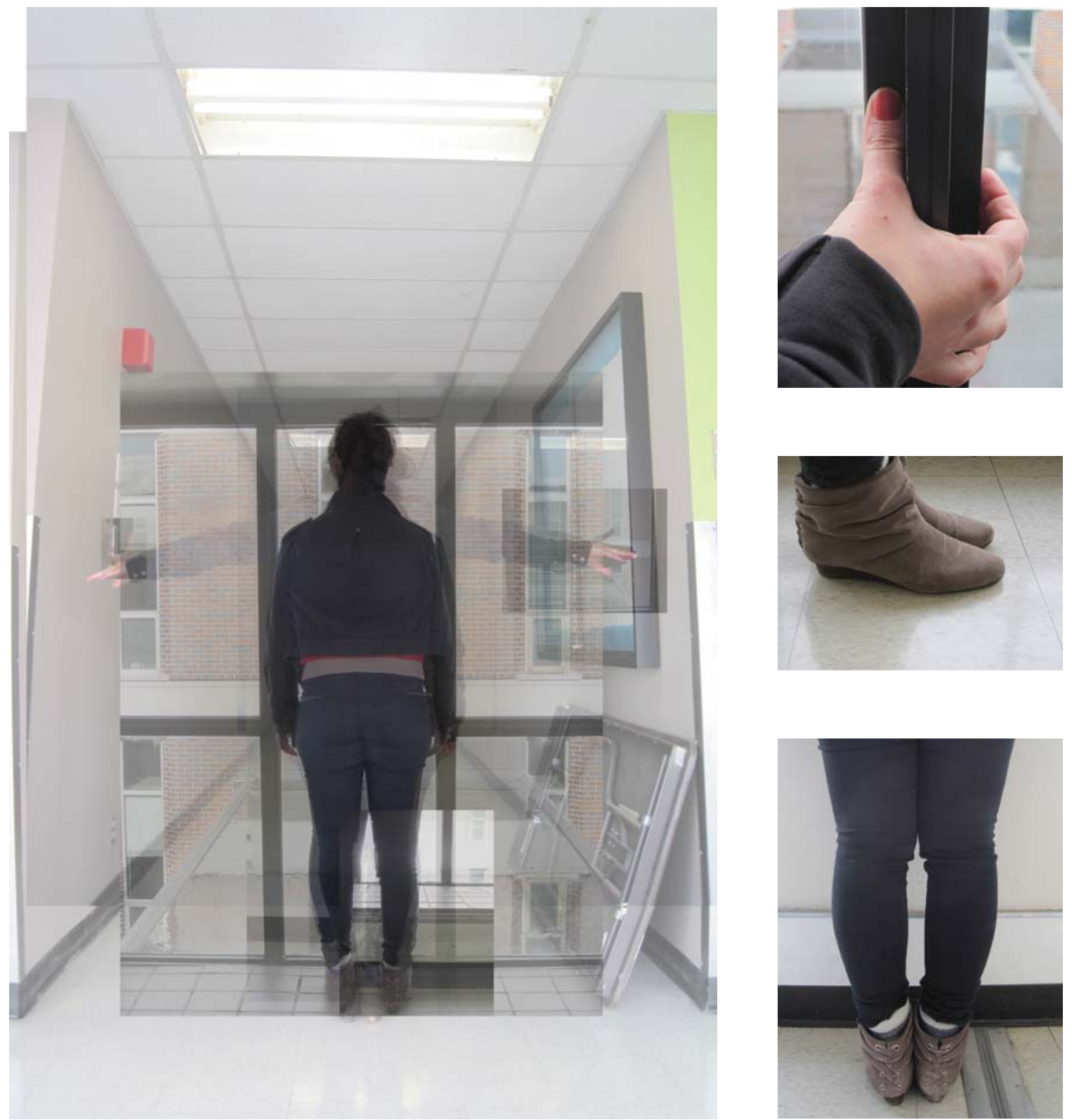

(Figure 19) Left: Compilied Body Model

(Figure 20) Right, Top: Finger Width Against Window Frame

(Figure 21) Right, Middle: Foot Width Against Tile

(Figure 22) Right, Bottom: Knee Height Against Drywall

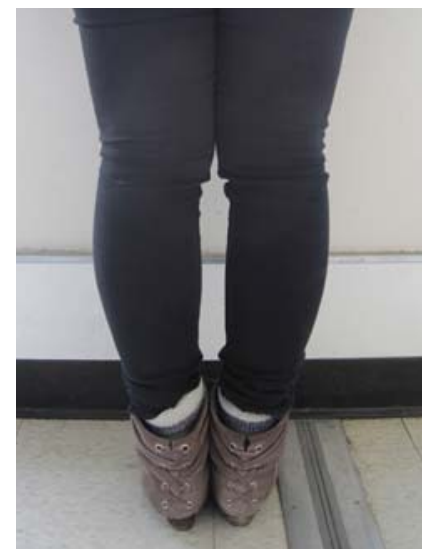




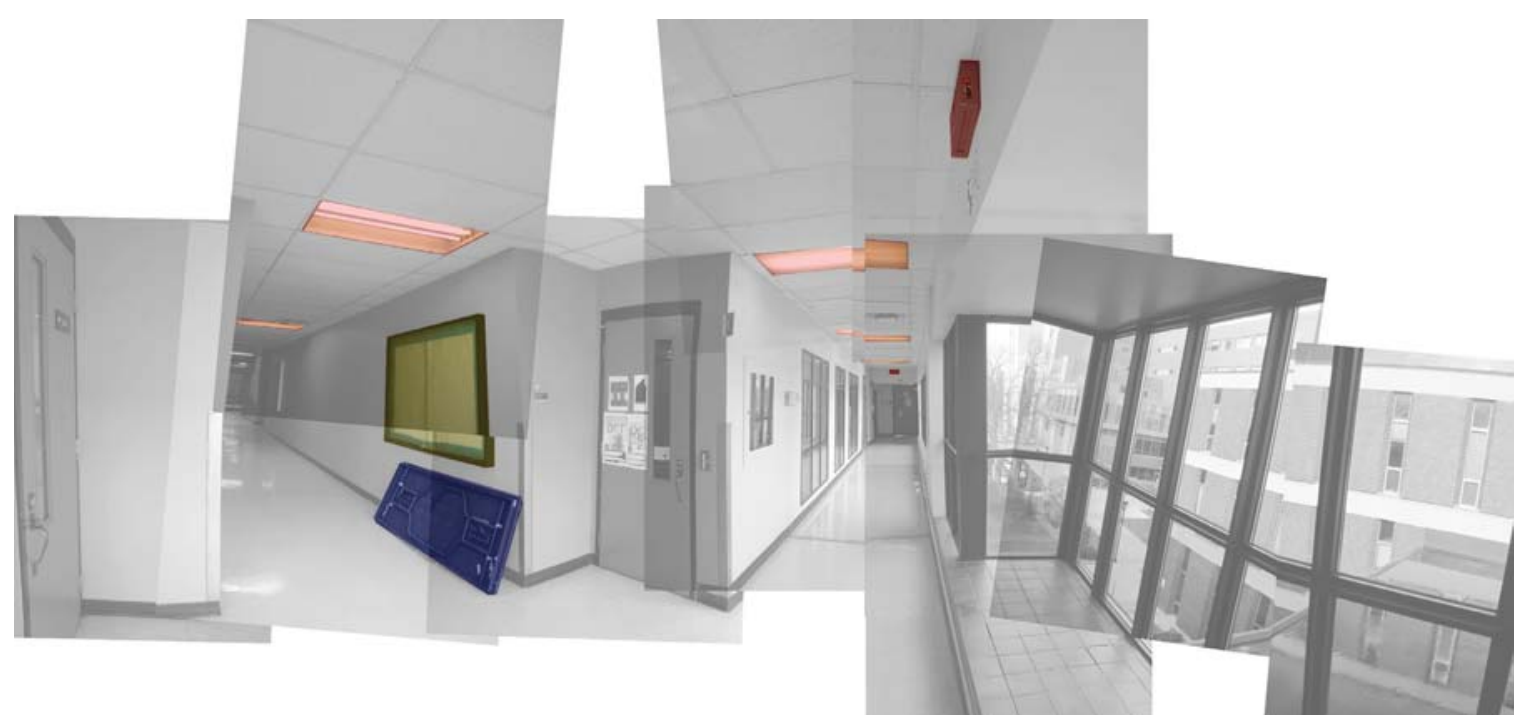

(Figure 23) Above: Systems, Junk, Ergonomic Materials Within 5th Floor Hallway 


\section{The Detail: \\ Changing the Scale of the Body \\ (Micro)}


Constructing 
In the "The Tell-the-Tale Detail", Marco Frascari, discusses the notion that both the construing and constructing of architecture occurs at joints. Joints are a subset of details, more appropriate to architectural constructing and construing, since details are typically understood as, "small parts in relation to a larger whole"". This definition of details when applied to architecture considers the scale of architectural parts in relation to the larger building. Architectural joints therefore, inherently operate within an architectural whole enabling material (connections between parts of a column) and formal (connection between interior and exterior space) architectural relationships to be established. Joints are also capable of mediating the programmatic, social and functional uses of constructed space.

In addition to enabling programmatic, social and functional mediation, the most successful types of joints enable learning through experience. Specifically, this means that successful joints are capable of engaging knowing and learning as processes which requires active following. Tim Ingold discusses this notion in "Making: Anthropology, Archaeology, Art and Architecture", stating that the process of knowing (learning) is not the studying of something, but rather studying with something. Consequently, study with someone allows the individual to learn from them, rather than only about them. Learning from an individual or learning from an architectural joint, consequently means that learning also occurs with the individual and within a building. In architecture school this statement may seem redundant, if the building is treated as an artifact within which teaching, and by proxy learning, occurs. However, building in this context is not intended to describe a static condition (artifact), or represent it, but rather building should respond to a condition and facilitate a dynamic interaction. Building should therefore be considered a dynamic process rather than a static artifact, and this type of building is the basis for both successful learning and successful joints. This notion of learning based 
on dynamic interactions is also discussed in "The Tell-the-Tale Detail", when Frascari states that joints "are appropriated in a twofold manner, by use and by perception, or rather touch and sight ... tactile appropriation is accomplished not so much by attention as by habit ${ }^{2}$." Therefore, details are based on experience which is facilitated through programmatic, social, and functional mediation.

Specifically, within Building 22, the concrete bench which lines the street of the $4^{\text {th }}$ floor acts as a successful joint (Figure 24), enabling programmatic, social and functional mediation. Functionally the bench is utilized not only to move between spaces, but acts as a seat; consisting of one $30 \mathrm{~cm}$ tall concrete bench, punctuated by two $15 \mathrm{~cm}$ concrete steps periodically. The bench also has a multiplicity of programmatic uses, since it is an un-programmed space (Figure 26, 27) and therefore re-appropriated by the student body for eating, sleeping, studying and group discussions. Essentially, un-programmed space is essential because "the building appears incomplete without the constant presence and ever-changing installation of its occupants. ${ }^{3 "}$ Finally, the bench enables chance social interactions between students, faculty and professors because of its centralized location along the primary circulation corridor. Overall, the Building 22 bench is a successful joint and successfully enables dynamic interaction between programmatic, functional and social uses.

The remainder of Building 22 is composed of semi-programmed, and programmed spaces. Semi-programmed space is constantly accessible to students, and can be occasionally appropriated for alternate use, yet has programmed use which the school occasionally requires. For example, the Pit would be an example of semi-programmed space which is officially programmed for presentations and group discussions, yet may be appropriated for model assembly and informal meetings. 
Programmed space is space which is regularly inaccessible to students, and has one or two intended functions. An example of programmed space would be a faculty office, or classroom. Broadly, joints in semi-programmed or programmed spaces enable fewer dynamic interactions, because they occur in more controlled environments. This reduces the ability of joints to mediate functional and programmatic uses, since typically the spaces they occur in have one or two designated uses. For example, a doorway to a faculty office would programmatically and functionally be used to move through, and has little social purpose. This type of joint most closely describes a static condition or artifact (entryway), and does not typically facilitate dynamic interaction.

A curious material and formal bench-detail in 1446-51 Florence, is the external bench of the Palazzo Rucellai (Figure 25), by Alberti. This bench demonstrates the ability of a detail to act as a joint mediating social and programmatic functions. The bench is part of the external façade, which Marco Frascari describes in "The Tell-the-Tale Detail", as visually incomplete. Yet, despite the facades' incompleteness the details of the Palazzo, in particular the bench, still retain the unique ability to provide human scale to a visually massive architecture. Specifically, the entrances of the Palazzo Rucellai are approximately twice the height of a typical entrance, creating a visual distortion to the approximate proportions of the architecture as a whole. Frascari discusses the notion of proportions of an architectural body in the "The Tell-the-Tale Detail", stating that an architectural body is defined with a series of proportions, where a basic module is the norm from which all the lengths, widths, and heights are derived. In the Palazzo Rucellai, the bench combats this distortion, providing a relatable, functional scale through which social interaction may occur. 
The bench of Palazzo Rucellai would be considered a semi-programmed space, and a mildly successful joint. Programmatically, it is intended to be a seat, upon and around which social interaction may occur. Functionally, it is utilized only to sit upon, and socially it mediates public and private interactions. Therefore, while the bench does facilitate dynamic interactions socially, this interaction is still controlled within the boundaries of the programmatic and functional uses. 


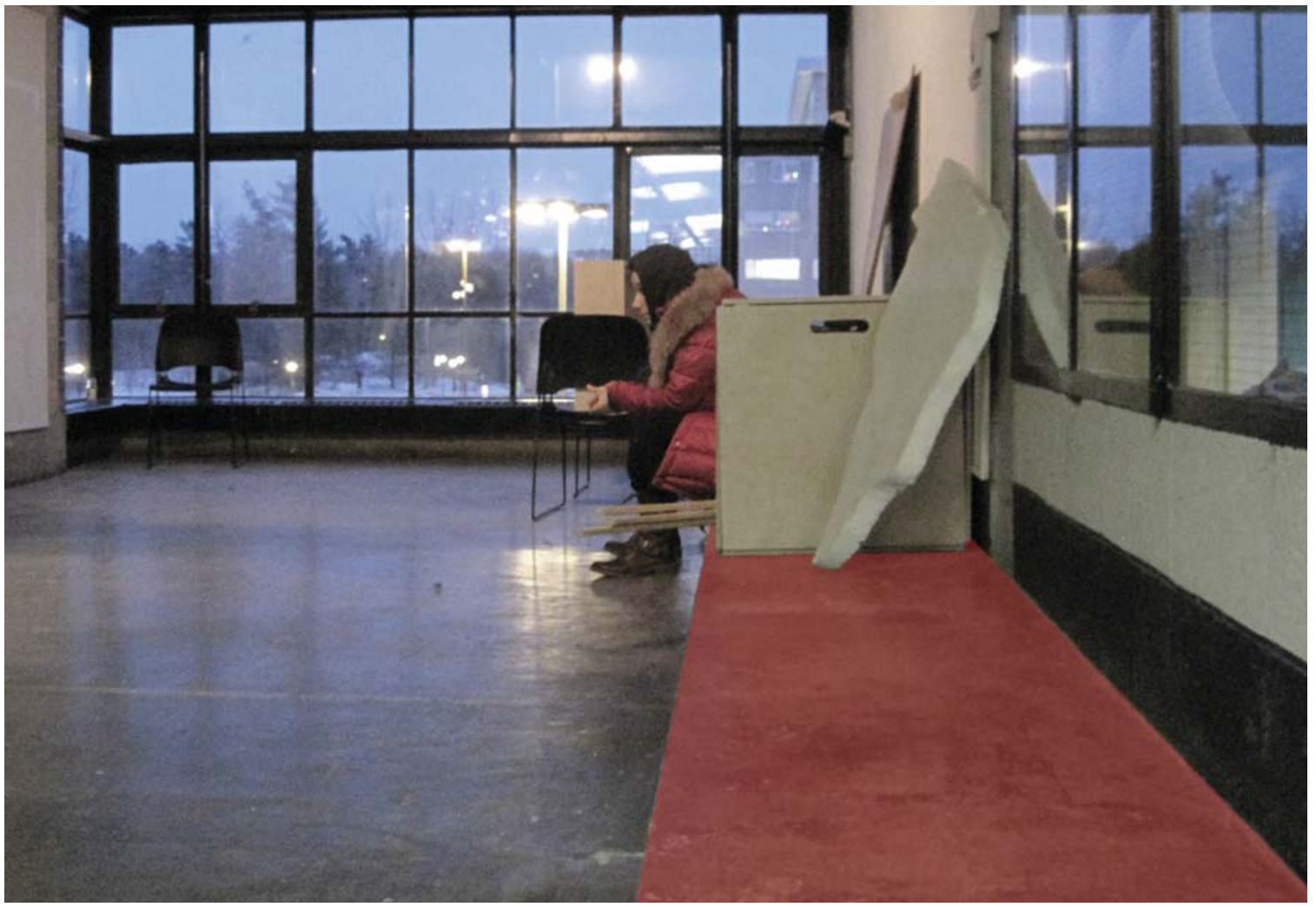

(Figure 24) View Towards 4th Floor Street 'Benches' 


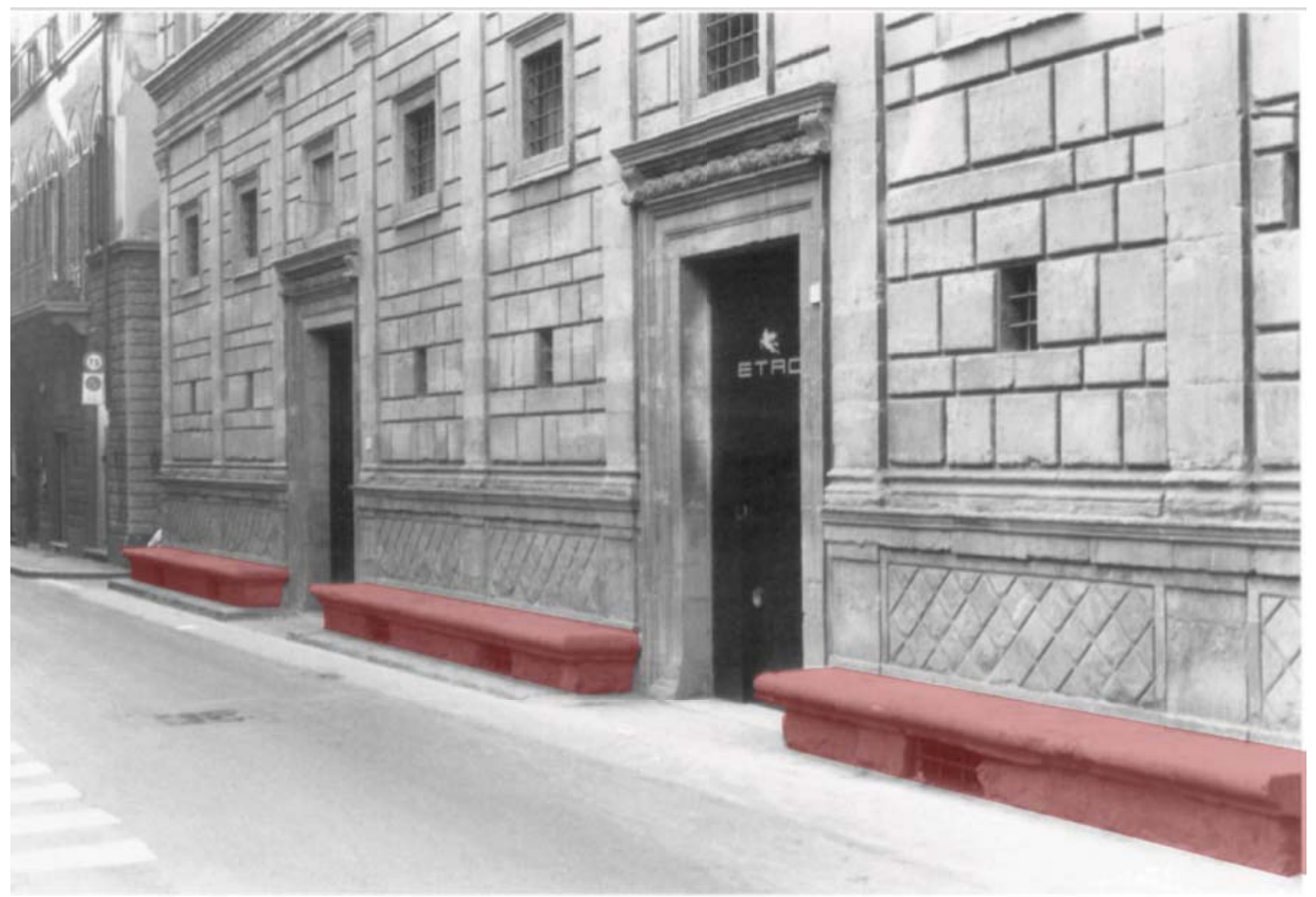

(Figure 25) Palazzo Rucellai Bench 
Construing 
In "Translation and Representation", Joseph Rykwert discusses the notion of representation within the context of drawing, as an action which is not only an expressive, but also a cognitive activity. Drawing, Rykwert iterates, requires a series of translations from imaginative conception through to final design documentation, each of which ultimately reduces spontaneity. Rykwert continues that this spontaneity has come to be more valued than the final work. This view reduces the final work, whether at the scale of an architectural detail or complete building, to an artifact ${ }^{4}$. The evolution of a design within this context is complete once the product, or artifact of the design process, is constructed. This disregards the active process of the body living within, through and around a design, which typically follows the completion of any construction. This active process of living which at the least surrounds a design artifact necessitates a certain quantity of translation as each body re-interprets the artifact. This inevitable reinterpretation enables the body to interact with the artifact, removing the artifact from its temporal constraints and enabling it to become a palimpsest. It is these active processes of translation, which inscribe the compounding presence of the human body into the material world in the form of traces.

Within Building 22, the bench operates distinctly as a palimpsest which engages the body, transcending the limits of an artifact. This transition from artifact to palimpsest has occurred, because the bench was able to be re-appropriated by multiple users, over many years and for a multiplicity of functions, and to a degree has held the traces of those uses. These traces particularly, which have compounded over time, enable the transition away from artifact, because they enable new and changing interpretations with use and age. A criticism of the bench consequently, is that because of its durable materiality (concrete), it is actually less able to reflect the changing interpretations and uses which students and professors find for it. If the bench were made a less durable material, such 
as wood, it would more readily accept the transfer of traces. A shift in material would enhance the impact of the body in the iterative design process, and also extend the life cycle through which the bench is both visually and physically understood.

The essential difference between the design palimpsest and the design artifact then, is that the artifact while conceived through experiential qualities requires a user to consistently refer back to the original form of the artifact. This provides a limited number of interpretations, and uses for the artifact, as well as reducing the ways in which the body may interact with the artifact. Contrastingly the palimpsest, while also conceived through experiential qualities, transcends the original design because it physically and mentally adapts to multiple uses. This adaption is based on the ability of the design palimpsest to accept the traces of multiple functions, essentially enabling a compounding re-interpretation by new users. In this way the palimpsest's function is not based solely on a single design, by a single designer, but rather its physical and intellectual representations are based dynamically on re-interpretation by multiple users'. 


\section{Renovating the Body}


Exercise \#2 identified key guidelines for design, which facilitate both physical and visual student inhabitation of spaces in Building 22. These guidelines are;

\section{1) Visual / Physical Porosity}

2) Systems Demonstrating their Construction

\section{3) Street Model as Primary Circulation}

\section{4) Multiplicity of Functionalities}

The renovation of the 5th floor begins with an expansion of the central circulation corridor, to partially align with the current northern portion of the 4 th floor street. At the existing skylight, the street renovation shifts to the west, neighbouring the original N1 mechanical room. This shift occurs for two reason, first to preserve the structural integrity of the existing skylight and secondly to reduce the contact of spaces which have extended occupancy, away from the mechanical N1 room ${ }^{1}$. The preservation of the skylight maintains the existing visual connection back to the 4th floor of Building 22, as well as into a renovated computer lab. While the structure of the skylight remains unaltered, the floor plate opening for the skylight has in fact been slightly expanded to align with the renovated street and existing structural grid.

The original light steel structure of the 5 th floor also remains unaltered in the interest of economy. The light steel structure and current light materiality of the 5 th floor provide cues towards an appropriate materiality for the renovated portions of the project. Specifically, because the 5 th floor was an addition it necessitated a physically lighter construction than the original Building 22. Acknowledging this, materially renovations 
also need to be lightweight to maintain the structural integrity of the original Building 22. This provides a unique opportunity to explore more temporary materials, such as plywood and softwoods.

With this materiality in mind, rather than physically enclosing the spaces adjacent to the renovated street, a partition based on a module derived from Building 22 has been proposed. The application of this module, to 6 separate programs reinforce the identified design guidelines capable of reintegrating the body back into Building 22. The partition includes, in portions, a bench, which is capable of acting as a un-programmed space. The inclusion of the bench along the new street situationally enables the creation of informal meeting areas and discussion spaces. The exposure of two structural columns in the core of the street, also creates a unique situation where project panels may be hung between the existing structure in an informal presentation area. 
Module 
The base module has been developed through the horizontal division of the North / West structural grid, to enable the inclusion of 11 modules between any pair of columns. Within the module 11 pieces of birch plywood $1.82 \mathrm{~cm}^{2}$ thick $^{2}$ and $2 \mathrm{~cm}$ long are introduced, with varied spacing between each piece. Vertically, each of the eleven pieces is composed of either a series of varying vertical lengths of wood (as seen in Partition 5) or the combination of a vertical series of lengths of wood and a curved piece of plywood which acts as a bench (Partition 1).

The sectional integration of the module into the space is based on an analysis of the current varying heights of the steel pan roof. The current proposal necessitates the removal of the existing acoustic tile in an attempt to reveal the mechanical and electrical systems which are currently hidden. The module physically demonstrates its own construction by revealing the joining of each vertical segment of wood as well as the connection of these pieces to a structural column and sub-structural rod system. Overall the module design seeks to address the established design guidelines and re-integrate the student body into the 5 th floor. 
Scale 
Partition 1

(Figure 30 - 33)

... is the longest partition in the design, separating the main studio space from the central street. This partition crosses three structural columns to end at the new elevator wall. The windows in this partition occur in patterns of 3 and are capable of folding out to create short shelves which students can use for model display or storage (Figure 51). As the partition nears the elevator wall, the module for this design is physically reduced in stages to step gradually up into the ceiling; allowing physical passage through the module near the elevator. The spacing of the base module has not been filled in this partition because the studio does not require visual or acoustic isolation. This creates a very porous relationship between the street and the studio.

Partition 2

(Figure 34 - 37)

.. . bridges between an office and studio space which, respectively, require visual and acoustic separation and integration in the street. This shifting of porosity required a densification of the sub-structural wood system along the office, and a removal of the sub-structural system along the studio. The windows in this partition occur in patterns of 3 , and the window in the office side of the partition privileges a seated view out into the street.

\section{Partition 3}

(Figure 38 - 41)

. . . is constructed in close proximity to Partition 2, and mediates between a classroom and the street. The programming of the space as a classroom requires relative acoustic and visual isolation to avoid distractions. As such the partition is in-filled with a substructural wood system. The window in this partition occur is extended and infilled with glazing to create, a visually and acoustically more private space. 
Partition 4

(Figure 42 - 45)

... is constructed to mediate between a classroom space and the street. This partition is designed to be both visually and physically more porous and includes a bench. The space created between Partition 4 and Partition 5 could also be utilized as a group discussion or presentation area. Windows in this partition occur in patterns of 4 .

\section{Partition 5}

(Figure 46 - 49)

... is constructed between the primary computer lab and the street. This partition is unique in that the sub-structural wood in-fill is removed from below the windows, based in patterns of 3 and 5 . The removal of the variant privileges the seated viewer from within the computer lab, or the viewer seated along the bench of Partition 4. The removal of the sub-structure also allows venting of the computer lab into the street to regulate computer lab temperatures.

Partition 6

(Figure 54 - 55)

... is a secondary partition designed to mediate between studio bays. The partition is constructed of 2 in $x$ in $x 8 \mathrm{ft}$ pine timbers divided into quarters. The partition would physically mediate circulation pathways, as well as partially visually and acoustically separate studio bays. Visual and acoustic separation would be dependent on the rearranging of the horizontal cloth channels, into vertical panels. While in the horizontal orientation, the cloth channels could also provide a storage space for pencils, food, and other objects. The horizontal pine members on which the cloth channels are supported, could also be used as a grid to pin work in progress drawings and site analysis graphics. This would reinforce the belief, that "the building is seen as a helpful supporting framework to which the inhabitants bring their own infill and action." 
The Drawings 
Space Programming Analysis 


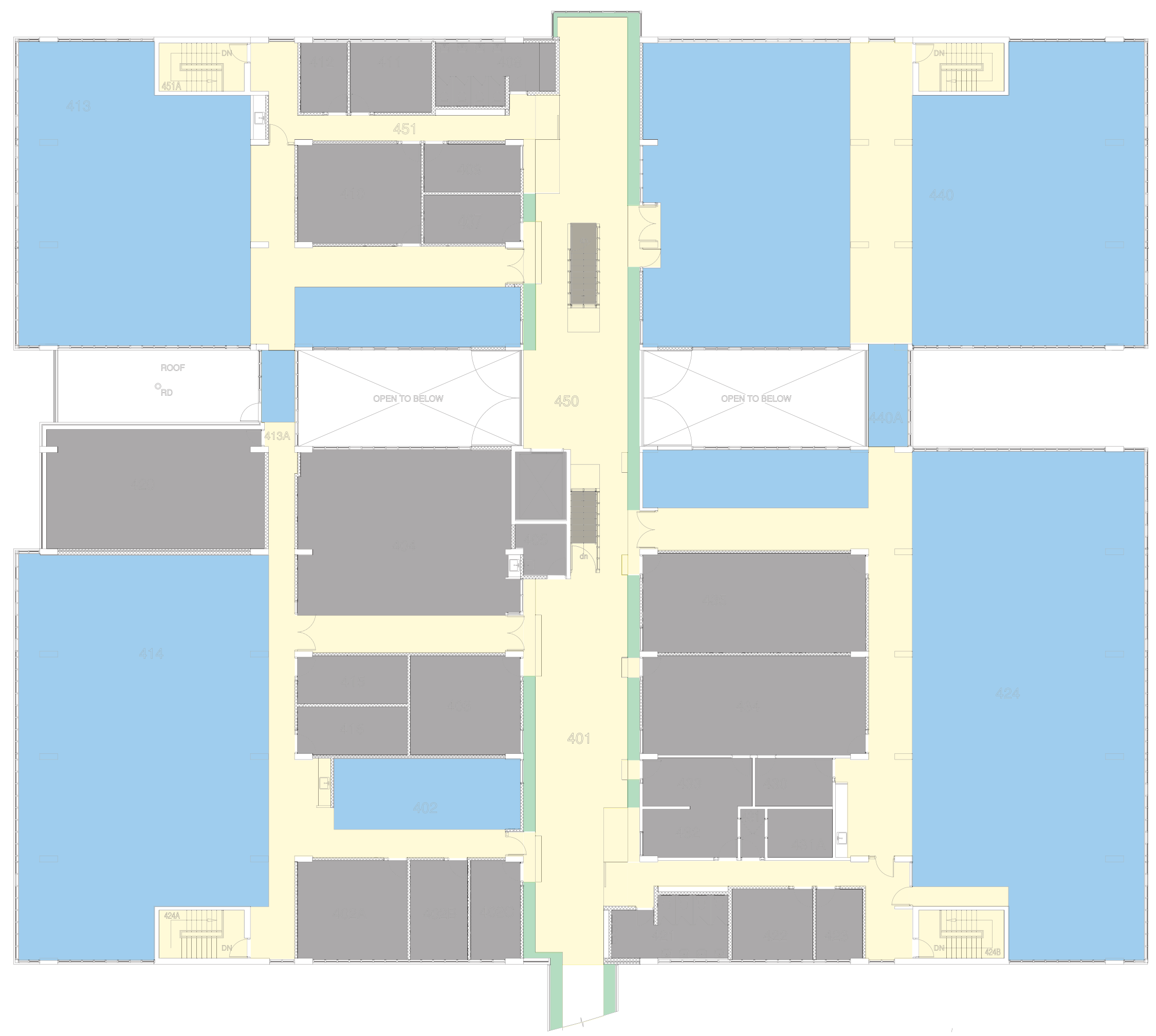




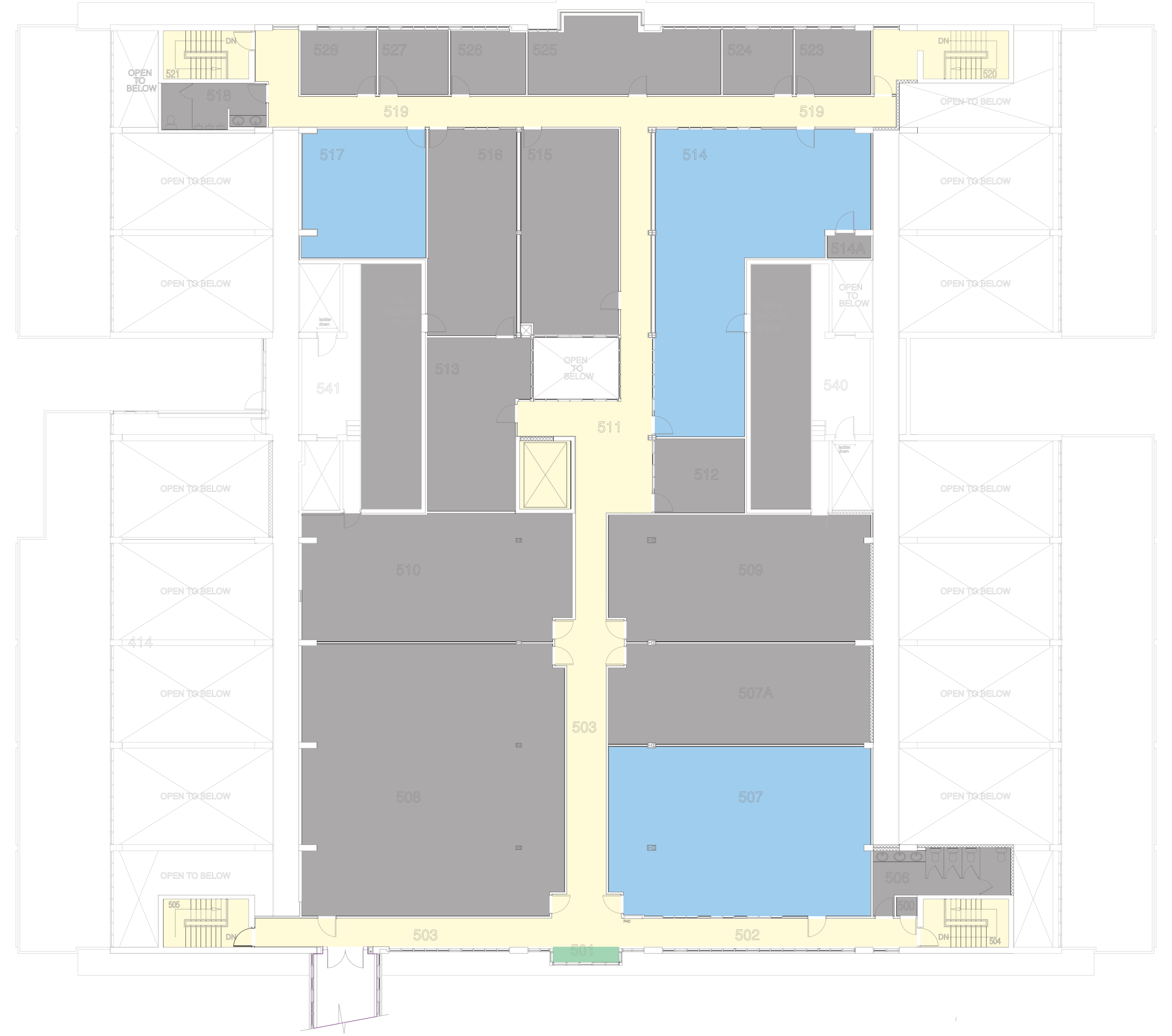




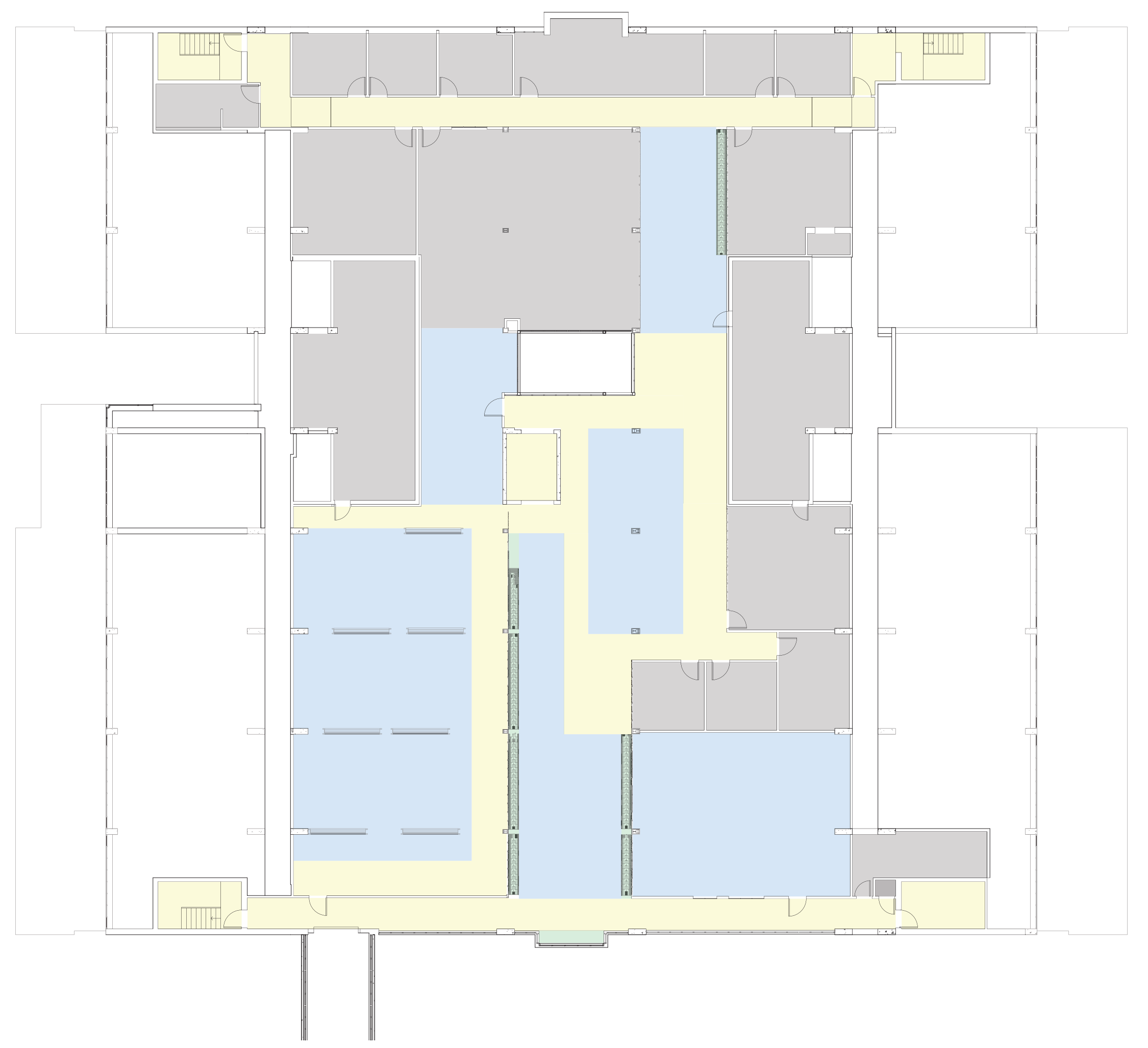




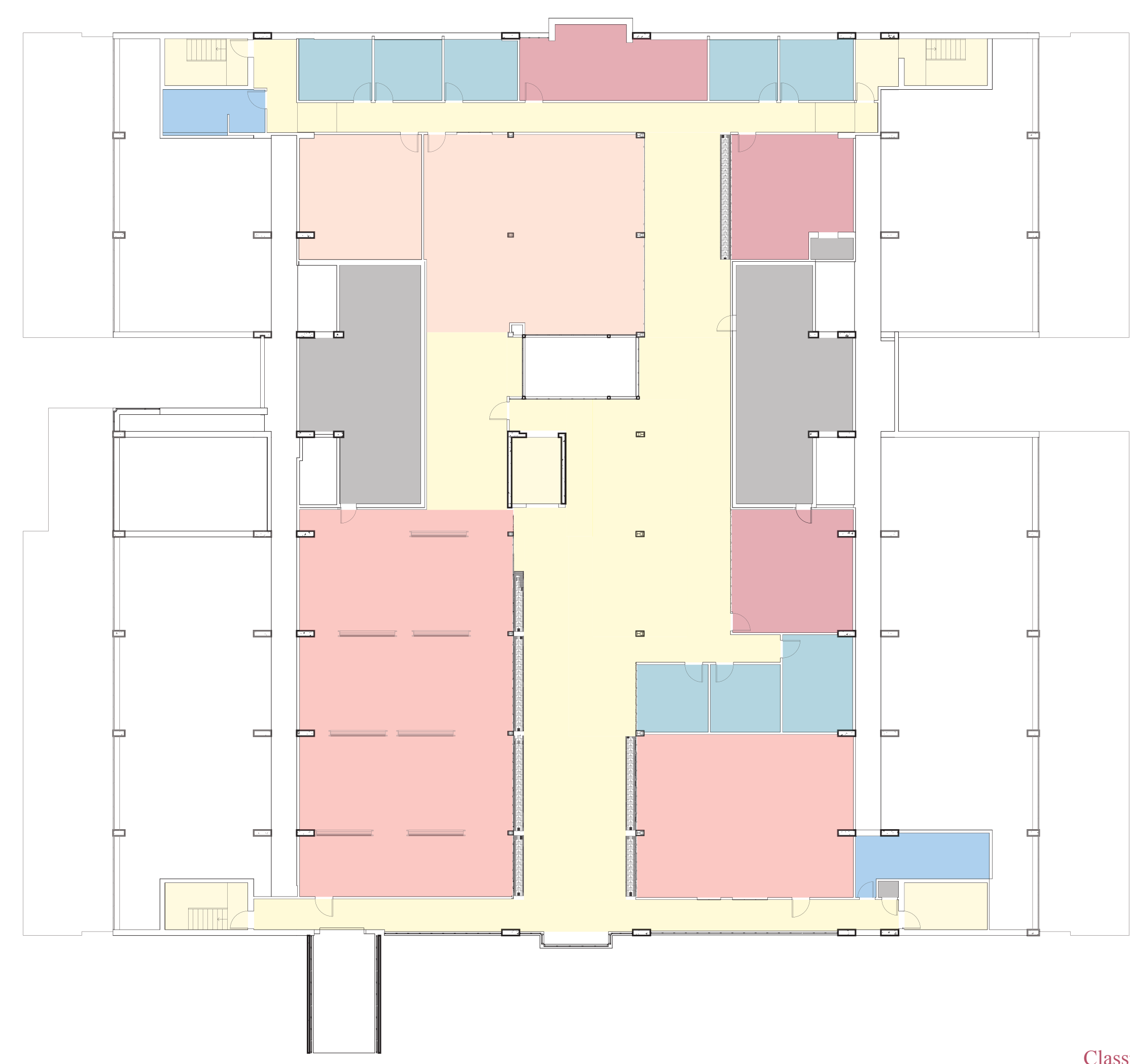

Program Analysis 
Partitions 


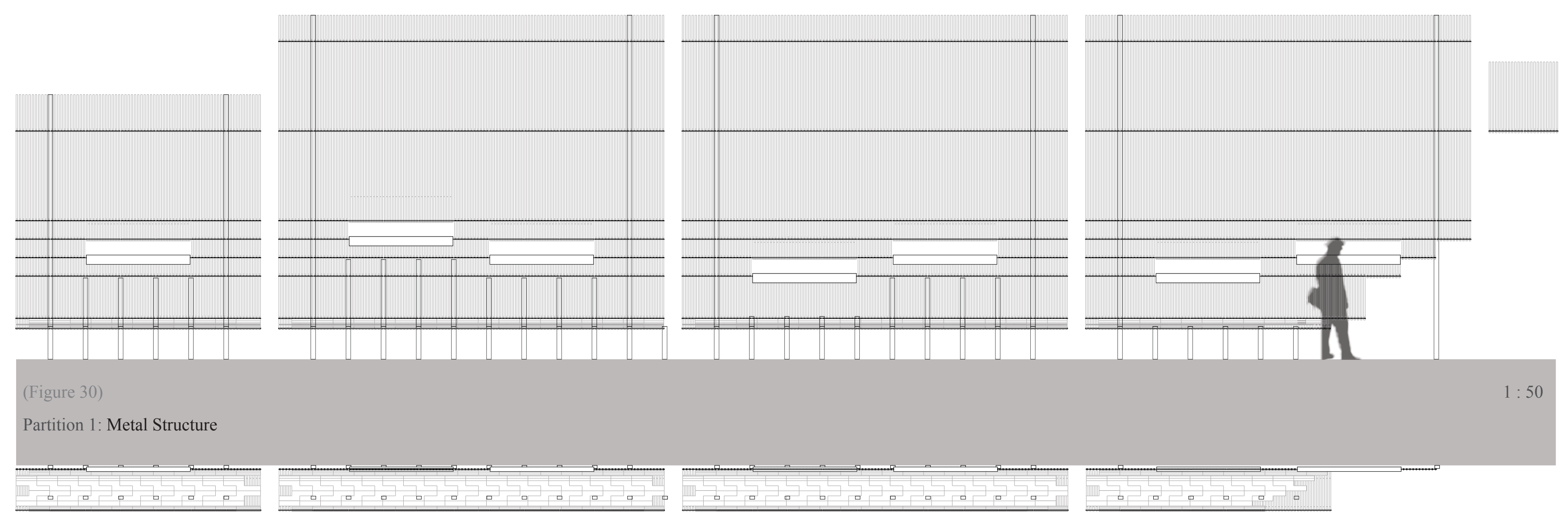



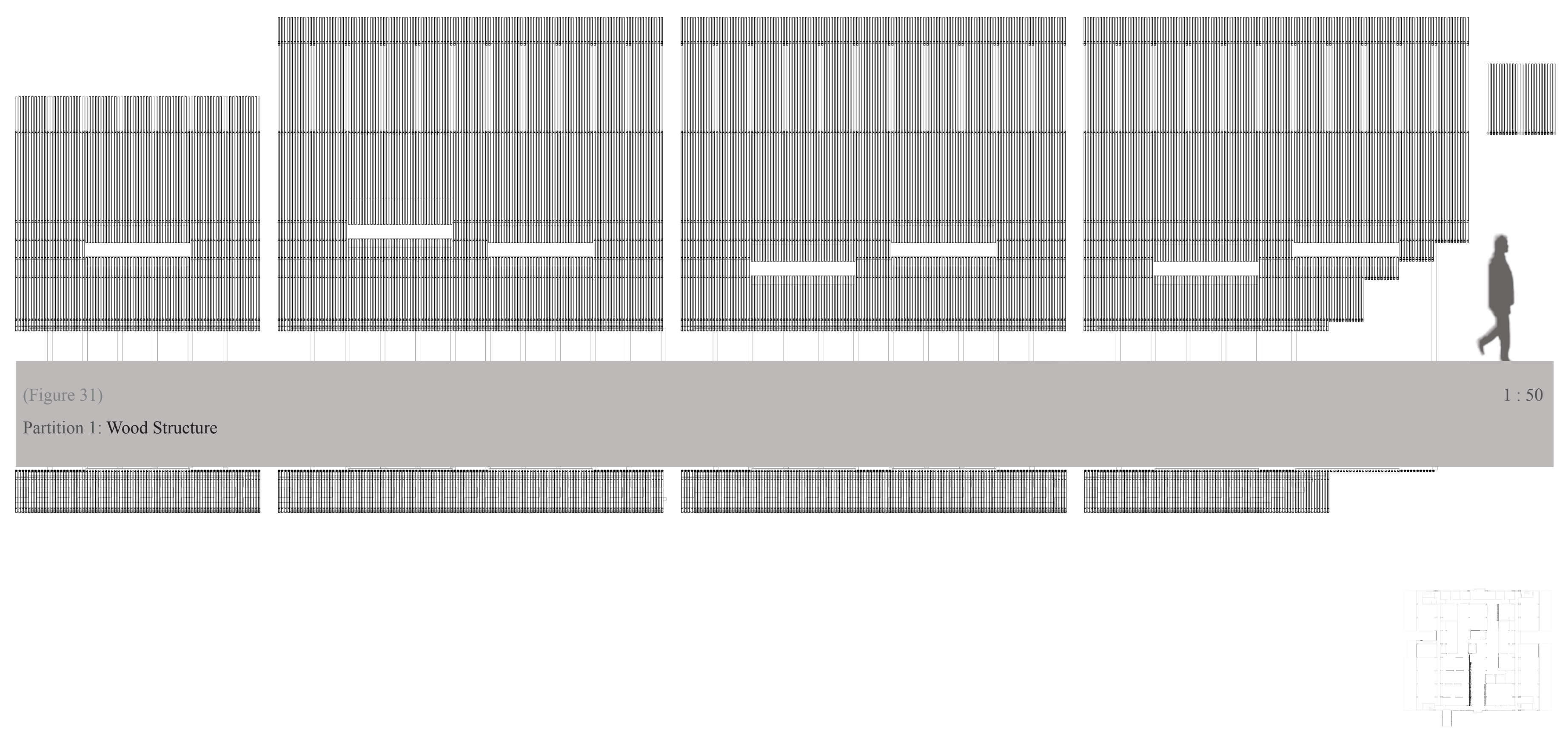


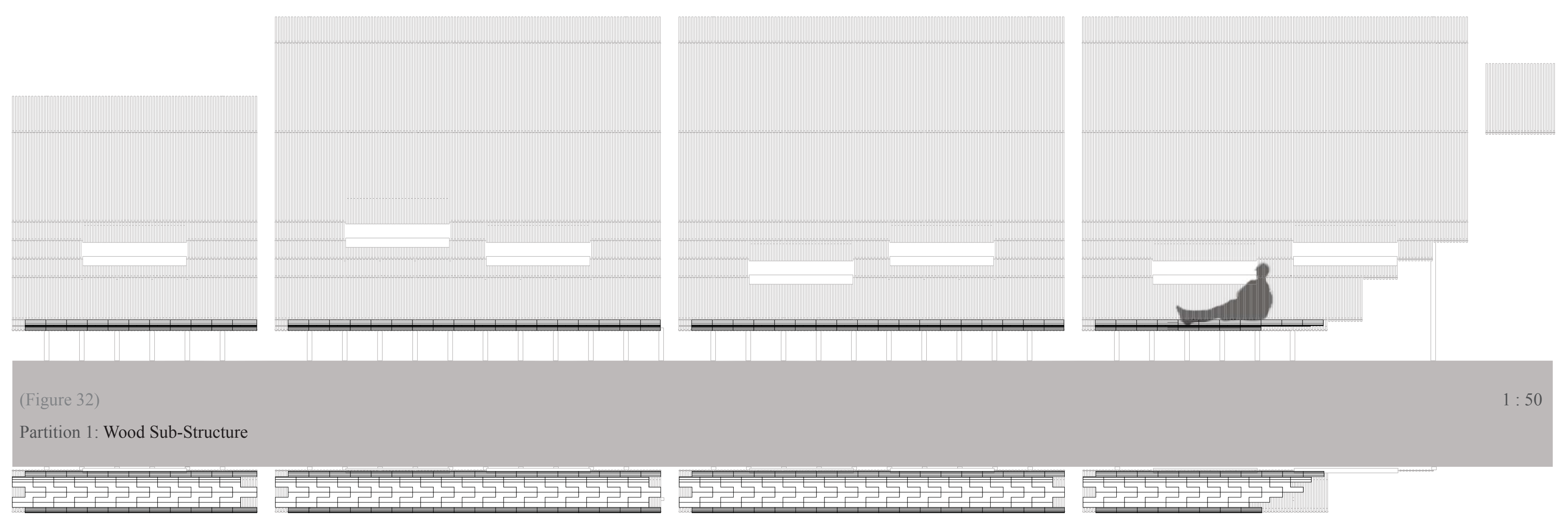



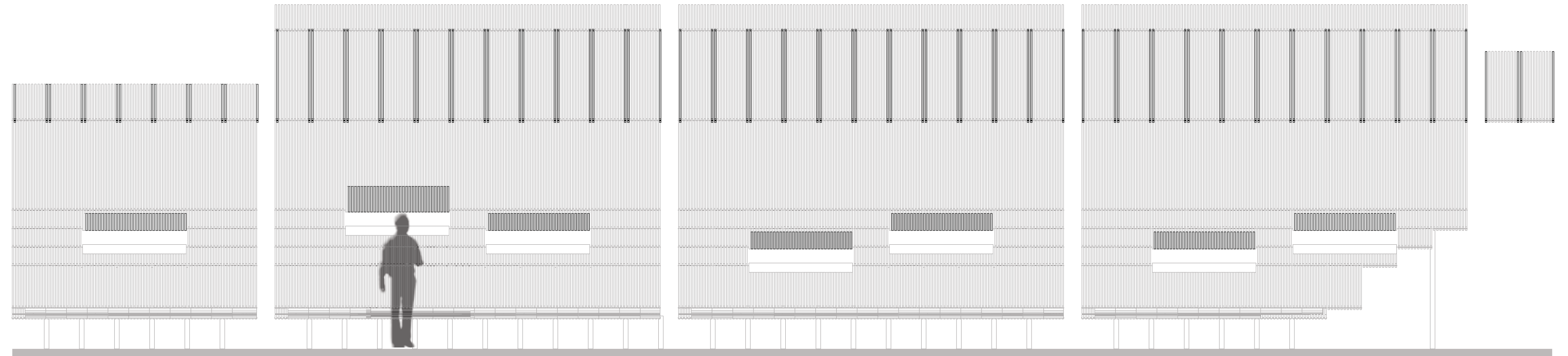

Partition 1: Glazing and Wood Variant

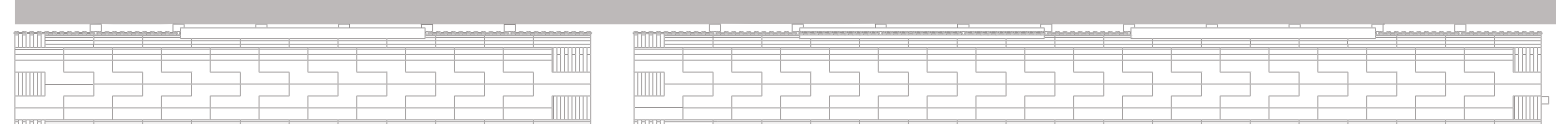

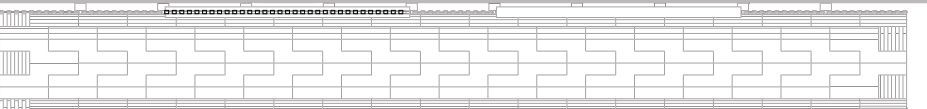

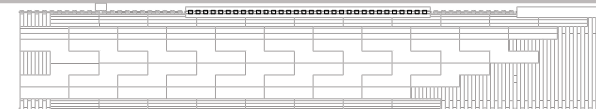



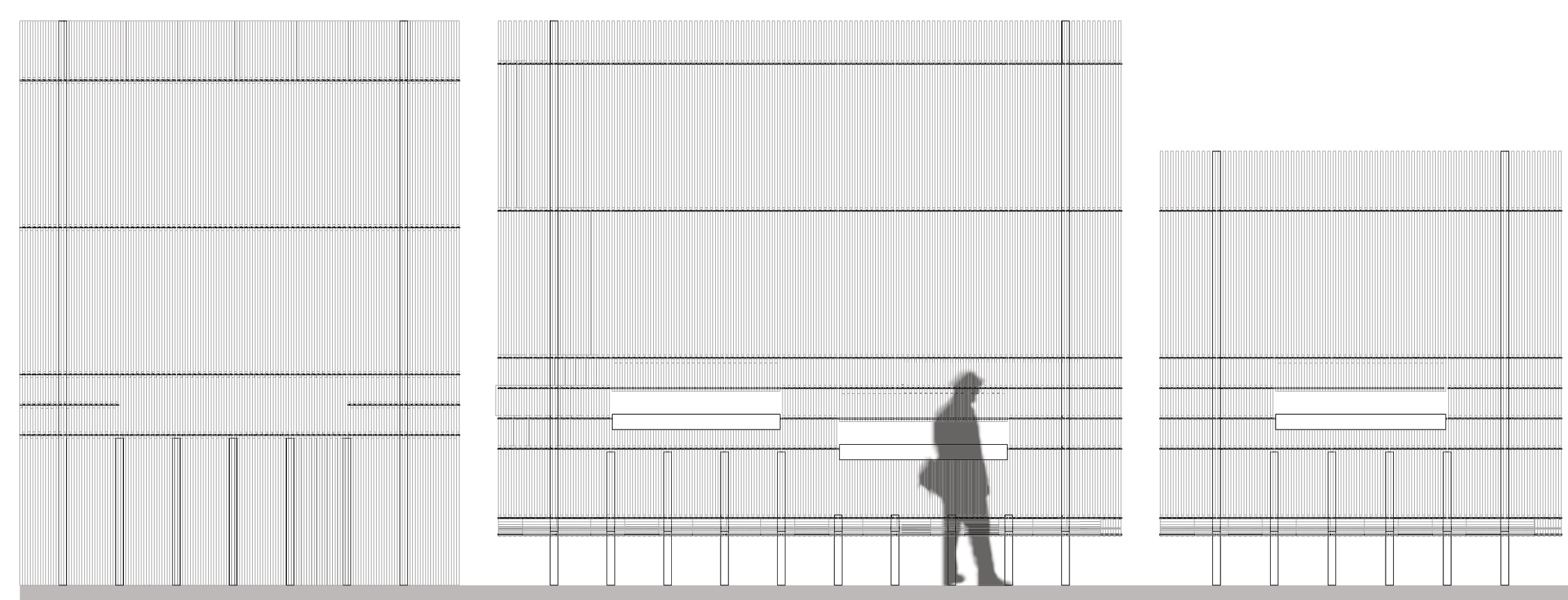

(Figure 34)

Partition 2: Metal Structure

P. 

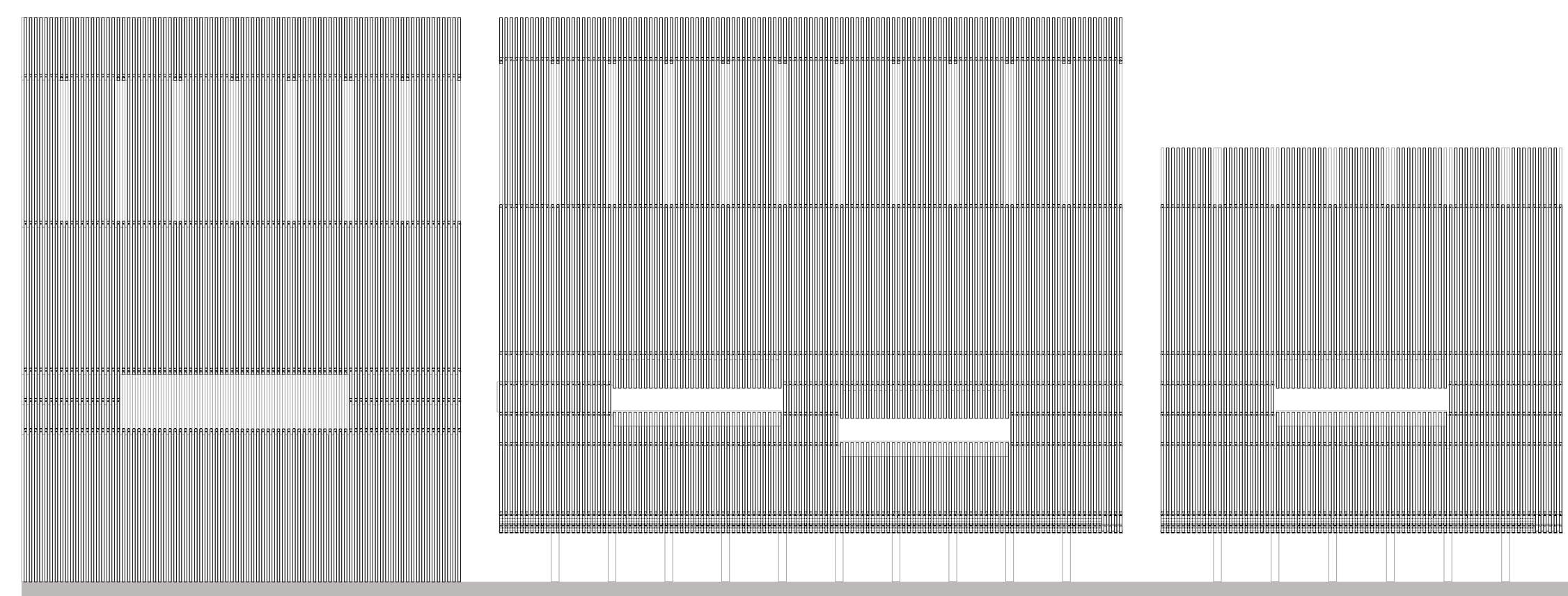

$\uparrow$

Partition 2: Wood Structure

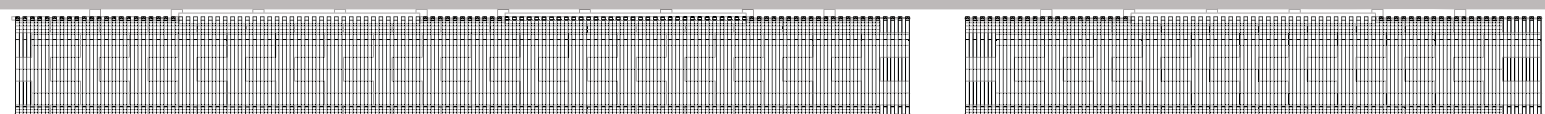



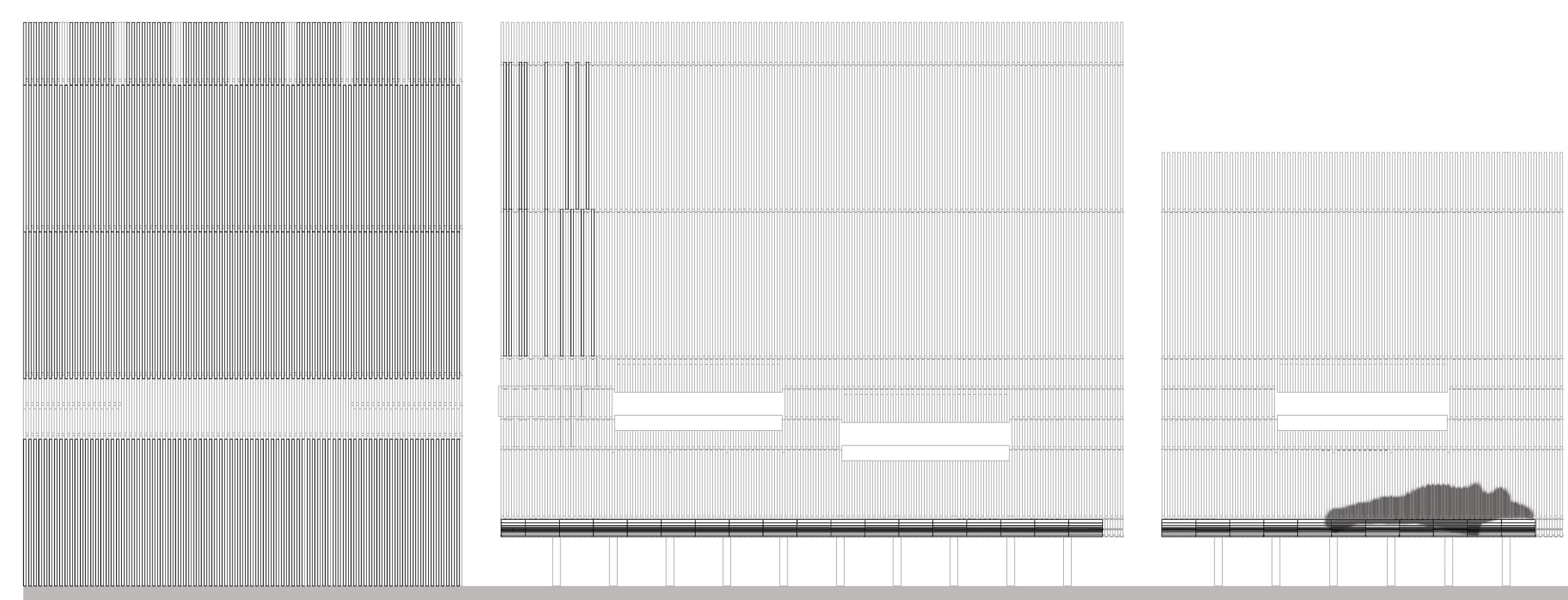

(Figure 36)

Partition 2: Wood Sub-Structure

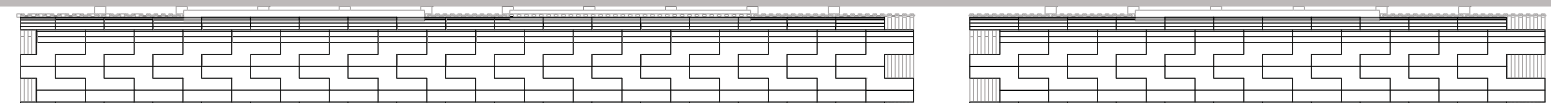




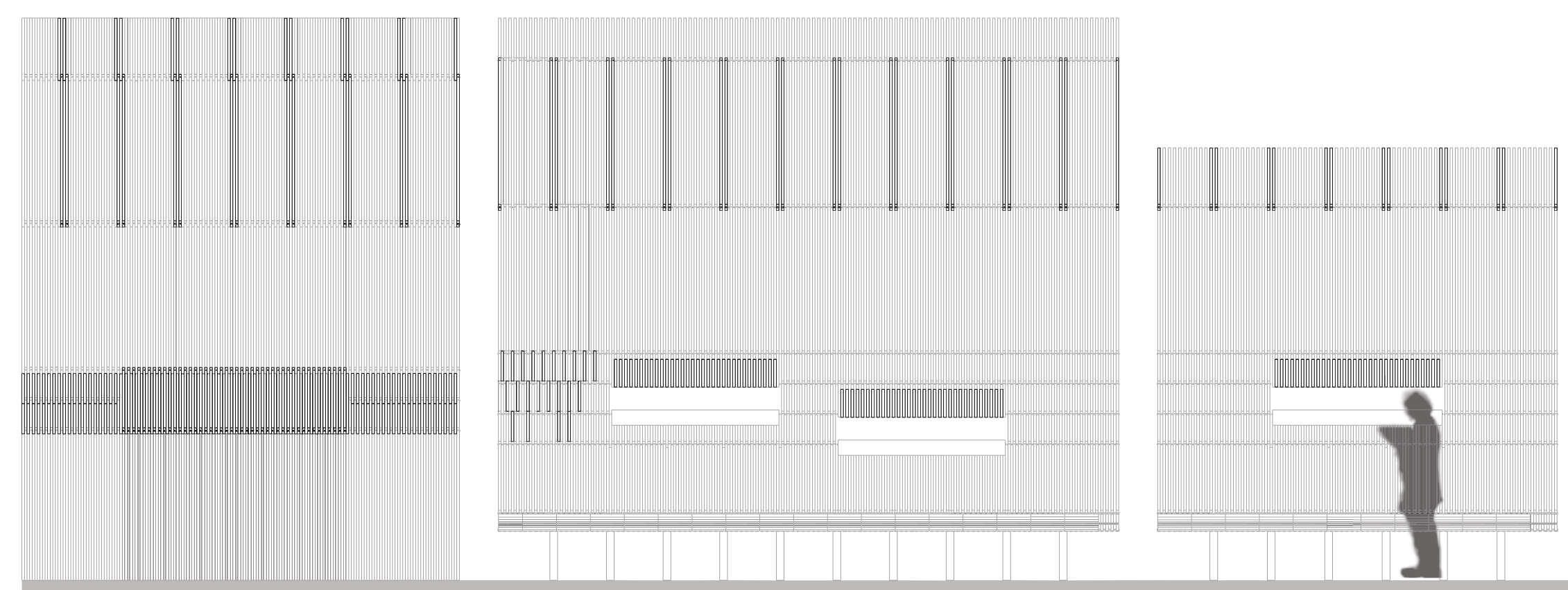

-

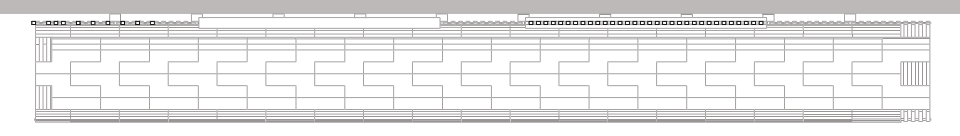

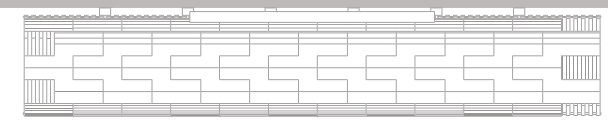



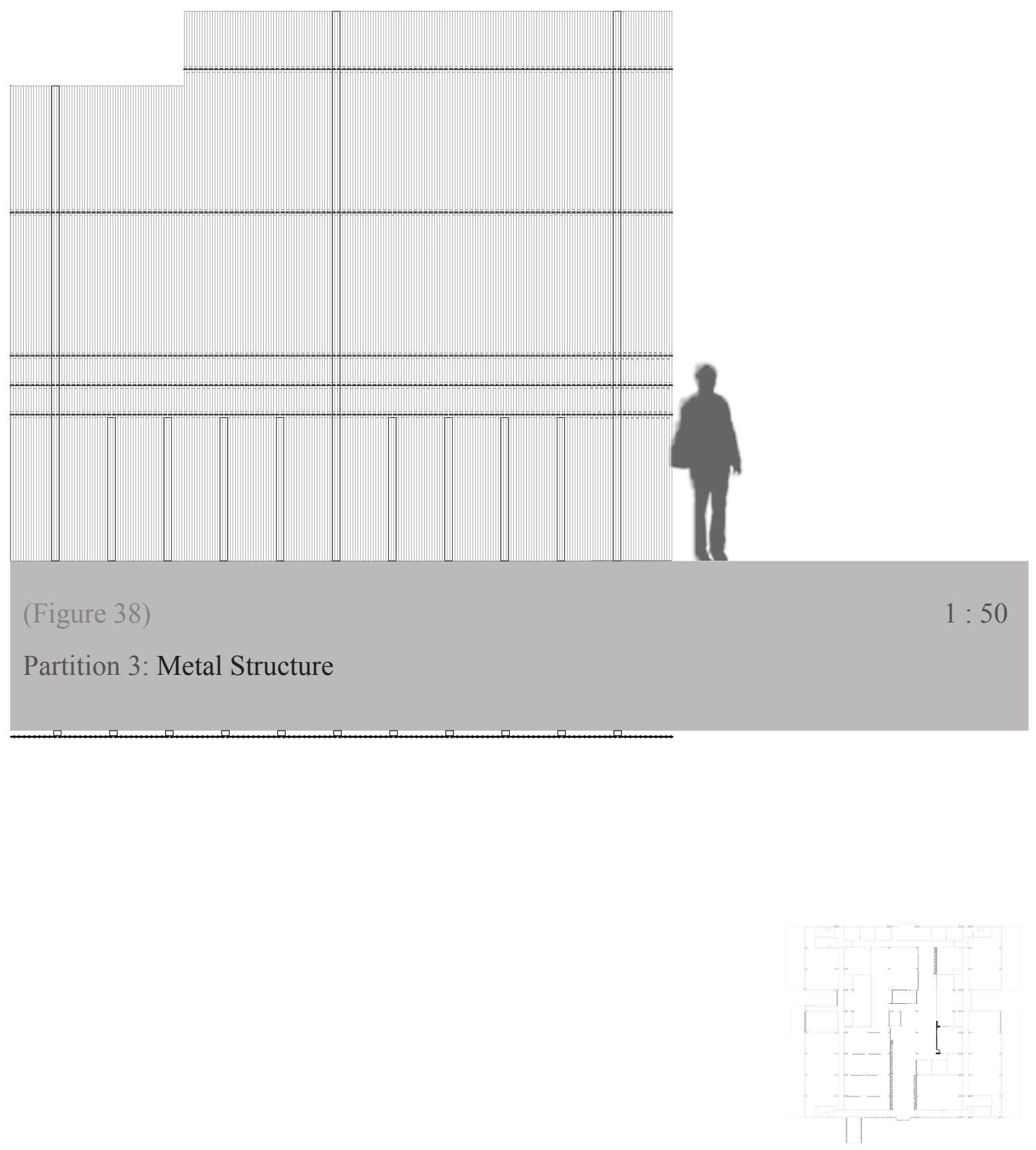


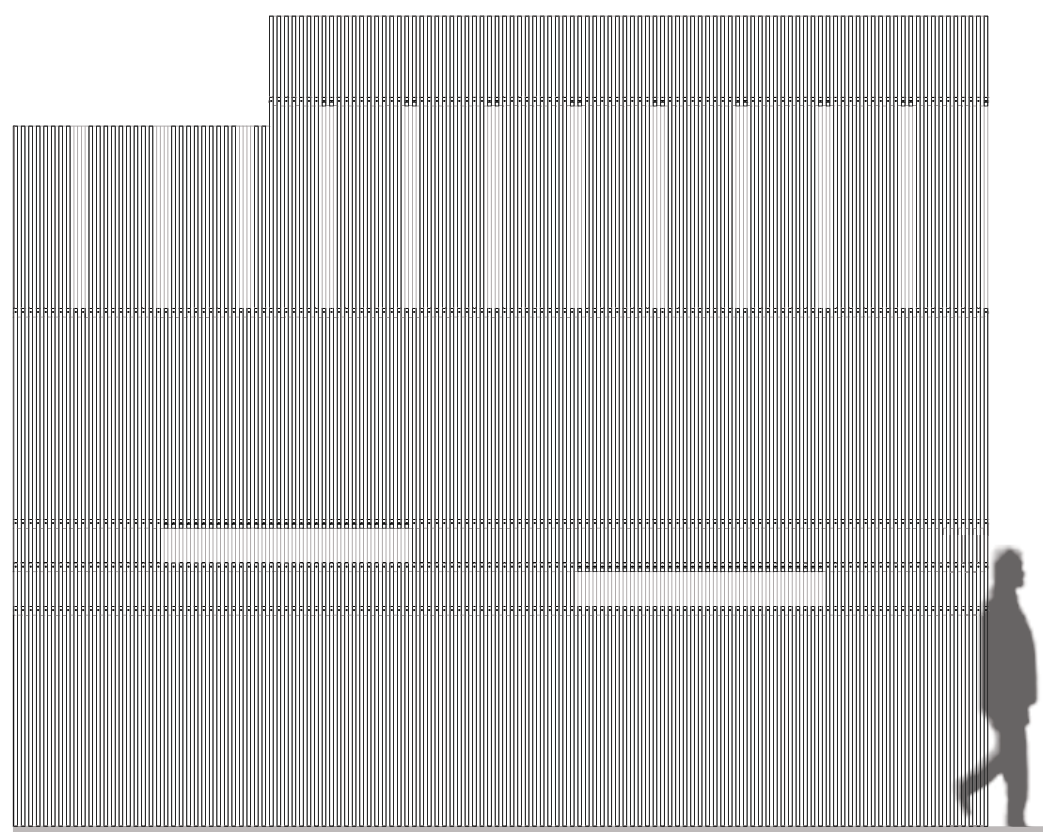

(Figure 39)

Partition 3: Wood Structure

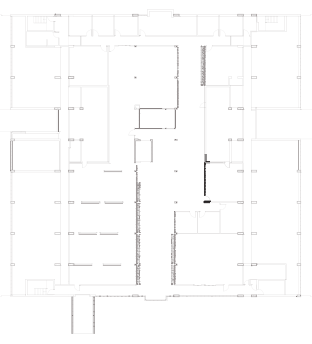




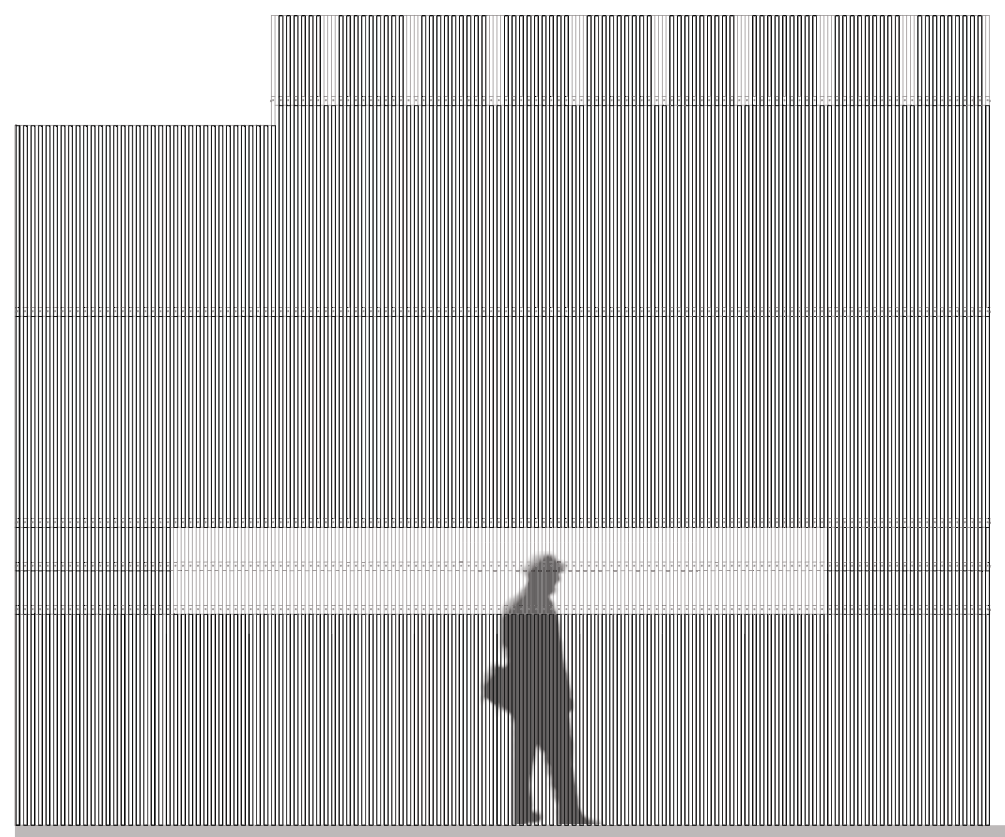

(Figure 40)

Partition 3: Wood Sub-Structure

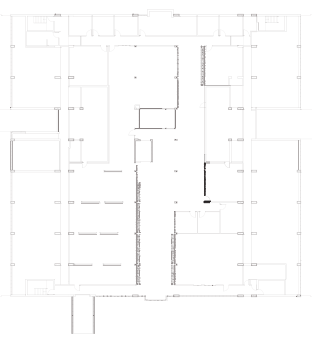



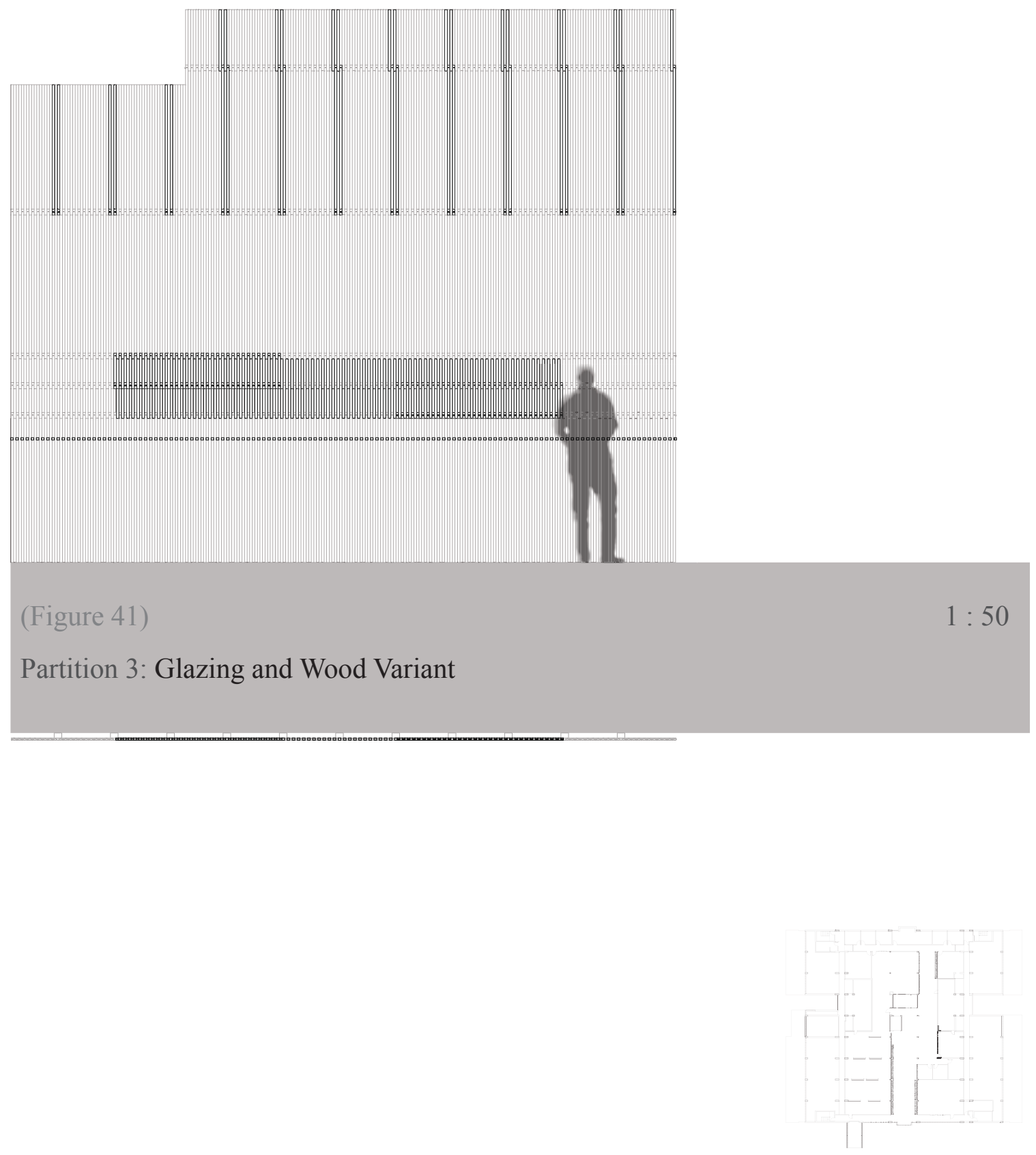


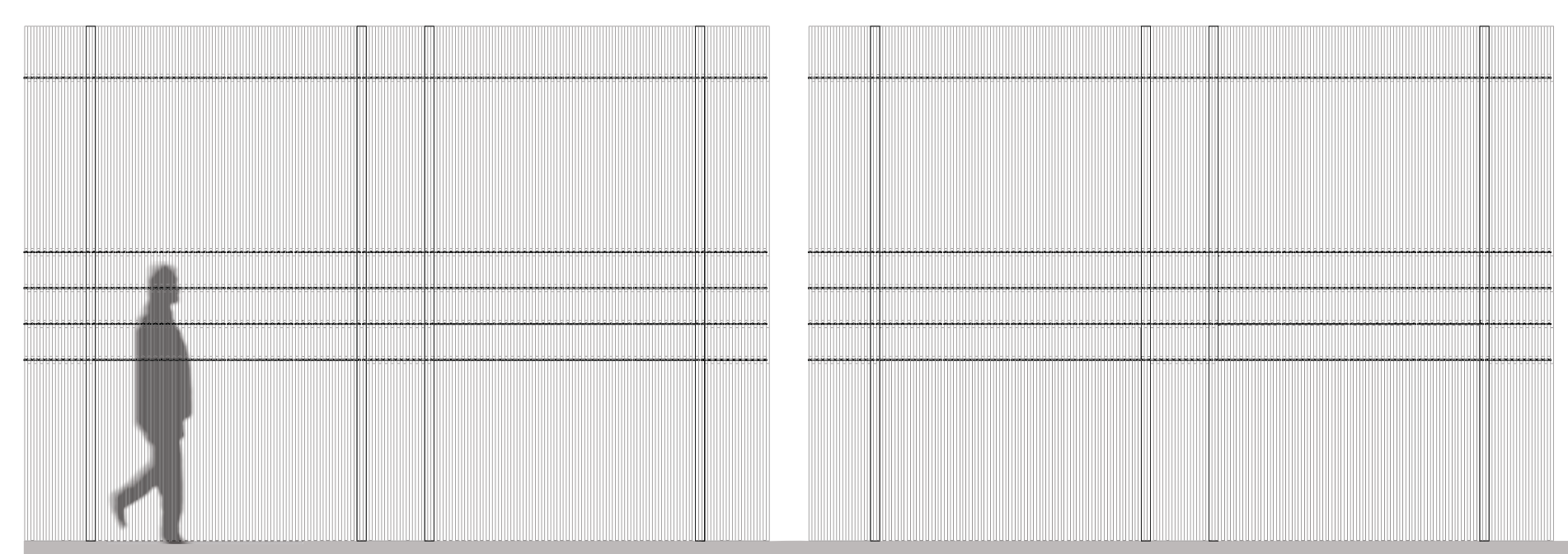

(Figure 42)

Partition 4: Metal Structure

. 


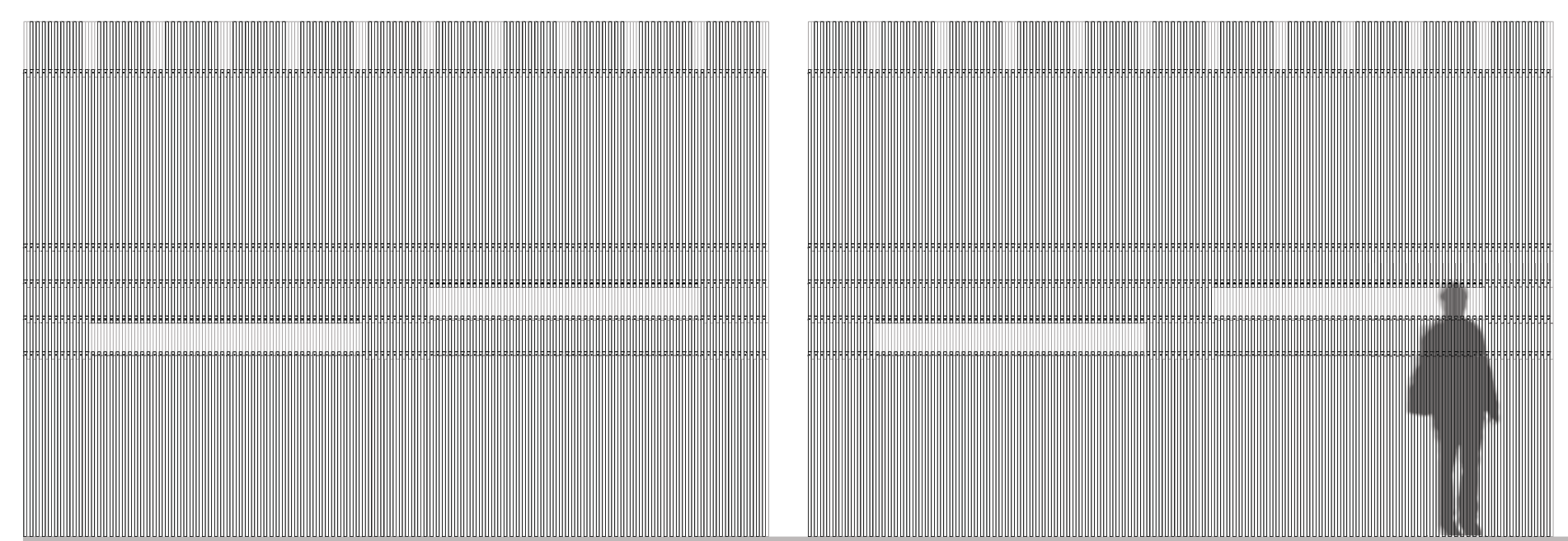

(Figure 43) 


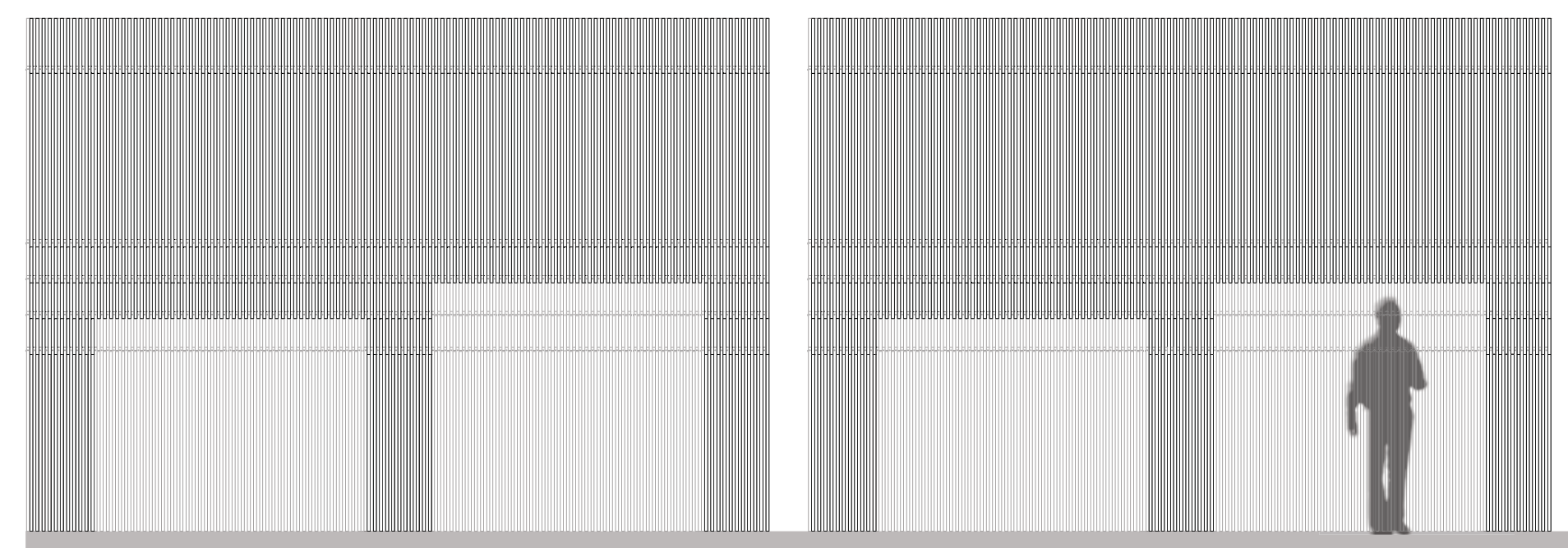

(Figure 44)

Partition 4: Wood Sub-Structure

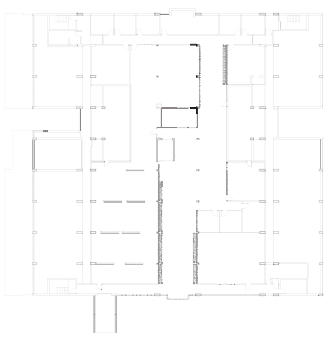




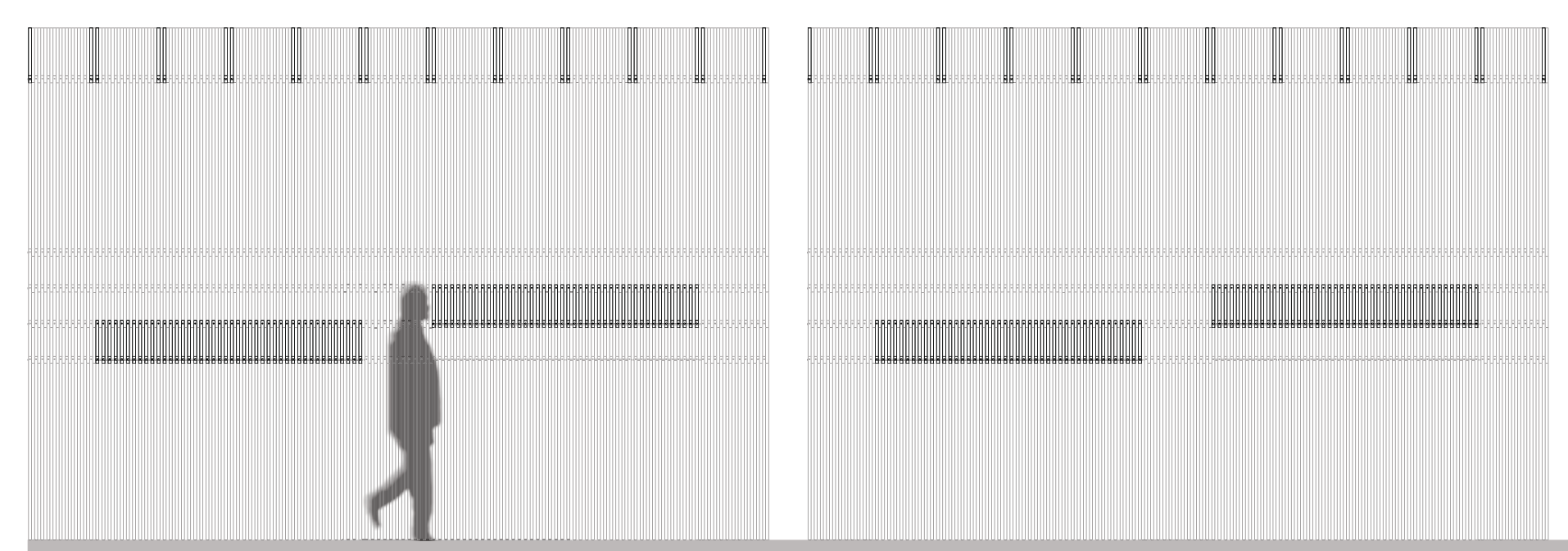




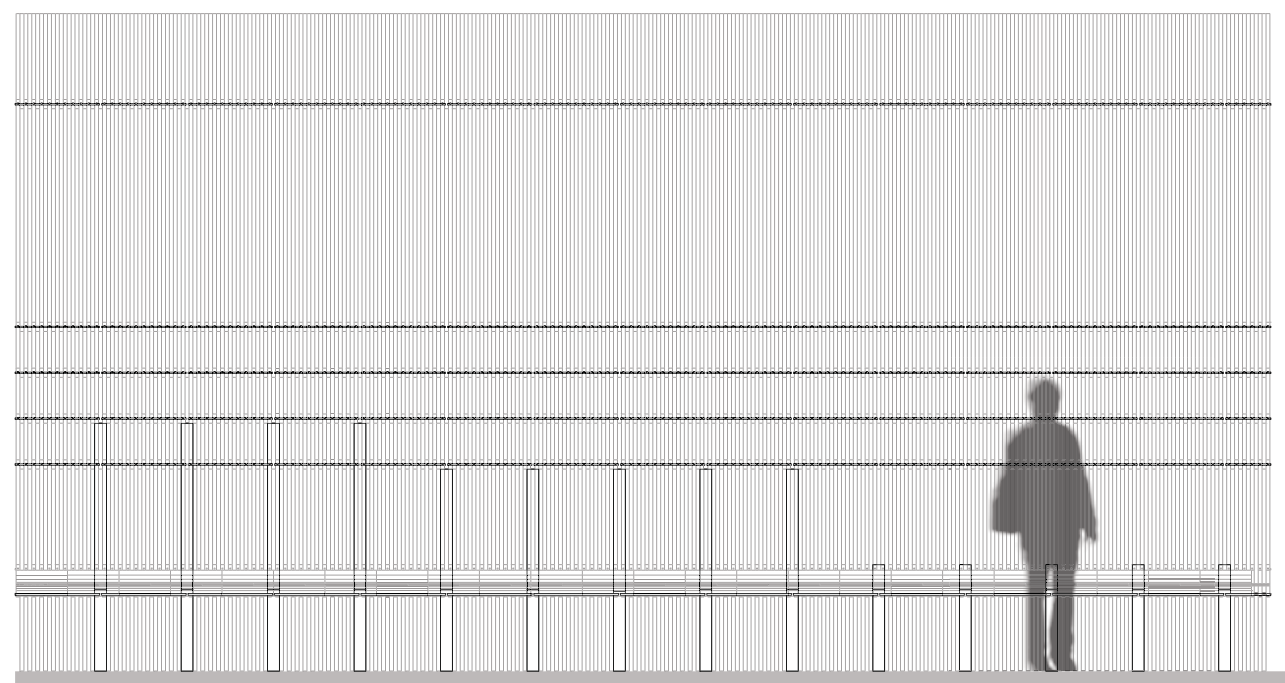

$\begin{array}{ll}\text { (Figure 46) } & 1: 50\end{array}$

Partition 5: Metal Structure

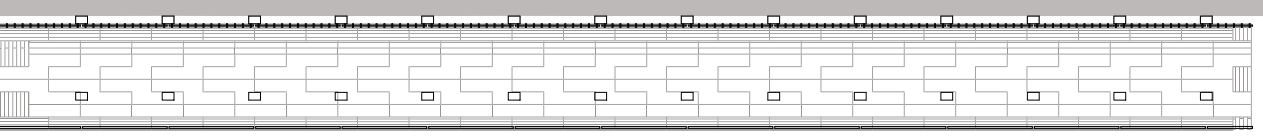

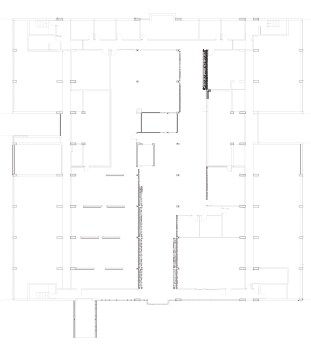




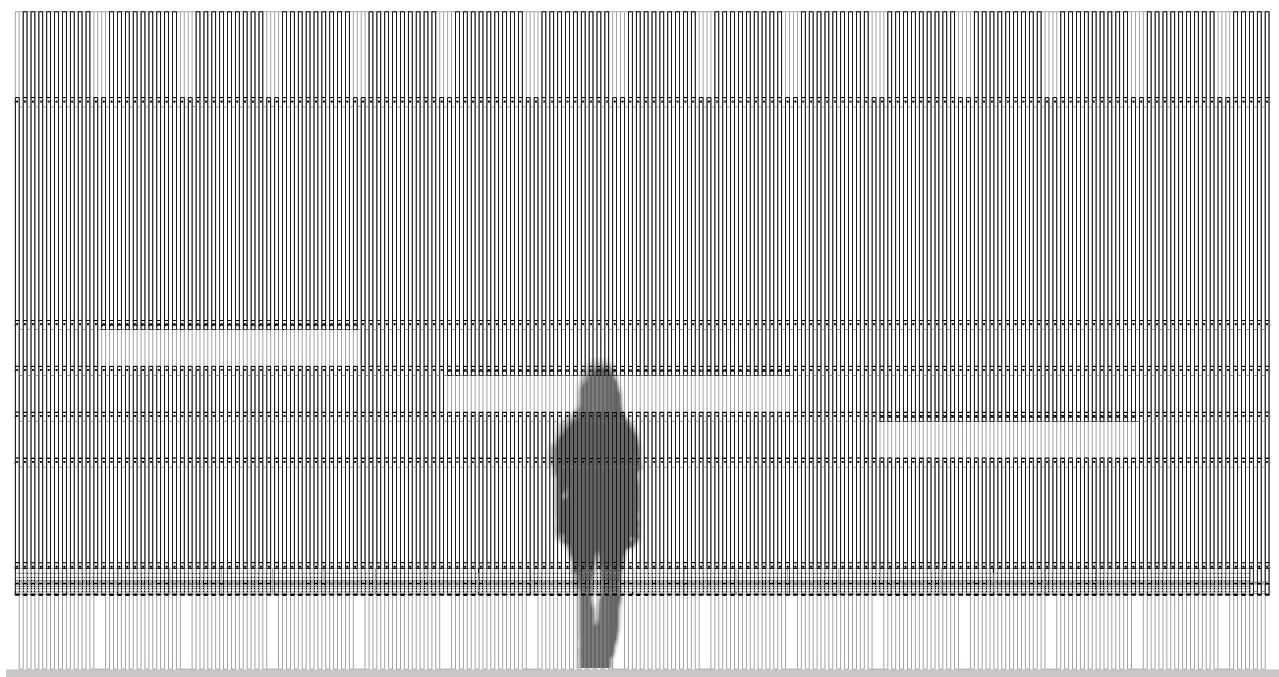

(Figure 47)

Partition 5: Wood Structure
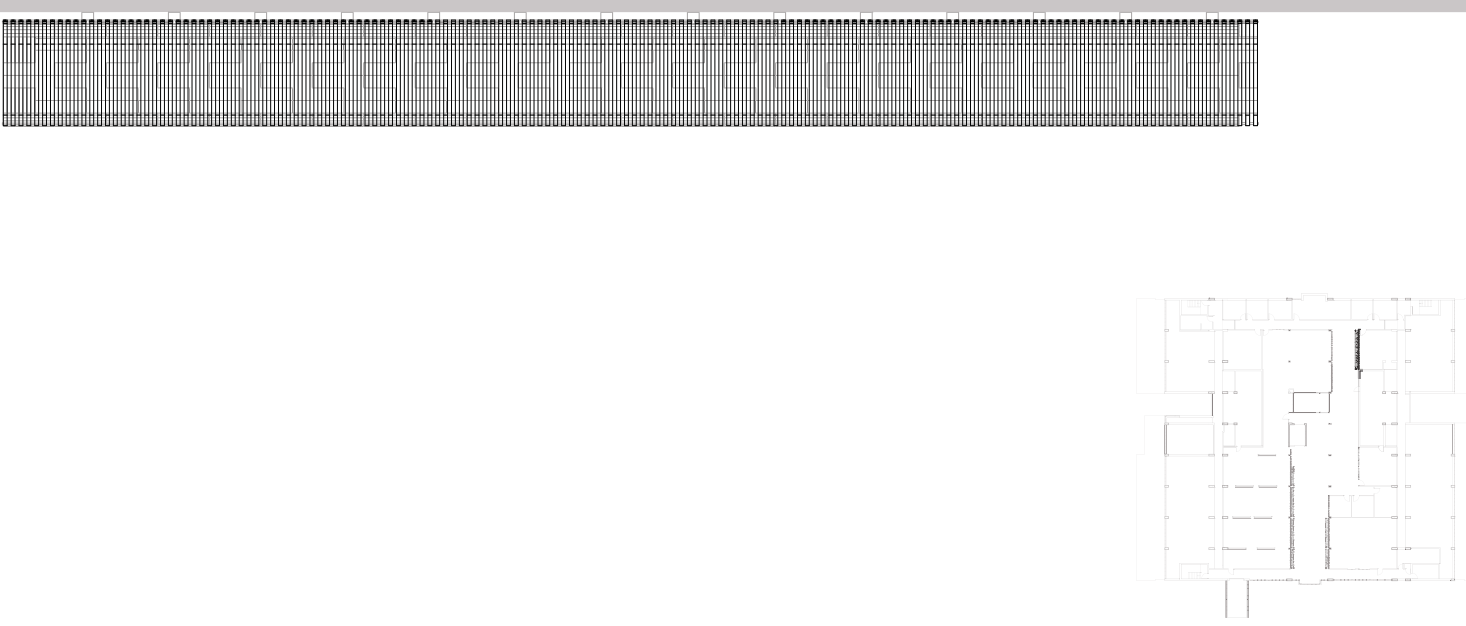


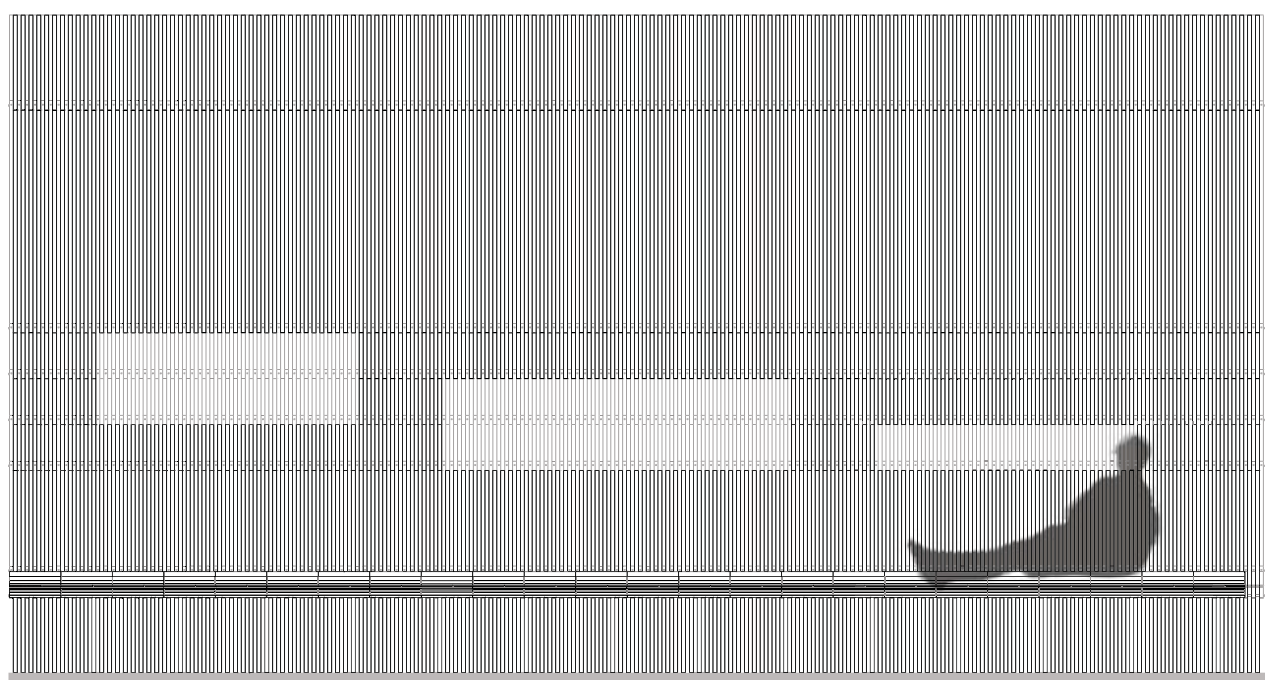

(Figure 48)

Partition 5: Wood Sub-Structure
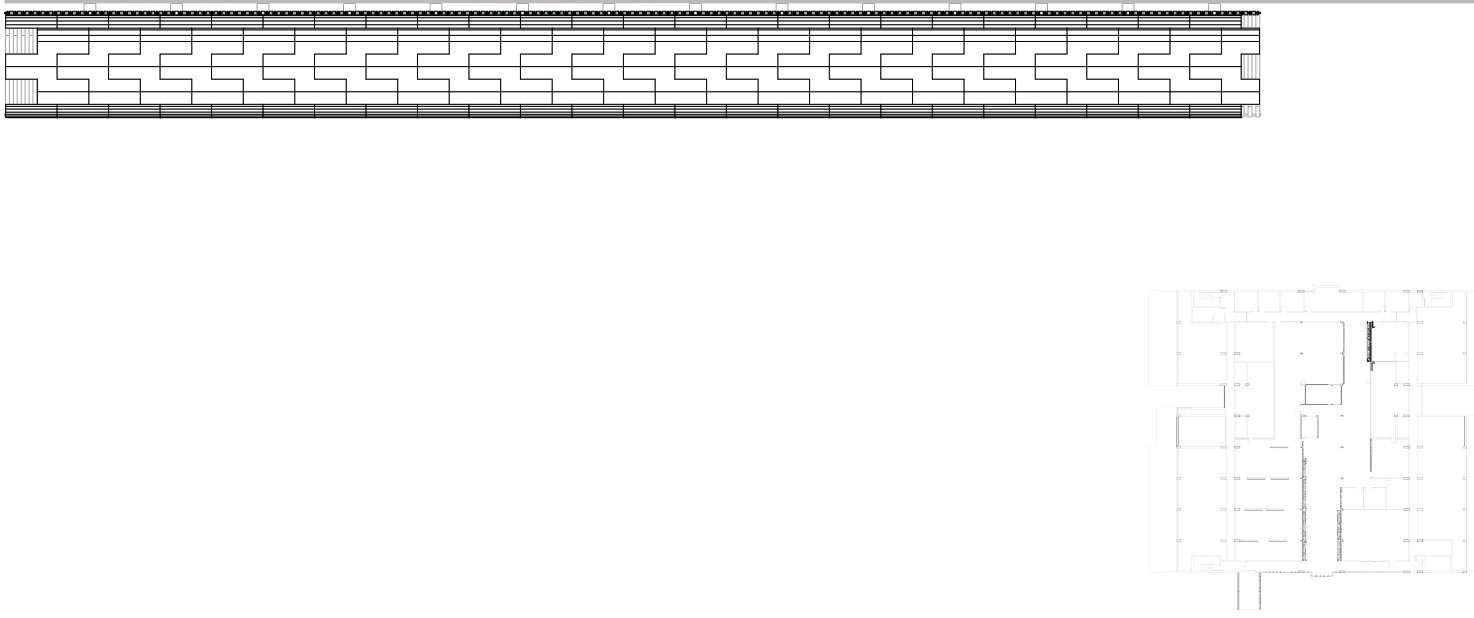


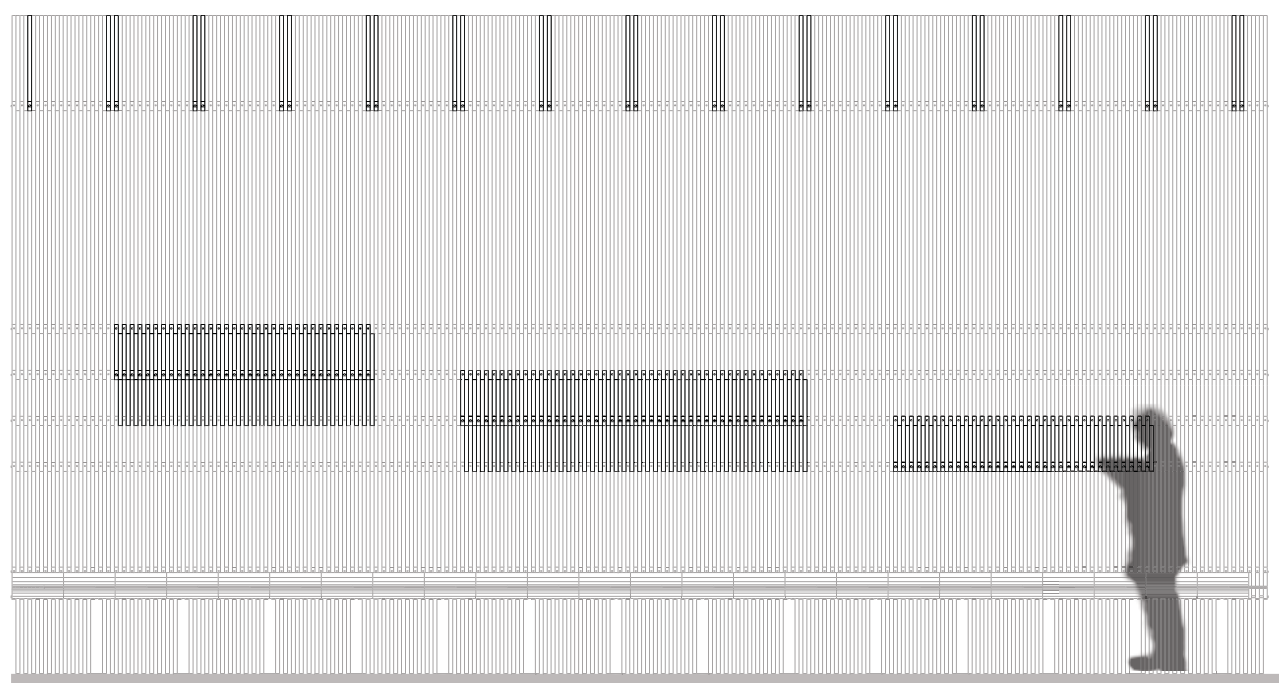

(Figure 49)

Partition 5: Glazing and Wood Variant
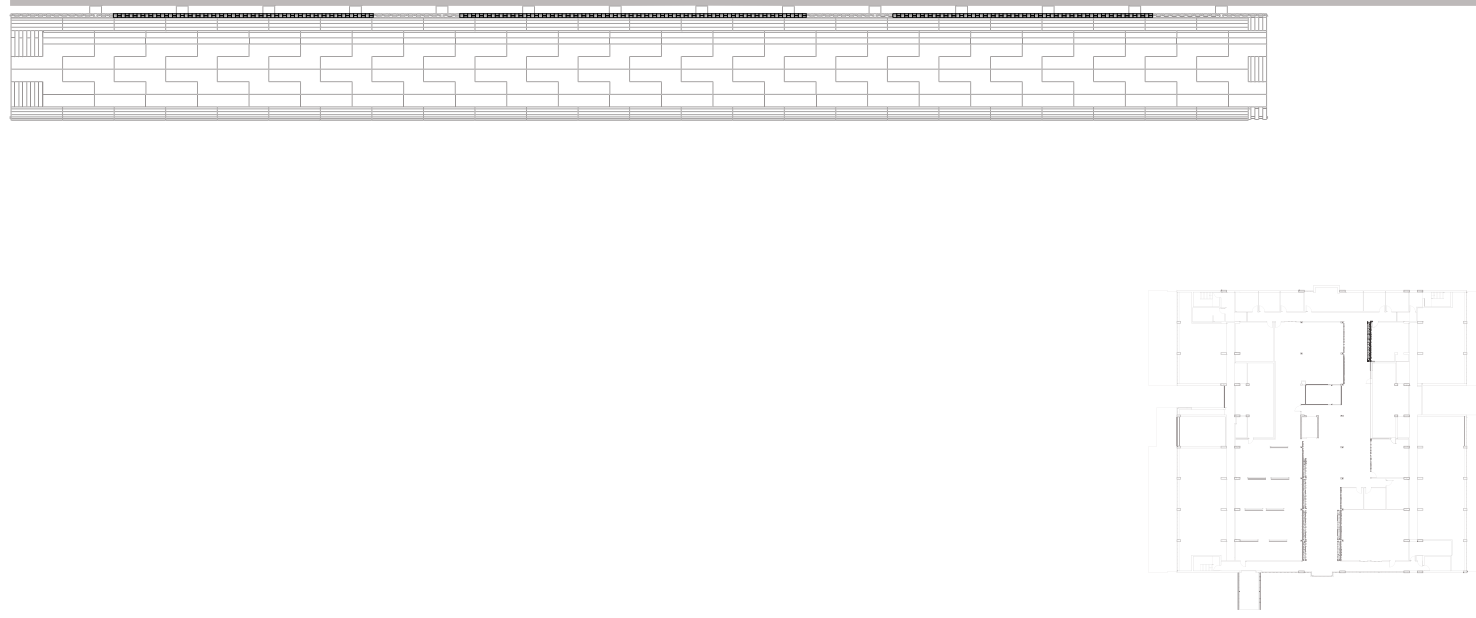


\section{Details}




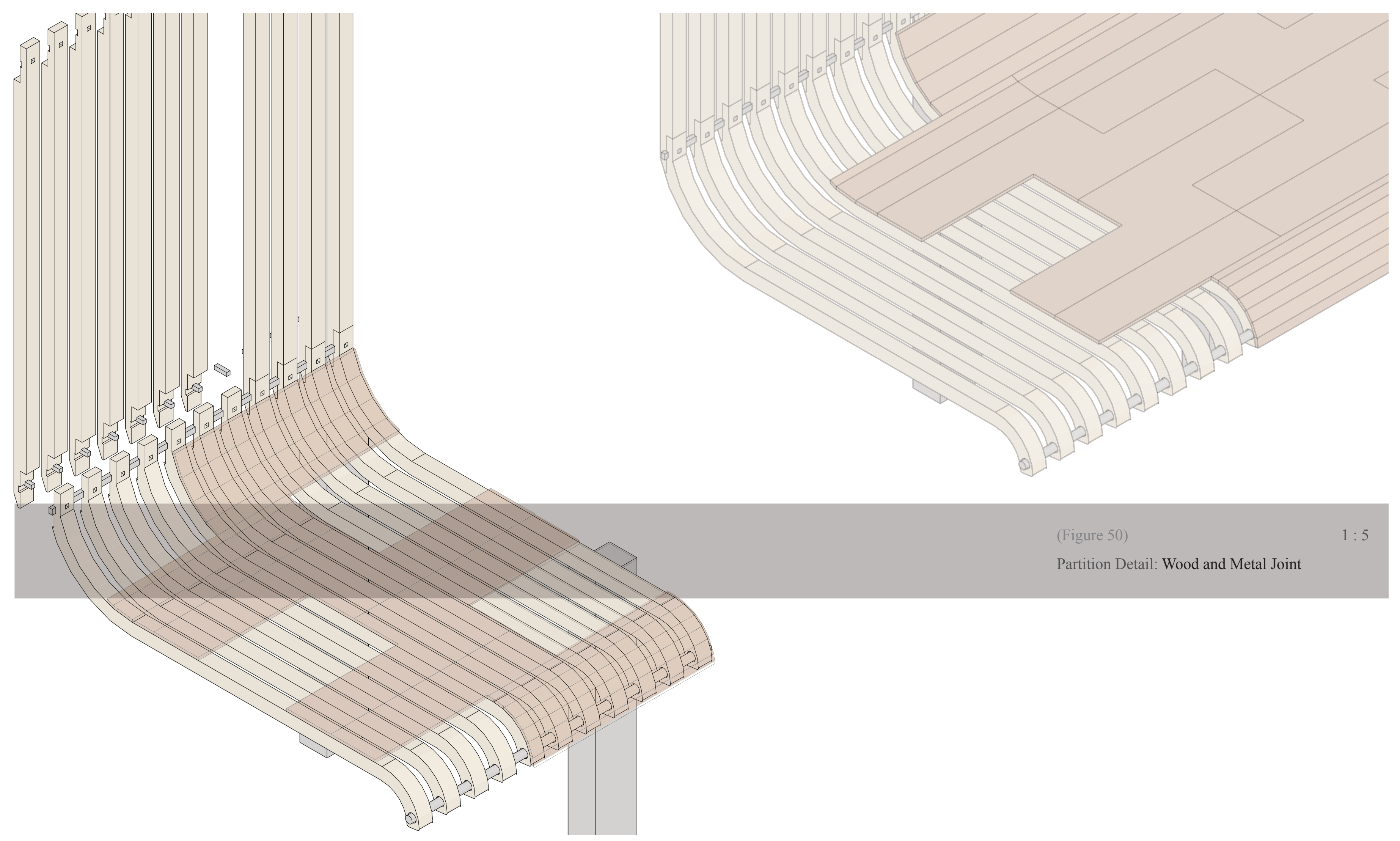




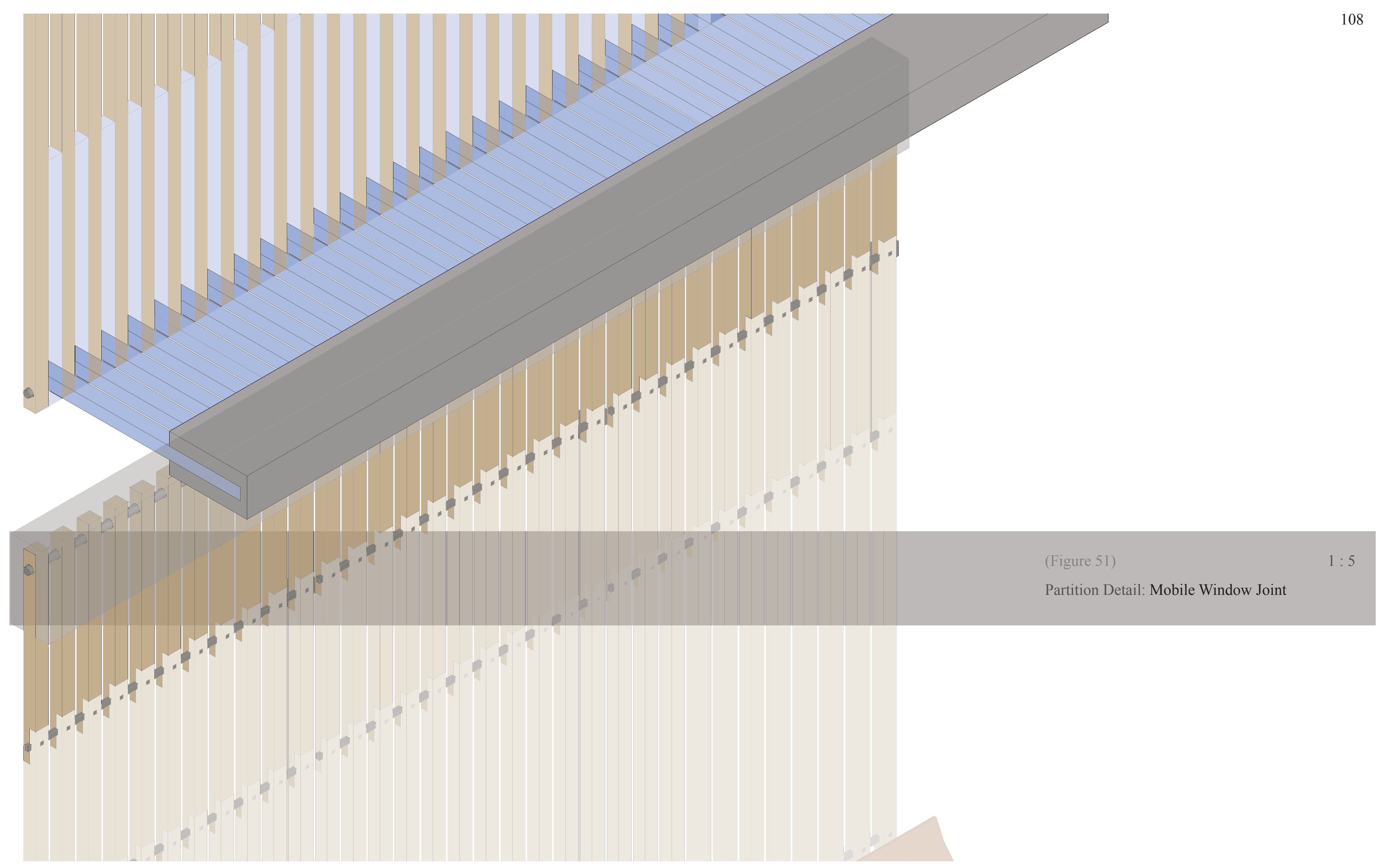


Views 


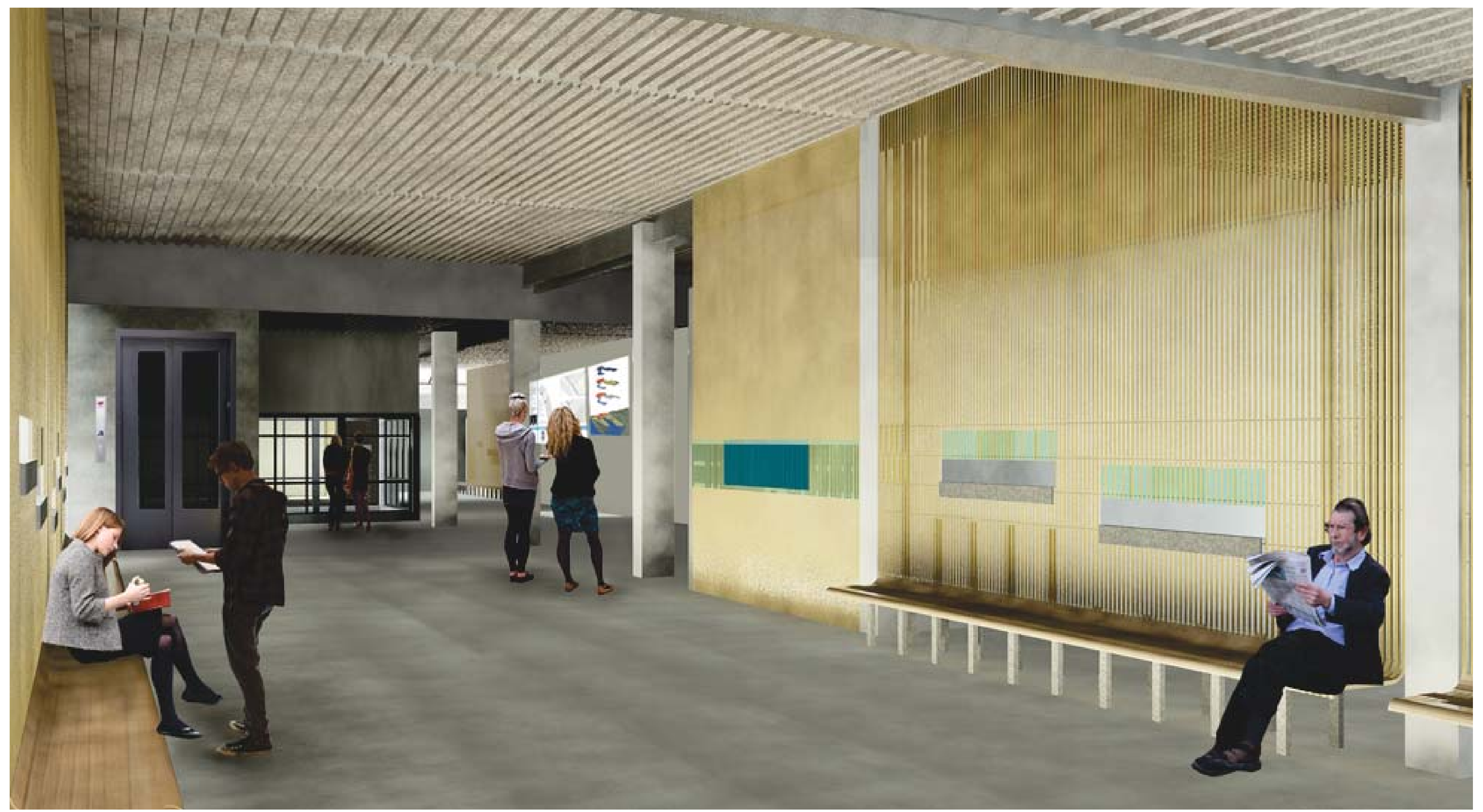




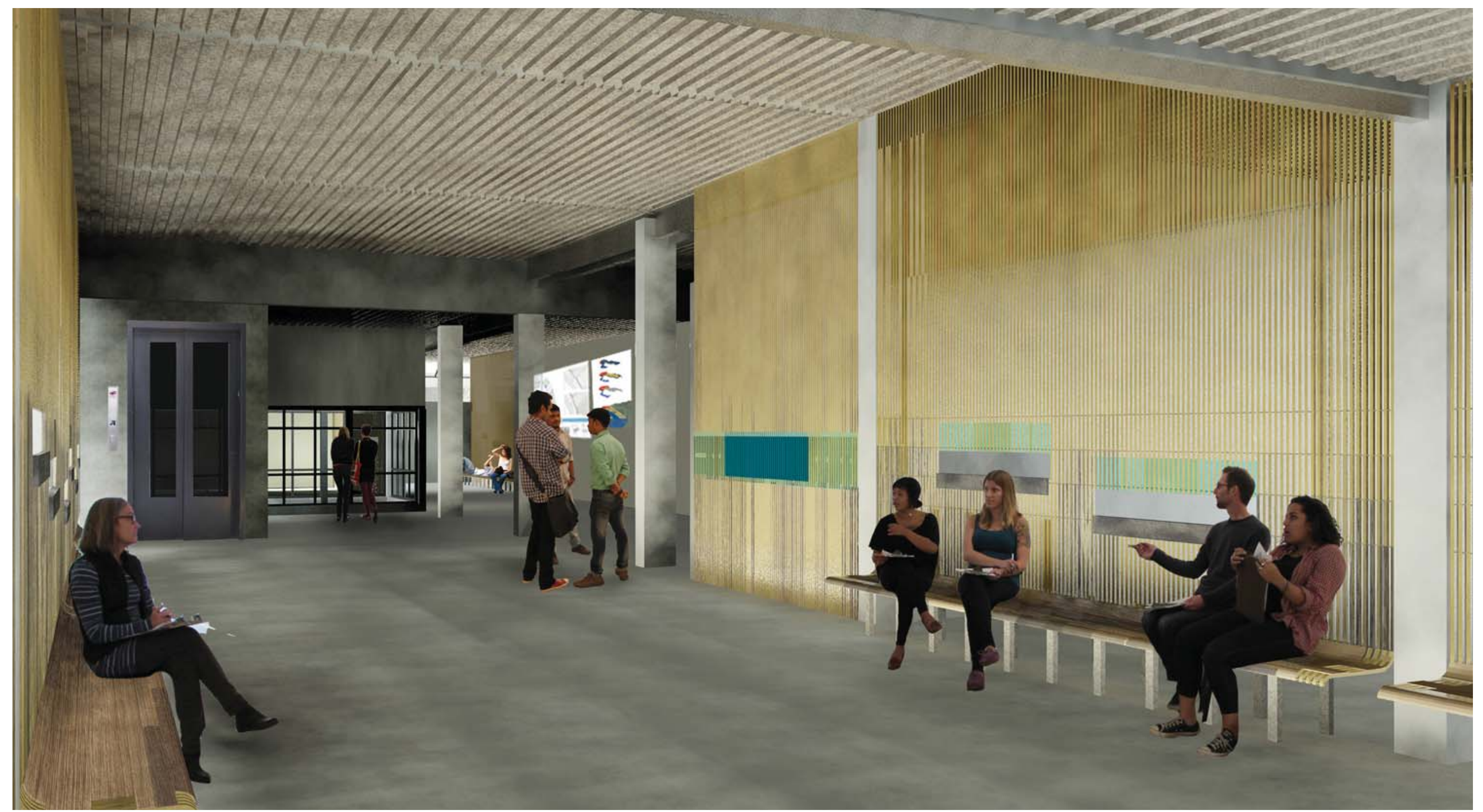




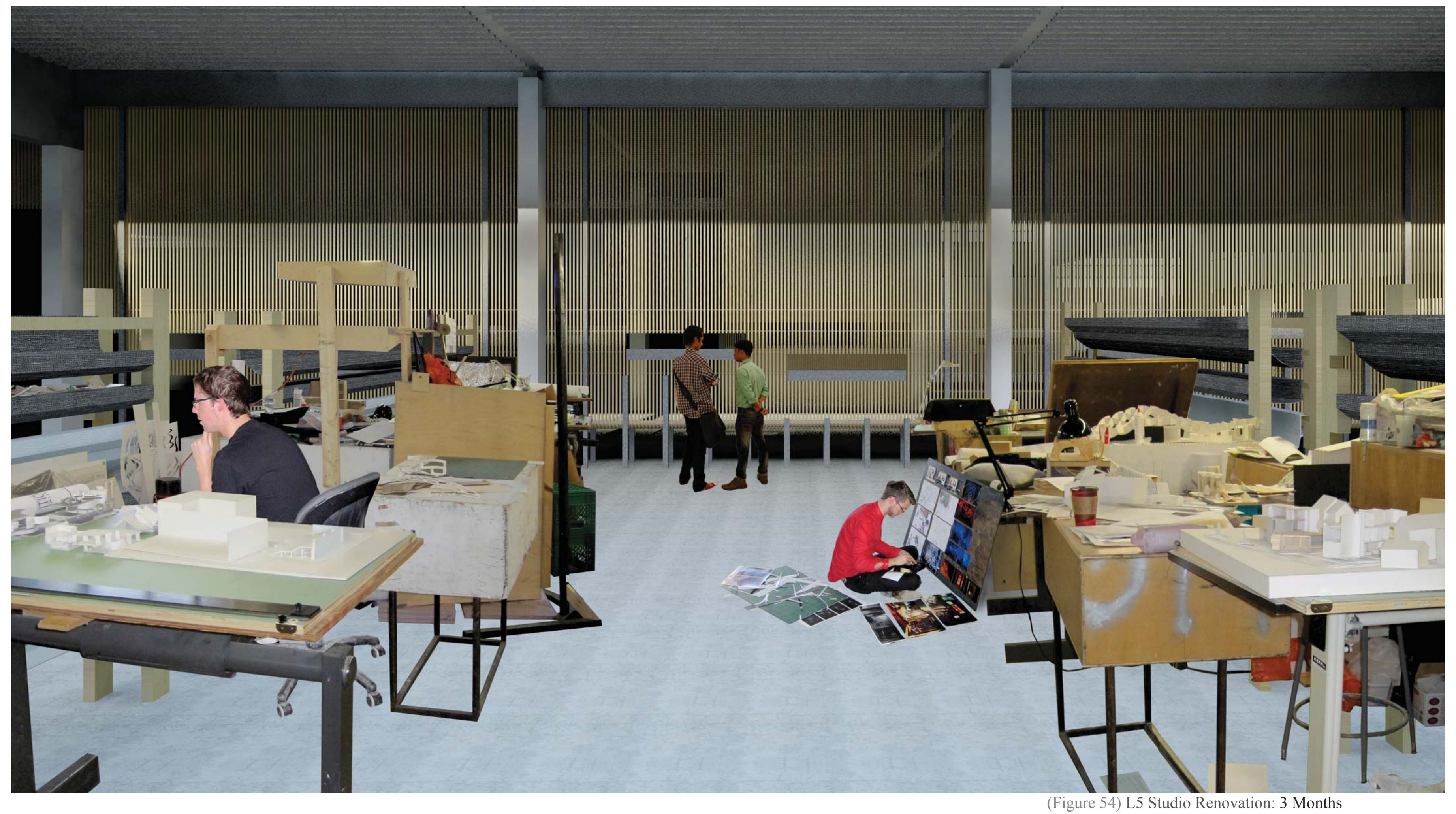




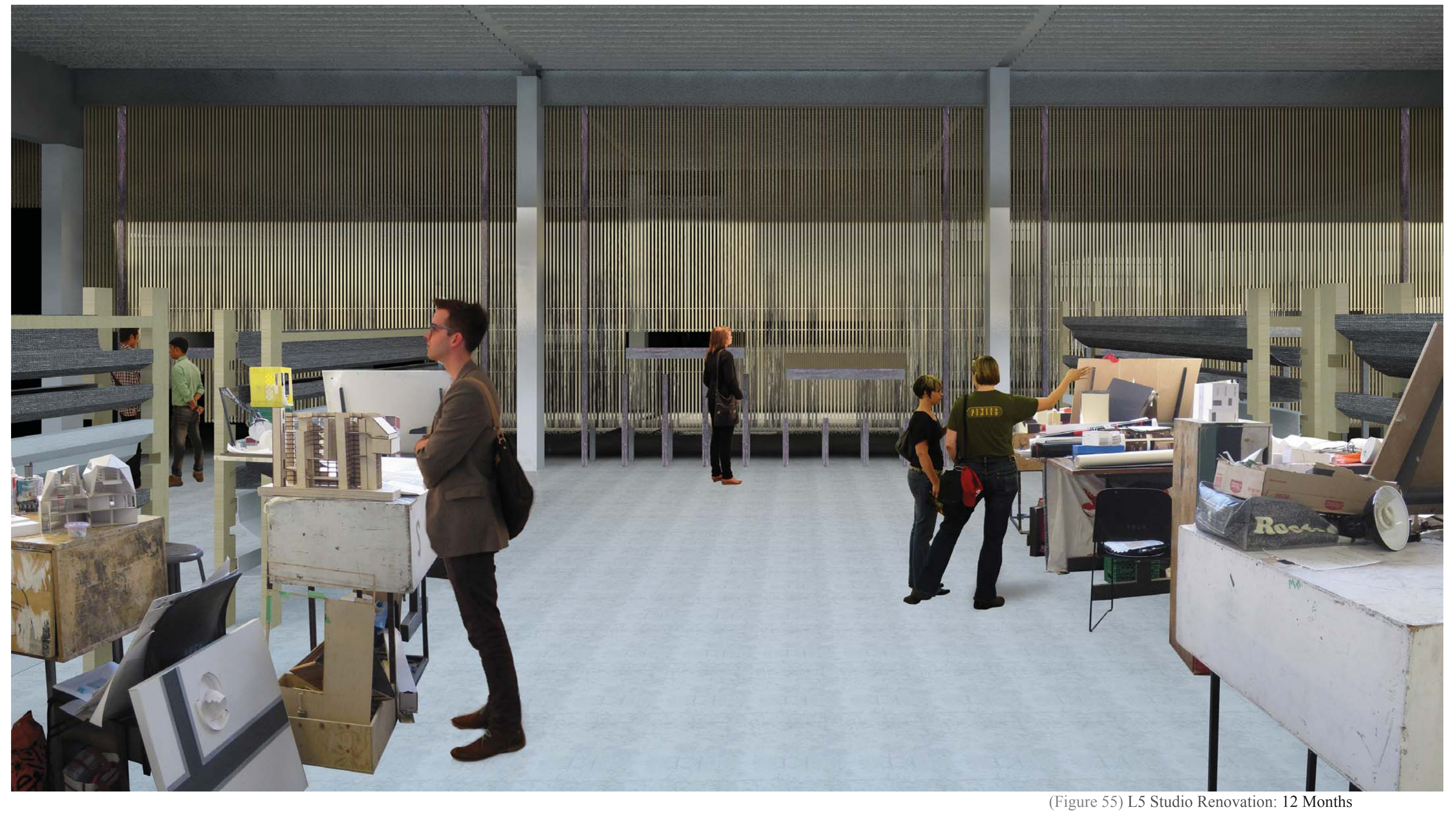




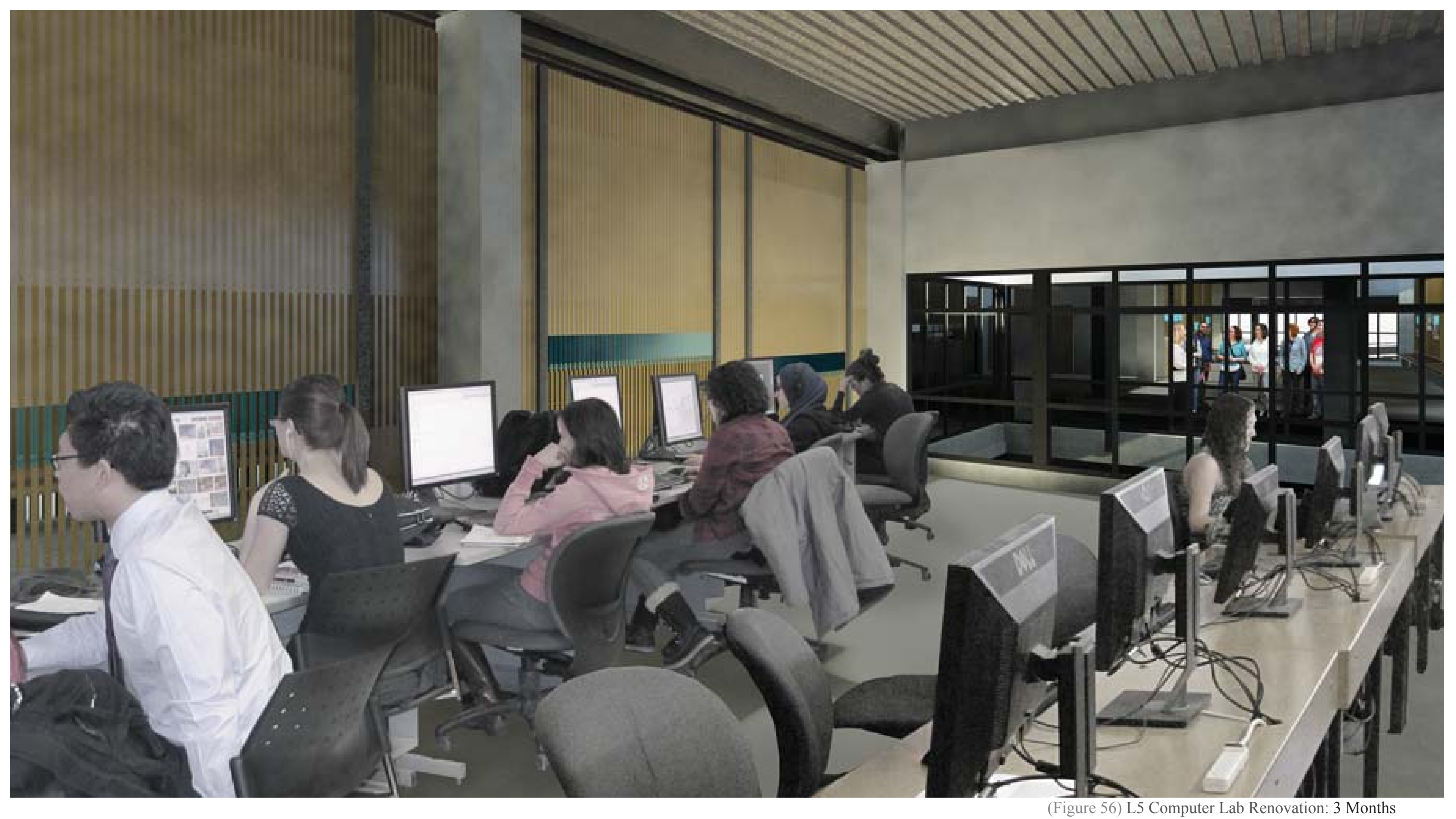




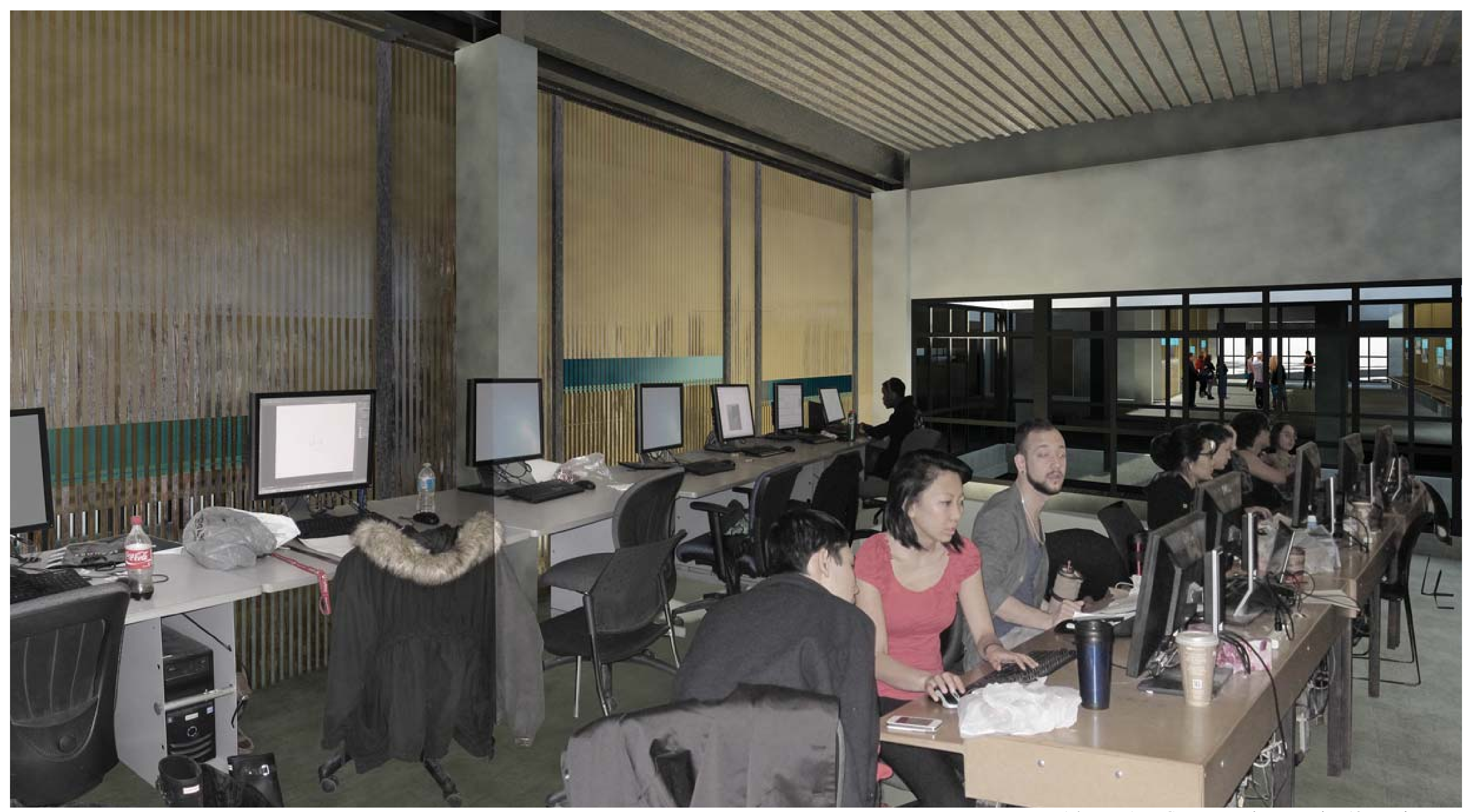


Porosity 

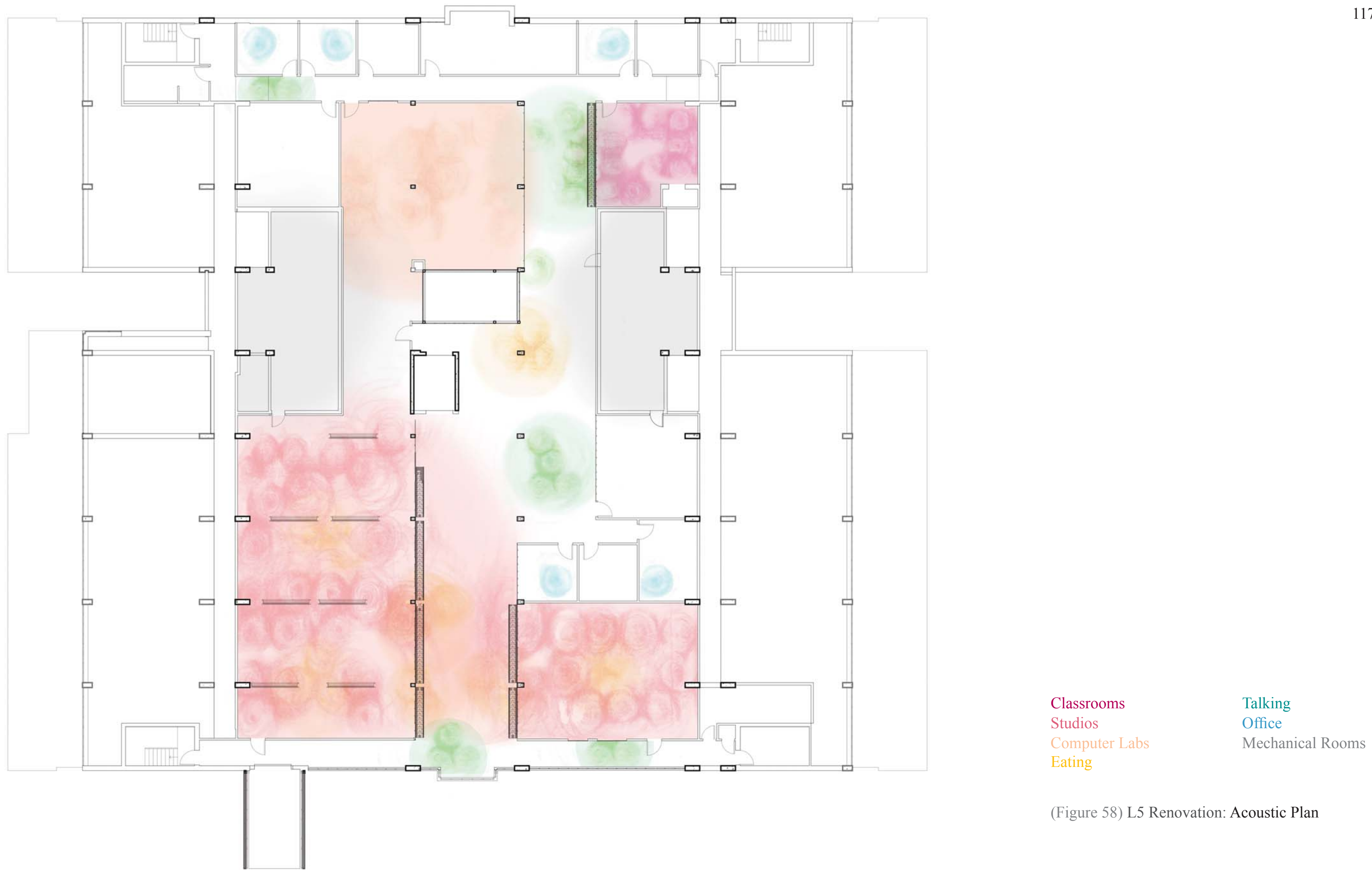


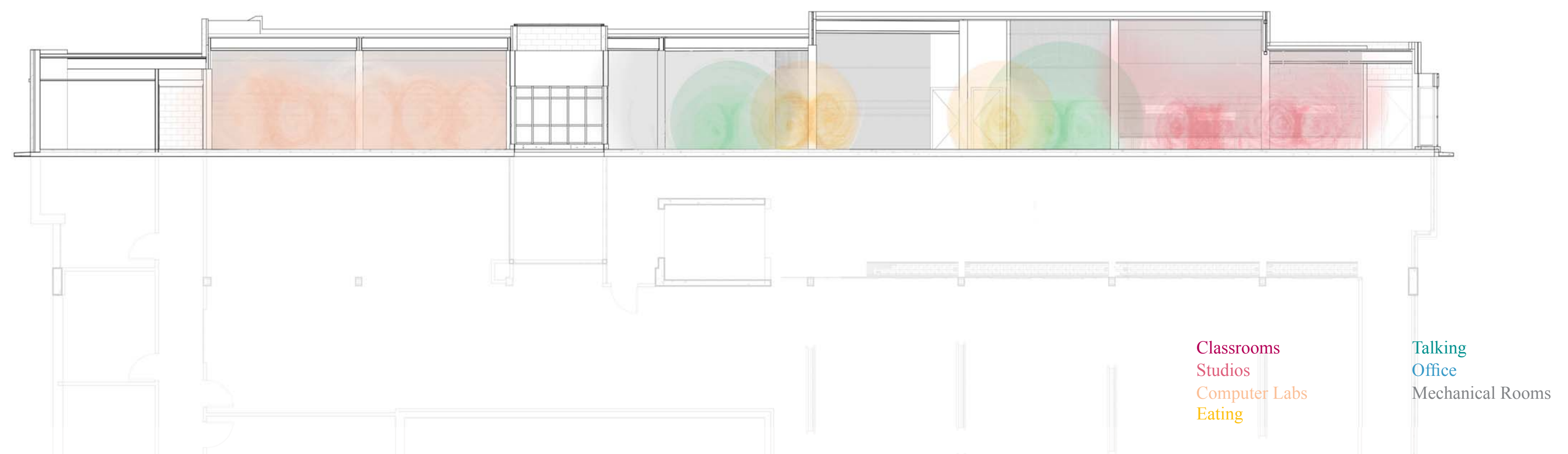

(Figure 59) L5 Renovation: Acoustic Section A 


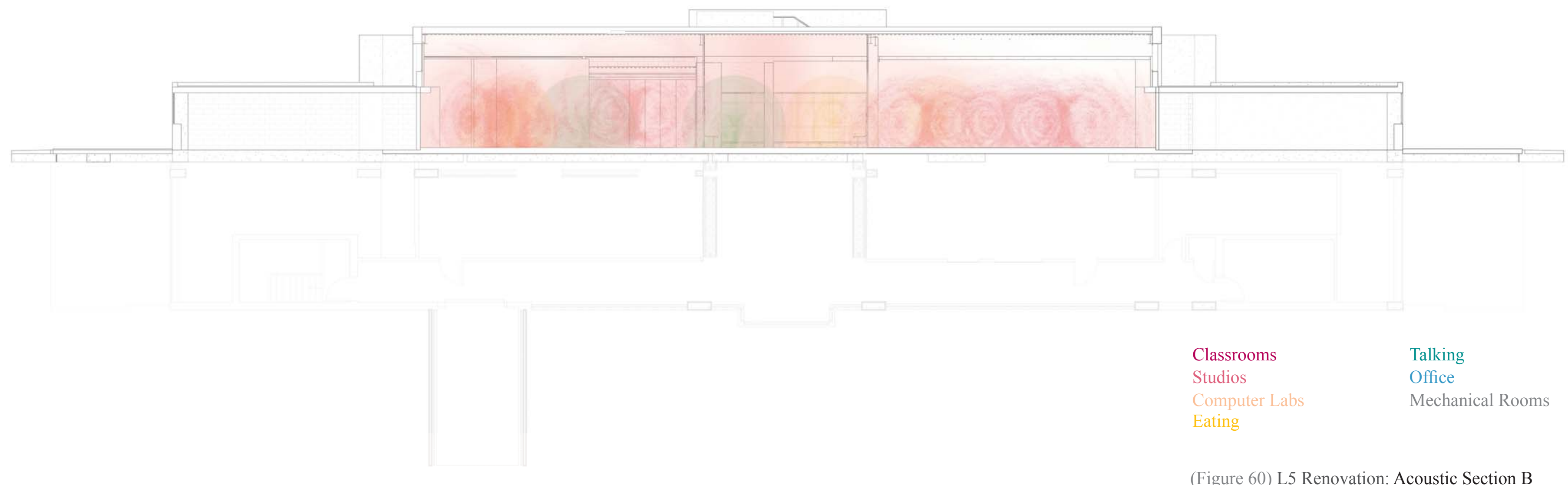

Figure 60) L5 Renovation: Acoustic Section B 


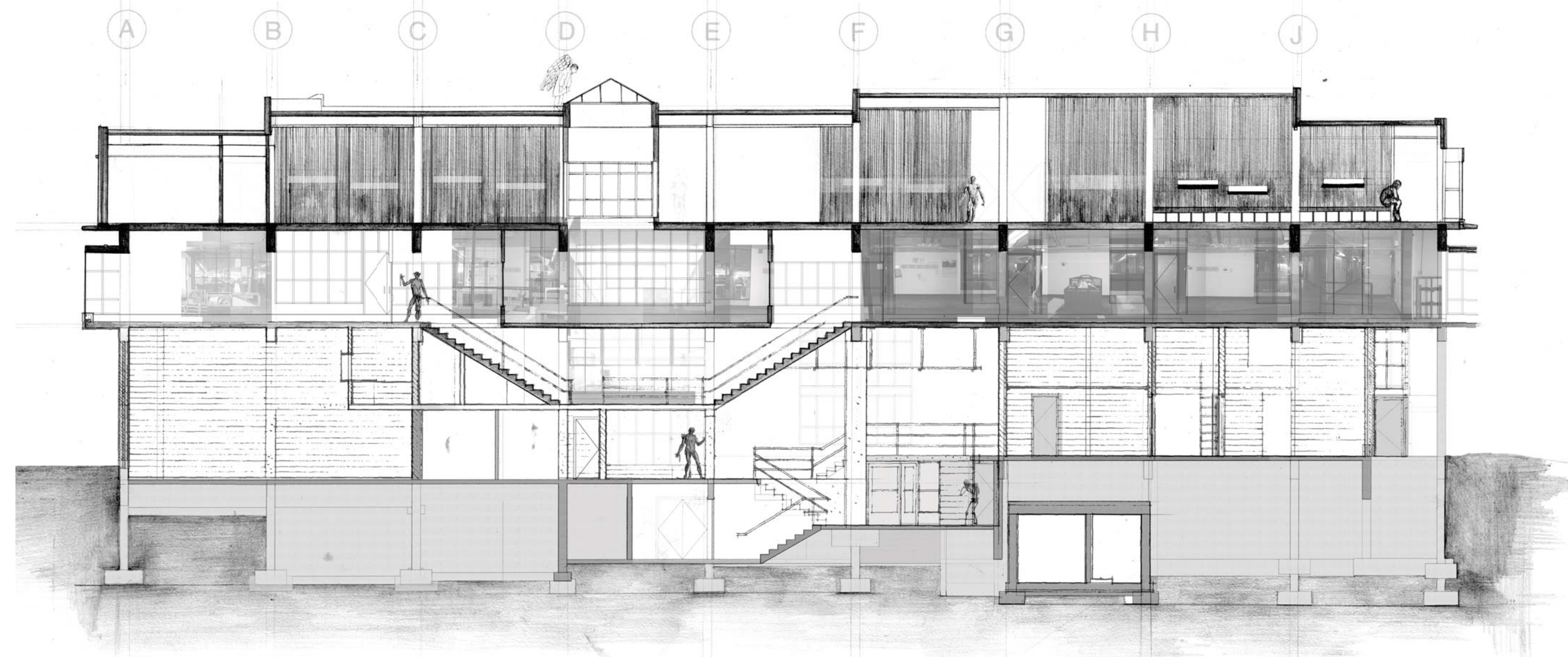




\section{Post-Script}


I'm sure you are wondering why I chose the title 22 Grams: Quantifying the Contemporary Human Body in Building 22.

The title 22 Grams comes from an experiment performed by Duncan McDougal in 1901 on six tuberculosis patients, who were in the process of dying. Without moving into specifics, McDougal weighed his patients prior to the exact moment of their death and just after they had passed away. The purpose of this experiment was an attempt to identify the moment the soul departed the body and the corresponding weight of this ephemeral entity. The popularized results were that the perceived departure of the soul was coupled with a minute weight change; leading to the determination that the weight of the soul was exactly 21 grams. In this thesis an extra gram has been added, to McDougal's total, in an attempt to quantify the soul of Building 22.

Now, whether or not we believe the validity of McDougal's experiment or even in the existence of a soul, the notion of quantifying something that has been culturally and religiously un-quantifiable is bizarre and ironic. That said, I think this quantification of the soul perfectly identifies the shift in the value of the body away from a cosmological model that had the ability to inspire wonder, towards a mechanistic model that could be weighed, categorized and understood absolutely.

22 Grams also identifies one of the greatest difficulties I had through this thesis process; identifying the value of the body itself, as a physical thing, in Building 22. The reason I thought that this was important, was that most examples of the body in architecture that I researched were based first in the physical relationship of the body to the building, and secondly in the experiences that these relationships produced. The 
methodology I have followed in the design of the project has been similar, in that I have identified key quantitative relationships between the body, the existing architecture and new design (Eye height, seat height ETC), and then explored the qualitative results of the design (Acoustics, views). In this way, the project provides mediation not only between the body, and the partitions but also attempts to reconcile the relationship of the body to the existing architecture of Building 22. This third element means that the translation of the quantifiable body is based in both the architectural body of Building 22 and the human body of the students. For example, horizontally the length of each module shifts slightly depending on its location in the $5^{\text {th }}$ floor, to accommodate the slight changes in the structural grid. The Appendix that I have included as a sequel to the thesis takes only the body as a model, and does not need to mediate between the body, a site, and a design.

22 Grams also reintroduces the value in understanding the body as a Janus faced entity; being a vessel for the eternal, yet physically temporal. The importance of this mortality is reflected in the temporality of the partition materiality and the ability of the materiality to record traces left by the body. For example, if students preferred to sit, eat and sleep in the middle of Partition 1, the continued use of the partition would rapidly age the plywood bench covering. As use of the renovation is recorded, this record mediates between mechanical and cosmological body models by addressing the contradiction between a replaceable system of parts and an aging mortal body. Without this understanding of the body as a finite, yet essential vessel, the mechanistic body model in architecture becomes a system of parts that is continually replicable and replaceable. While the project is replaceable, the system of parts I have proposed enables innovation, beyond the original renovation. This gives students the opportunity to adapt the partitions not only as portions need to be replaced, but also as the needs of the students change. 
"They say we all lose 21 grams at the exact second of our death, everyone.

And how much fits into 21 grams, how much is lost?

How much goes with that?

How much is gained? ...

21 grams, a weight of a stack of 5 nickels,

the weight of a humming bird, a chocolate bar.

How much do 21 grams weigh?"

- 21 Grams (The Film) 
11

Foot-notes 
$0 \quad$ Pre-Face

1 Marco Frascari, was the Director of the Azreli School of Architecture and Urbanism from 2005 - 2010. He was an Italian architect and architectural theorist, and founded the PhD program at the Azreli School of Architecture and Urbanism. His most recent work "Eleven Exercises in the Art of Architectural Drawing: Slow Food for the Architects Imagination (2011)" examines the relationship between drawing and building.

2 Marco Frascari provides a comprehensive understanding of the relationship between architectural construing and construction in "Monsters of Architecture"; with the example of a health care facility Frascari describes that the subject of the architectural construction is the contents, yet the purposes of the hospital (health) would be the subject of the architectural construing (Monsters of Architecture, 11).

3 The belief that analog systems are less relevant in the profession, is reiterated here from personal experience, in both architectural offices, and discussions with Undergraduate and Master programs' students.

4 Frascari introduces the notion of cosmopoiesis in "Eleven Exercises in the Art of Architectural Drawing: Slow Food for the Architect's Imagination". Frascari discusses that broadly cosmopoiesis (world-making) is the ultimate goal of architectural construing and construction.

5 Also known as "The Azrieli School of Architecture and Urbanism", and the current home of the Bachelor of Architectural Studies program.

6 This shift away from studio use, towards a reliance on computer lab space is also reflected in the M. Architecture and M. Architecture 1 programs which are currently housed in the Azreli Pavilion.

7 Ockman, Joan. Architecture School: Three Centuries of Educating Architects in North America. Cambridge: MIT Press, 2012. 399.

8 Currently, based on personal experience, the physical separation of the Master programs into Azrieli, creates a social and academic separation between the Undergraduate and Master programs. This essentially means that the undergraduate have no knowledge of the work the Master student's complete, and the Master student's have no knowledge of the work the Undergraduate student's complete. This disconnect was addressed in Catalogue 22, a student project completed by myself, Vanessa Haddock, and Chris Cormier, which attempted to create a database of both Master and Undergraduate work. http://en.wikiversity.org/wiki/Category:Catalogue_22 


\section{The Basic Body}

1 Pollio, Vitruvius. Vitruvius: Ten Books on Architecture. New York: Cambridge University Press, 1999. pg 25.

2 Ten Books, pg 27. (Italics my own)

3 Ten Books, pg 27. (Italics my own)

$4 \quad$ Ten Books, pg 29. (Italics my own)

$5 \quad$ Ten Books, pg 31. (Italics my own)

6 Weston, Richard. 100 Ideas that Changed Architecture. London: Lawrence King Publishing, 2011. pg 44.

7 Mallgrave, Harry-Francis. The Architects Brain: Neuroscience, Creativity, and Architecture. West Sussex: Wiley-Blackwell, 2010. pg 9.

8100 Ideas that Changed Architecture, 44.

$9 \quad$ "Proportion." $<$ http://www.etymonline.com/index.hp?term=proportion\&allowed in_frame $=0>$

10100 Ideas that Changed Architecture, 56.

11100 Ideas that Changed Architecture, 56.

12100 Ideas that Changed Architecture, 56.

13100 Ideas that Changed Architecture, 57.

14 "Symmetry." $<$ http://www.etymonline.com/index.php?term=symmetry\&allowed in frame $=0>$.

15 "Symmetry." $<$ http://www.etymonline.com/index.php?term=symmetry\&allowed in_frame $=0>$.

16 "Symmetry." <http://www.etymonline.com/index.php?term=symmetry\&allowed in frame $=0>$.

17 "Meter, N.1." <http://www.etymonline.com/index.php?term=meter\&allowed_in frame $=0>$. 
18 "Mete." $<$ http://www.etymonline.com/index.php?term=mete\&allowed_in_ frame $=0>$.

19100 Ideas that Changed Architecture, 52.

20 "Module." <http://www.etymonline.com/index.php?allowed_in_ frame $=0 \&$ search $=$ module $\&$ searchmode $=$ none $>$.

21 "Mode. N1" <http://www.etymonline.com/index.php?term=mode\&allowed_in_ frame $=0>$.

22 "Module." <http://www.etymonline.com/index.php?allowed_in frame $=0 \&$ search $=$ module $\&$ searchmode $=$ none $>$.

23 Keith Mitnick uses the example that "in the case of buildings, a wall may be defined as a coplanar assortment of studs, sheetrock ... but each of these subcomponents in turn comprises another set of secondary elements." (Mitnick, Keith. Artificial Light: A Narrative Inquiry into the Nature of Abstraction, Immediacy, and Other Architectural Fictions. New York: Princeton Architectural Press, 2008. pg 43-44.)

24 "Scale N.1." <http://www.etymonline.com/index.php?term=scale\&allowed_in_ frame $=0>$.

25 "Scale N.1." <http://www.etymonline.com/index.php?term=scale\&allowed_in_ frame $=0>$.

26 "Skull. N.2" <http://www.etymonline.com/index.php?term=skull\&allowed_in_ frame $=0>$.

27 "Skull. N.2" <http://www.etymonline.com/index.php?term=skull\&allowed_in frame $=0>$.

28 "Scale N.2." < http://www.etymonline.com/index.php?term=scale\&allowed_in_ frame $=0>$.

29 "Scale V.1." < http://www.etymonline.com/index.php?term=scale\&allowed_in_ frame $=0>$.

30 "Scale V.1." < http://www.etymonline.com/index.php?term=scale\&allowed_in frame $=0>$.

$31 \quad$ Vers Une Architecture. 
1 See "Monster's of Architecture", by Marco Frascari for a complete analysis of construing and constructing.

2 Frascari, Marco. "The Body and Architecture in the Drawings of Carlo Scarpa". Res 14. (1987): 123 - 142. pg 124.

3 Jonathan Hale, in "The Old Way of Seeing", reinforces this idea with the belief that man is able to relate to and embody his environment, because he finds himself proportionally reflected in its constructed forms; "Trees and people contain the same kind of patterns. Harmonious buildings that embody life forms refer to us, they are about us. That is why we are so attracted to them". (Hale, Jonathan. The Old Way of Seeing. New York: Houghton Mifflin Company, 1994. pg 67.)"

4 The Body and Architecture, 123.

5 The Body and Architecture, 124.

6 Fowler, F.G. The Concise Oxford Dictionary of Current English, $6^{\text {th }}$ Edition. Oxford: Oxford University Press, 1976. pg 890.

7 Jae-Jin, Lee. Anatomical Architecture: Building is Body. Ottawa: Carleton University, 2012. pg 35.

8 The Architects Brain, 12.

9 "Columns ... are the bones of a building, the infill walls ... serve as muscles and ligaments, the finish of a building is its skin." (The Architects Brain, 13)

10 The Architects Brain, 9.

11 Sawday, Jonathan. The Body Emblazoned: Dissection and the Human Body in Renaissance Culture. New York: Routledge, 1995. pg 16.

12 The Body Emblazoned, 28.

13 The Body Emblazoned, 31.

14 This view is essentially a contemporary understanding of cosmological anthropomorphism.

15 The Brion Tomb is a private burial ground from the Brion Family, originally commissioned by the window of the founder of the Brionvega company. Construction of the tomb was completed in 1978. 
16 This projection of symmetrical proportionality is similar to the anomaly of the missing window in the Jonathan Stone House.

17 The Body and Architecture, 130.

18 The Body and Architecture, 130.

19 The Body and Architecture, 131. (Italics my own.)

3 The Body in Construing (Macro)

1 Rykwert, Joseph. The Sitting Position, in The Necessity of Artifice. New York: Rizzoli, 1982. pg 23.

2 Corbusier, Le. The Modulor: A Harmonious Measure to the Human Scale. Boston: Birkhauser, 2000. pg 19.

3 The Modulor, 33

4 The Modulor, 20.

$5 \quad$ Alder, Ken. The Measure of All Things: The Seven-Year Odyssey and Hidden Error That Transformed the World. New York: The Free Press, 2002.

6 Frascari, Marco. Eleven Exercises in the Art of Architectural Drawing: Slow Food for the Architect's Imagination. New York: Routledge, 2011. pg 2.

7 Eleven Exercises, 9.

8 Eleven Exercises, Chapter 3.

4 Ex. \#1: Reification of the Body in Analog Drawings

1 Ingold, Tim. Lines: A Brief History. New York: Routledge, 2007. pg 28.

2 Lines, 3.

3 Lines, 24.

4 Lines, 24-26.

$5 \quad$ Lines, 26. 
1 Fuglem, Terri. Carmen Corneil at Carleton. Architecture and Ideas, Vol. 8. (2009): 71-87. pg 71.

2 Carmen Corneil at Carleton, 75.

3 Carmen Corneil at Carleton, 83.

$4 \quad$ The need for more offices, studio, presentation areas, computer lab and classroom spaces was established in 2007, during the open forum discussion, "This House Believes That Architecture Has Left the Building”.

\section{Ex. \#2: Anthropomorphic Models in Building 22}

1 The 5th floor corridor was chosen for analysis because the majority of programmed spaces are locked and require keypad access.

2 Fontein, Lucie. Reading Structure through the Frame. Perspecta, Vol. 31. (2000). 50 - 59. pg 56.

3 This structure is hidden from view.

1 Frascari, Marco. The Tell-the-Tale Detail. VIA, 7. (1984): 22-37. pg 24.

2 The Tell-the-Tale Detail, 28.

3 Reading Structure through the Frame, 57.

$4 \quad$ Artifact is used here within the context of Tim Ingold's understanding of an artifact, discussed in "Making: Anthropology, Archaeology, Art and Architecture". Specifically, Ingold defines an artifact as the product of an idea, which has taken on a static, and intended material form.

\section{The Project: Renovating the Body}

1 The mechanical N1 room specifically was previously enclosed within a M. Architecture studio space. However, students complained that the mechanical equipment would make frequent and distracting noises.

2 This is the actual thickness of $3 / 4$ inch plywood.

3 Reading Structure through the Frame, 83. 


\section{Bibliography}


Alder, Gerald and Timothy Brittain-Catlin and Gordana Fontana-Giusti. Scale:

Imagination, Perception and Practice in Architecture. New York: Routledge, 2012.

Alder, Ken. The Measure of All Things: The Seven-Year Odyssey and Hidden Error That Transformed the World. New York: The Free Press, 2002.

Amerlinck, Mari-Jose. Architectural Anthropology. Westport: Greenwood Publishing Group, 2001.

Corbusier, Le. The Modulor: A Harmonious Measure to the Human Scale. Boston: Birkhauser, 2000.

Dodds, George and Tavernor, Robert. Body and Building: Essays on the Changing Relation of Body and Architecture. Cambridge: MIT Press.

Elet, Yvonne. Seats of Power: The Outdoor Benches of Early Modern Florence. Journal of the Society of Architectural Historians. Vol. 61, ( 2002). pp $444-469$.

Feher, Michel and Naddaff, Ramona. Fragments for a History of the Human Body: Part One. New York: Provincial Graphics, 1989.

Feher, Michel and Naddaff, Ramona. Fragments for a History of the Human Body: Part Two. New York: Provincial Graphics, 1989.

Feher, Michel and Naddaff, Ramona. Fragments for a History of the Human Body: Part Three. New York: Provincial Graphics, 1989. 
Fontein, Lucie. Reading Structure through the Frame. Perspecta, Vol. 31. (2000). 50 - 59

Fowler, F.G. The Concise Oxford Dictionary of Current English, 6th Edition. Oxford: Oxford University Press, 1976.

Frascari, Marco. Eleven Exercises in the Art of Architectural Drawing: Slow Food for the Architect's Imagination. New York: Routledge, 2011.

Frascari, Marco. "The Body and Architecture in the Drawings of Carlo Scarpa". Res 14. (1987): $123-142$.

Frascari, Marco and Hale, Jonathan. From Models to Drawings: Imagination and Representation in Architecture. New York: Routledge, 2007.

Frascari, Marco. Monsters of Architecture: Anthropomorphism in Architectural Theory. Maryland: Rowan \& Littlefield Publishers Inc., 1991.

Frascari, Marco. The Tell-the-Tale Detail. VIA, 7. (1984): 22-37.

Frascari, Marco. The Drafting Knife and Pen, in Implementing Architecture. Atlanta: Nexus Press, 1988.

Fuglem, Terri. Carmen Corneil at Carleton. Architecture and Ideas, Vol. 8. (2009): 71-87.

Ginzburg, Carlo. Representation: the Word, the Idea, the Thing. in Wooden Eyes. New York: Columbia University Press, 2001: 63-78. 
Gallagher, Shaun. How the Body Shapes the Mind. Oxford Scholarship Online, February 2006.

Goldhoorn, Bart. Schools of Architecture. Netherlands: Rotterdam, 1996.

Hale, Jonathan. The Old Way of Seeing. New York: Houghton Mifflin Company, 1994.

Hersey, George. The Lost Meaning of Classical Architecture: Speculations on Ornament from Vitruvius to Venturi. London: MIT Press, 1988.

Ingold, Tim. Lines: A Brief History. New York: Routledge, 2007.

Ingold, Tim. Material versus Materiality, in Being Alive: Essays on Movement, Knowledge, and Description. New York: Routledge, 2011.

Ingold, Tim. Making: Anthropology, Archaeology, Art and Architecture. New York: Routledge, 2013.

Jae-Jin, Lee. Anatomical Architecture: Building is Body. Ottawa: Carleton University, 2012.

Johnson, Mark. The Meaning of the Body: Aesthetics of Human Understanding. London: University of Chicago Press, 2007.

Lindstrom, Martin. Buy-ology. New York: Random House, 2008. 
Mallgrave, Harry-Francis. The Architects Brain: Neuroscience, Creativity, and Architecture. West Sussex: Wiley-Blackwell, 2010.

Mitnick, Keith. Artificial Light: A Narrative Inquiry into the Nature of Abstraction, Immediacy, and Other Architectural Fictions. New York: Princeton Architectural Press, 2008.

McGregor, Wayne: A choreographer's creative process in real time http://www.ted.com/talks/wayne_mcgregor_a_choreographer_s_creative_process_in_ real_time.html

Ockman, Joan. Architecture School: Three Centuries of Educating Architects in North America. Cambridge: MIT Press, 2012.

Piedmont-Palladino, Susan. Tools of the Imagination. New York: Princeton Architectural Press, 2007.

Plato. "Timaeus.” Plato Complete Works. Indiana: Hackett Publishing Company, Inc, 1997.

Ramachandran, Vilayanur. The Tell-Tale Brain: A Neuroscientists Quest for What Makes us Human. New York: W.W. Norton, 2011.

Rykwert, Joseph. The Sitting Position, in The Necessity of Artifice. New York: Rizzoli, 1982. 
Rykwert, Joseph. Translation and / or Representation. CCA Mellon Lectures. April 2005.

Sawday, Jonathan. The Body Emblazoned: Dissection and the Human Body in Renaissance Culture. New York: Routledge, 1995.

Schvan-Ritecz, Zsofia. See(k)ing Phantoms. Ottawa: Carleton University, 2010.

Vitruvius. Vitruvius: Ten Books on Architecture. New York: Cambridge University Press, 1999.

Weston, Richard. 100 Ideas that Changed Architecture. London: Lawrence King Publishing, 2011. 


\section{Daedelic Detail: An Anthropocentric Bench}


In its most basic form the bench is a construct which accepts and supports the weight of at least two bodies, distributed horizontally through the seat. The origins of the word "bench" support this functional and communal purpose, with the Old English "benc" meaning "long seat". Not surprisingly because of its communal use the bench has traditionally been a fixture in public spaces, in both mobile and immobile forms. Architecturally the placement, and use, of benches provide an opportunity for the analysis of the functional and social use of spaces; this prioritizes benches above a basic utilitarian construct. Benches also vary in their levels of physical integration into building interiors and facades, enabling them to occasionally be identified as integral parts of a building. However, over the last 100 years, the social function of the bench has been increasingly overlooked and instead the ability of the bench to relate to, and accommodate, the physical human body has been prioritized.

The traditional social importance of the bench is perhaps best identified in the external bench of the Palazzo Rucellai located in Florence (Alberti, 1446 - 51). Specifically in Renaissance Italy, benches were typically found in Civic Centers and were used to mediate social interactions. The placement of the bench along the external public facade of the Palazzo Rucellai indicates a desire to shape urban experience around the residence, and mediate between public and semi-private space. The bench in this instance also has the unique ability to provide human scale to a visually massive architecture. In particular, the entrances of the Palazzo Rucellai are approximately twice the height of a typical entrance; creating a dramatic visual distortion between the architecture and the perceived scale of the human body. Marco Frascari discusses the notion of proportions in an architectural body in the "The Tell-the-Tale Detail", stating that an architectural body is defined with a series of proportions, where a basic module is the norm from which all the lengths, widths, and heights are derived. The ability of the bench to combat the 
distortion inherent in the facade, by articulately providing a relatable anthropocentric scale, is therefore essential to an understanding of the social and functional use of the building.

However, the evolution of the bench also demonstrates a gradual removal of a necessity to accommodate the human body, in both the form and the selection of materiality in contemporary benches. Currently public benches, especially those located in parks, are actually designed with the intention of deterring prolonged seating. Specifically, the horizontal metal slats are intended to be reactive to temperature fluctuations ${ }^{2}$. This preference to remove the human body, or at the least control the time it lingers, in public spaces demonstrates a dramatic shift in social value and purpose of the bench. Perhaps because of this removal of the body from the common public bench, design of individual benches currently seeks to accommodate the body in extreme and complicated ways. An example of this over-accommodation can be seen in the perceived ergonomic design of the "Wa" Bench". Specifically, the "Wa" bench is constructed with a gradual formal curvature that accommodates at once the seated individual, couple and family with a small dog. While the design of this bench does comfortably accommodate the seat, the body is used only to provide approximate horizontal measurements which indicate the appropriate placement and length of seats.

In an attempt to return to an anthropocentric design, the body could be taken as both a functional and metaphoric model for the design of a bench. This would remove the perceived necessity for the inclusion of complicated forms popular in contemporary bench design; enabling the body to become the location and form, both of and for, the bench. While this removes the design from a traditional architecture site, it reorients the purpose of the design towards creating anthropomorphic relationships in both form and 
function. This condition also enables the functional reduction of the bench to its most fundamental components. 


\section{Footnotes}

1 http://www.etymonline.com/index.php?term $=$ bench\&allowed_in_frame $=0$

2 Green, J. The Humble Public Bench Becomes Comfortable, Inclusive, and Healthy. Uniting the Built and Natural Envionments. 12 / 18 / 2013. <http://dirt. asla.org/2013/12/18/the-humble-public-bench-becomes-comfortable-inclusiveand-healthy/>

3 The "Wa" bench was a semi-finalist in the "Street Seats: Reimagining the Public Bench", which was an outdoor design competition in Boston's Four Point Channel. The written goals of the competition were to improve the livability of the city in socially and environmentally conscious ways. 


\section{Bibliography}

Boston Design Museum. Street Seats: Re-Imagining the Public Bench. 2014. (http://

designmuseumboston.org/exhibits/streetseats/)

Brandon, Justin. Street Plans Collaborative. 2013.(http://www. streetseats.org/street-seat-photos/)

Chun, Joseph and Natalie Fizer. Knot Bench. New York, NY. February 28, 2013. (http://

designmuseumboston.org/exhibits/streetseats/\#exhibit)

Elet, Yvonne. Seats of Power: The Outdoor Benches of Early Modern Florence. Journal of the

Society of Architectural Historians. Vol. 61, December 2002, pp 444 - 469

Etymology Online Dictionary. 2014. (http://www.etymonline.com/index.

php?term=bench\&allowed_in_frame $=0$ )

Green, J. The Humble Public Bench Becomes Comfortable, Inclusive, and Healthy. Uniting the

Built and Natural Envionments. December 18, 2013. (http://dirt.asla.org/2013/12/18/the-humblepublic-bench-becomes-comfortable-inclusive-and-healthy/)

Hawkes, Dean. The Environmental Imagination: Technics and Poetics of the Architectural Environment. New York: Taylor and Francis, 2008

Knee Replacement. 20 April 2014. (http://en.wikipedia.org/wiki/Knee_replacement)

Lippi, Donatella and Marco Matucci-Cerinic. Inherited Knee Disorders in the Medici Family. The Knee. Issue 21, June 2013.

Snelson, Kenneth. Double Cross Bar. 1967. (http://kennethsnelson.net/sculptures/smallsculptures/double-cross-bar/)

WebMD. 2010. (http://www.webmd.com/pain-management/knee-pain/picture-of-the-knee) 


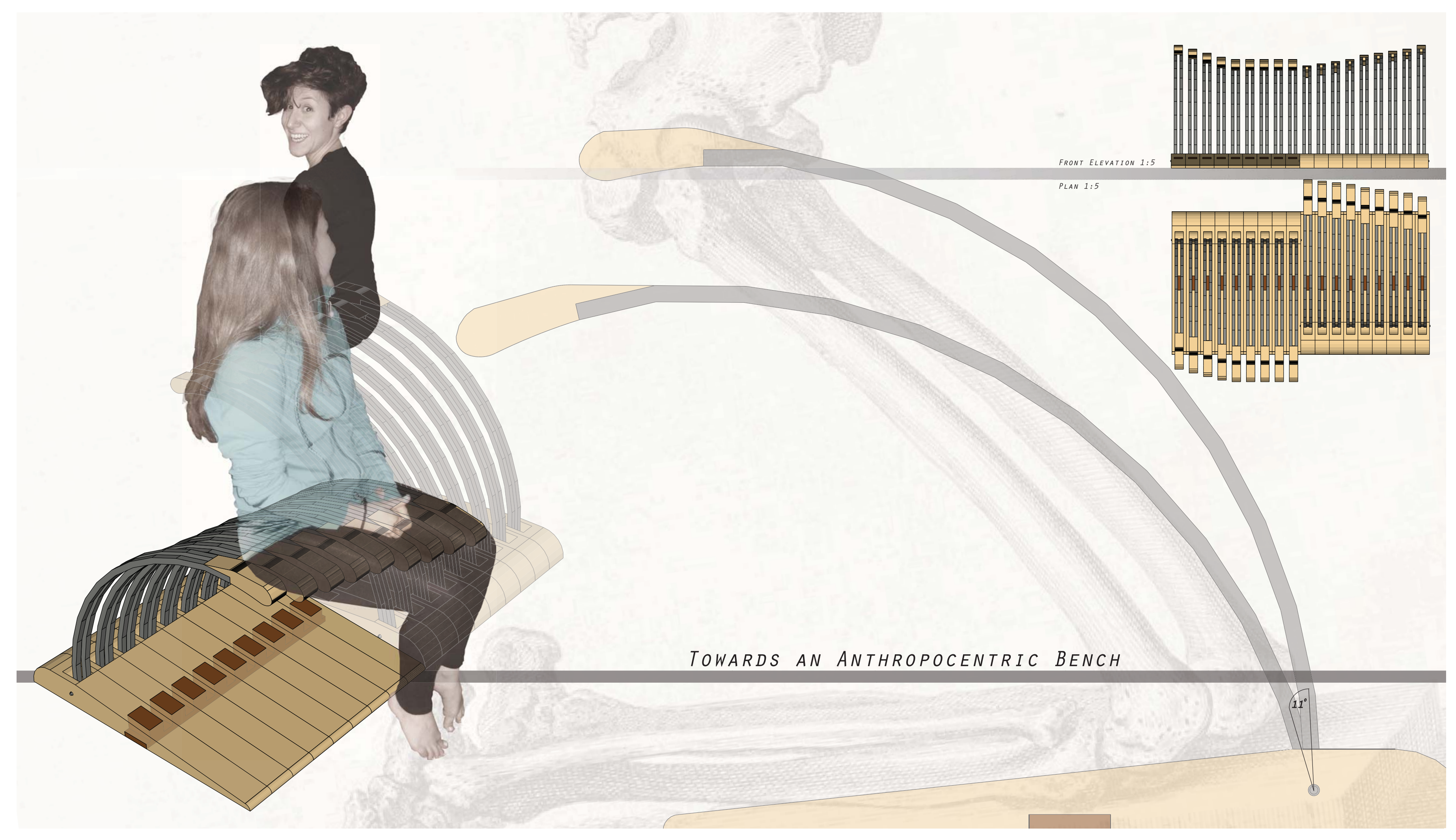

